\title{
ESTIMATES OF CORRELATION BETWEEN ESTRUS BEHAVIOR AND ESTRADIOL CONCENTRATIONS DURING ESTRUS
}

\author{
A Thesis \\ presented to \\ the Faculty of the Graduate School \\ at the University of Missouri - Columbia \\ In Partial Fulfillment \\ of the Requirements for the Degree \\ Master of Science \\ by \\ FAYTH KUMRO
}

Dr. Matthew Lucy, Thesis Supervisor

JULY 2020 
The undersigned, appointed by the dean of the Graduate School, have examined the thesis entitled:

\title{
ESTIMATES OF CORRELATION BETWEEN ESTRUS BEHAVIOR AND ESTRADIOL CONCENTRATIONS DURING ESTRUS
}

\author{
Presented by Fayth Kumro
}

A candidate for the degree of Master of Science,

And hereby certify that, in their opinion, it is worthy of acceptance.

Professor Matthew Lucy

Professor Scott Poock

Associate Professor Allison Meyer 


\section{ACKNOWLEDGEMENTS}

First, I would like to thank my committee for taking the time to guide me throughout my time at Mizzou. Dr. Matthew Lucy, thank you for accepting me as your student and introducing me to the life of a Mizzou trained reproductive physiologist. Your advice, jokes, and anecdotes provided me with great entertainment and knowledge to help me survive graduate school. Your No Drama training program is something that I will carry with me in my future endeavors. Next, I would like to thank Dr. Scott Poock, because without out him my projects would have been a disaster. Your endless on farm knowledge taught me so much and your great story telling provided lots of laughs. Thank you for helping me with my cows when I was helpless. You are the best "farm dad" that anyone could ask for. Finally, thank you Dr. Allison Meyer for being incredibly patient with me and all the trouble I caused. Your class was one of the first I attended in graduate school. I was intimidated and overwhelmed but you took the time to explain and help me whenever I was lost (which was a lot).

Thank you to the Foremost Dairy workers. Y'all had to deal with a lot of trouble from me, including the time I let the cows out. Whoops. Thank you to the morning milkers that would come and check on me after spending the entire night at the farm with my cows. To the undergraduate workers, thank you for helping me throughout my time at the dairy and teaching me the names of the farm cats. Finally, a special thank you to John Denbigh. Thank you for assisting me with every single project, class, or tour I participated in at the farm. Without your guidance, patient, and knowledge I would have been completely lost wondering the stalls still looking for a cow that never existed. 
I would like to thank all those that helped me with my projects. My labmates, Dr. Joao Moraes, and Monica Caldeira for taking the time to answer any questions I had and working at the farm during the day so I could sleep. A special thank you to Kelsey Clark, Jason Rizo, Erin Shangraw, and Maria Poock for coming together to cover shifts at the farm so the Lucy lab would not have to take samples alone. I would like to individually thank my forever lab mate, greatest friend, and assay queen Lauren Ciernia. You joined the lab for the last half of my program and I never knew that it would be the best thing to have happened during my time in the lab. Those late nights at the farm and long days in the fume hood will always mean the world to me. Thank you for taking the time to teach me ways of a true Texan and showing me the confidence of a woman of science.

This thesis would not have been possible without my fellow graduate students: Paula Chen, Jaclyn Ketchum, Eleanore O’Neil, Jessica Milano-Foster, Caroline Pffeifer, Megan McLean, Ashley Meyer, Harly Durbin, Troy Rowan, Emma Stephenson, Jenna Slaughter and Jade Cooper. Thank you for the laughs and advice throughout my time in graduate school. Honestly, every single graduate student has assisted me at some time, and I am incredibly appreciative to the Animal Science graduate students for being so helpful and amazing.

Finally, I would like to thank my friends and family outside of the MU Animal Science department. Thank you to my friends Rachel Mansker, Victoria Garza, and Lauren Mott. Even though y'all had no idea what I was talking about, you were still supportive and encouraging as I worked to reach my goal. To my heckin' goodest boy and fur-ever best friend Mosbey. I did this so you could have a better lifestyle. You're welcome. Thank you to my parents to supporting me throughout these $171 / 2$ years of 
school. Mom, you inspired me at a young age to pursue my goals no matter what life throws at you. Dad, you taught me to see all the possibilities in life and that going with the flow can sometimes take you to a better place originally planned. To my wonderful and incredible husband Corey Diaz. Thank you for staying up those late nights with me while I studied or wrote this thesis. I would not have made it this far without your provisions of snacks, coffee, and constant laughter. You taught me to be confident in myself and that failure is okay if I learn from it. Your encouragement and infectious tenacious attitude drove me to reach my goal and finish what I started.

To all those listed, the faculty and staff of the MU Animal Science Department, and the employees of the MU Electron Microscopy Core, thank you. My time at Mizzou would not have been as memorable or enjoyable without all of you. 


\section{TABLE OF CONTENTS}

ACKNOWLEDGEMENTS ........................................................

LIST OF TABLES ...........................................................

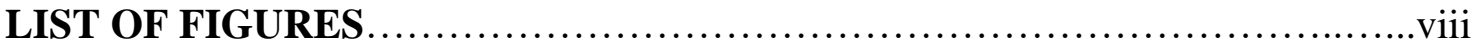

LIST OF ABBREVIATIONS ....................................................

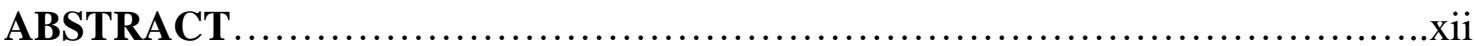

\section{Chapter}

1. LITERATURE REVIEW ..............................................

1.1. Introduction .............................................................

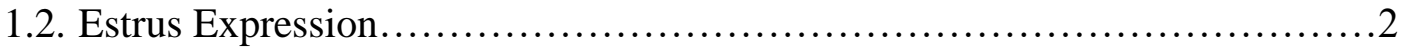

1.2.1. Physiological Changes During the Estrous Cycle.......................3

1.2.2. Factors Affecting Estrus Expression...............................

1.3. Estrus Detection Aids................................................... 10

1.3.1. Visual Detection............................................... 10

1.3.2. Electronic Detection................................................

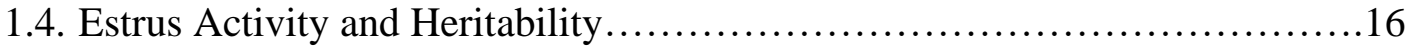

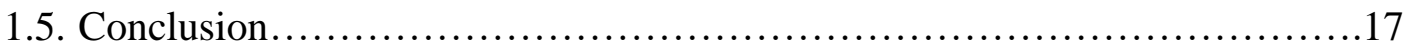

2. ESTIMATES OF INTRA- AND INTER-CLASS CORRELATION COEFFICIENTS FOR RUMP TOUCHES AND THE NUMBER OF STEPS DURING ESTRUS IN POSPARTUM COWS ............................18

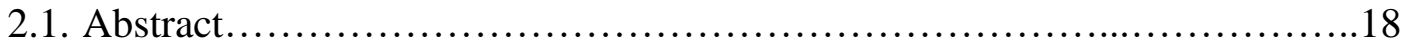




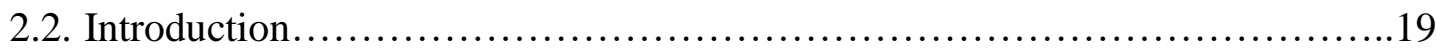

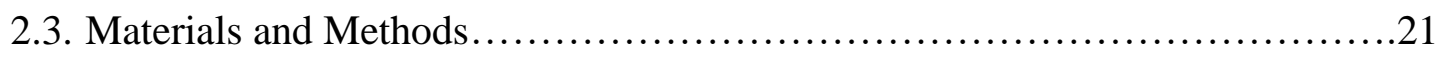

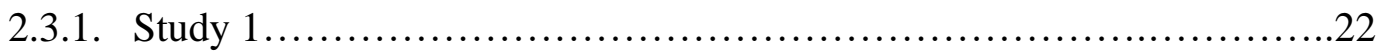

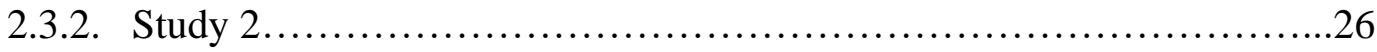

2.3.3. Capacitive Touch Sensing (CTS) Device Validation.......................30

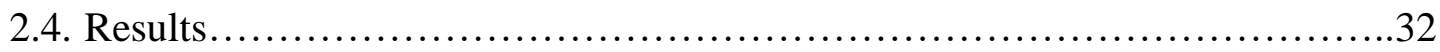

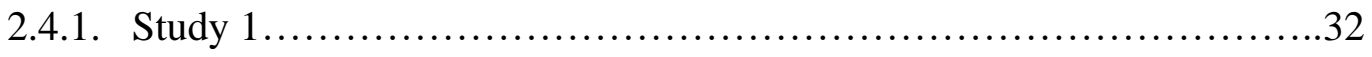

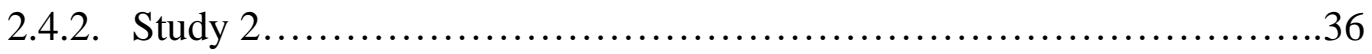

2.4.3. Capacitive Touch Sensing (CTS) Device Validation.....................43

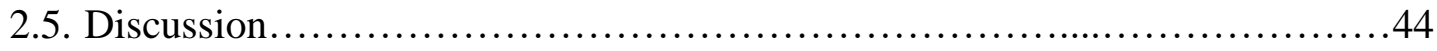

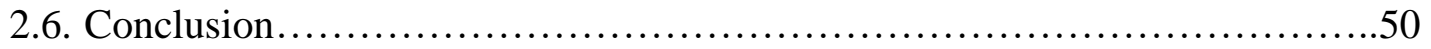

3. SIMULTANEOUS MEASUREMENTS OF ESTRUS BEHAVIOR AND PLASMA CONCENTRATIONS OF ESTRADIOL DURING ESTRUS IN LACTATING AND NONLACTATING DAIRY COWS .....................52

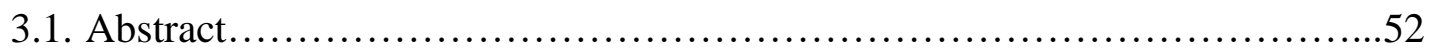

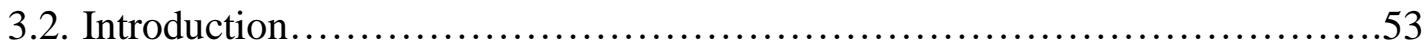

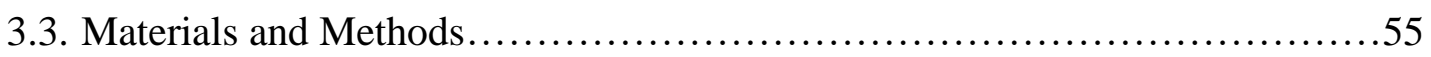

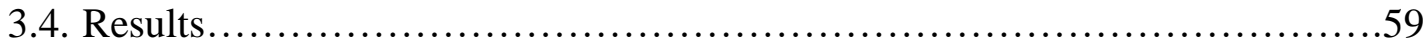

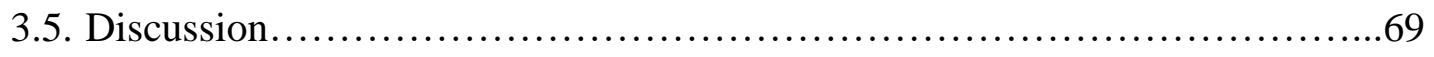

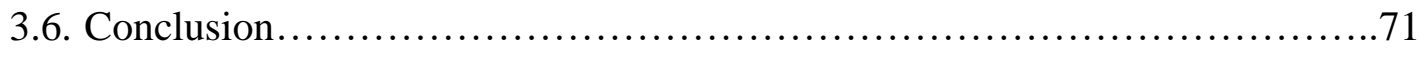

4. SUMMARY AND CONCLUSIONS .........................................

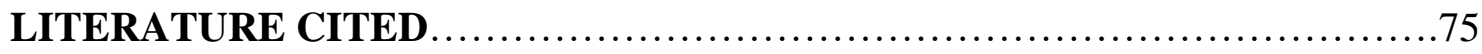




\section{LIST OF TABLES}

Table 2.1. Number of touches and total touch time during estrus and the number of days between estrus peaks (inter-estrus interval) identified by using CTS device

Table 3.1. Least square means and SE for estrus phenotypes in lactating and nonlactating dairy cows measured after an injection of $\mathrm{PGF}_{2 \alpha}$ 


\section{LIST OF FIGURES}

Figure 2.1. Anatomical location, removal, and disassembly for a CTS device used for measuring the number and duration of rump touches during estrus in postpartum dairy cows

Figure 2.2. Strategy for the identification and analysis of the number and duration of rump touches during estrus in postpartum dairy cows fitted with a CTS device

Figure 2.3. Timeline for the collection of phenotypic data for estrus expression in postpartum dairy cows using both an accelerometer and a CTS device

Figure 2.4. Strategy for the identification and analysis of estrus periods using an accelerometer and CTS device

Figure 2.5. Histograms for the number of estrus events with different number of touches and different total touch time during estrus as measured by a CTS device

Figure 2.6. Histogram for the number of days between estrus peaks (inter-estrus interval) as measured by a CTS device

Figure 2.7. Histogram for the number of days between estrus peaks (inter-estrus interval) as measured by a CTS device

Figure 2.8. Least square means and SEM (bar) for the number of steps measured using an accelerometer and the number of rump touches measured using a CTS device during an estrus period 
Figure 2.9. Histograms for the number of cows with different numbers of steps, rump touches, and total touch time during estrus as measured by using an accelerometer or a CTS device

Figure 2.10. Regression of the total number of steps measured by using an accelerometer on the number of rump touches measured by a CTS during an estrus period in postpartum dairy cows from Study 2 and the validation study

Figure 3.1. Number of steps taken per h, plasma estradiol concentrations, number of rump touches, and total touch time for lactating and nonlactating dairy cows after an injection of $\mathrm{PGF}_{2 \alpha}$

Figure 3.2. Number of steps taken per h, plasma estradiol and LH concentrations, number of rump touches, and total touch time for lactating and nonlactating dairy cows after an injection of $\mathrm{PGF}_{2 \alpha}$ 


\section{LIST OF ABBREVIATIONS}

\begin{tabular}{|c|c|}
\hline${ }^{\circ} \mathrm{C}$ & Degrees Celsius \\
\hline $305 \mathrm{ME}$ & 305-Day Mature Equivalent \\
\hline AI & Artificial Insemination \\
\hline CIDR & Controlled Internal Drug Release \\
\hline $\mathrm{cm}$ & Centimeter \\
\hline CTS & Capacitive Touch Sensing \\
\hline $\mathrm{CV}$ & Coefficient Variation \\
\hline $\mathrm{d}$ & Day \\
\hline DIM & Days in Milk \\
\hline EDTA & Ethylenediaminetetraacetic Anticoagulant \\
\hline ELISA & Enzyme-Linked Immunoassay \\
\hline GnRH & Gonadotropin Releasing Hormone \\
\hline $\mathrm{h}$ & Hour \\
\hline IACUC & Institutional Animal Care and Use Committee \\
\hline i.m. & Intramuscular \\
\hline $\mathrm{kg}$ & Kilogram \\
\hline LH & Luteinizing Hormone \\
\hline
\end{tabular}




$\begin{array}{ll}\text { LSM } & \text { Least-Squares Method } \\ \text { MHz } & \text { Megahertz } \\ \mu \mathrm{g} & \text { Microgram } \\ \mathrm{mg} & \text { Milligram } \\ \text { min } & \text { Minute } \\ \mathrm{mL} & \text { Milliliter } \\ \text { P4 } & \text { Progesterone } \\ \text { pg } & \text { Picogram } \\ \text { PGF } & \text { Prostaglandin } F_{2 \alpha} \\ \text { SD } & \text { Standard Deviation } \\ \text { SE } & \text { Standard Error } \\ \text { SEM } & \text { Standard Error of the Mean } \\ \text { TMk } & \text { Total Mixed Ration } \\ \text { Week }\end{array}$




\begin{abstract}
Estrus traits have economic value in dairy production systems and can potentially be incorporated into genomic selection. Three studies were performed to further understand selection responses. Study one and two explored the relationship between rump touches and number of steps during estrus. Holstein-Friesian cows ( $\mathrm{n}=1197$; Study 1) across five pasture-based grazing dairy herds were fitted with a capacitive touch sensing (CTS) device on the rump (FlashMate; Farmshed Labs Limited, Hamilton, NZ). The number of times touched and the sum of the touch duration were used to compare farms and estimate the intra-class correlation (repeatability). For Study 2, postpartum Holstein $(n=85)$ and Guernsey $(n=5)$ cows in a confinement-style dairy were used. Cows were fitted with an IceQube accelerometer (IceRobotics Ltd., Edinburgh, UK) to measure steps taken per hour and a CTS device was applied to both rumps. The interclass correlation for the number of rump touches and number of steps taken during estrus was calculated. Study 1 had an intra-class correlation (repeatability) for rump touches during estrus was approximately 0.2. For Study 2, the number of steps and the number of rump touches during estrus increased in a synchronous manner. The inter-class correlation (r) for rump touches and steps was approximately 0.45. Experiment 3 focused on the association between circulating concentrations of estradiol and overt phenotypes for estrus [greater activity and (or) rump touches (mounts, chinrests, etc.)] that can be easily observed on farm. We also tested the effect of lactation on the estrus traits that we measured. Cows $\left(\mathrm{n}=11\right.$ lactating and $\mathrm{n}=9$ nonlactating) were treated with $\mathrm{PGF}_{2 \alpha}$ to synchronize estrus. The jugular vein was cannulated to collect blood every $2 \mathrm{~h}$ for plasma estradiol measurement. Plasma LH was measured during the periestrual period to
\end{abstract}


determine the time of the LH surge. Cows were fitted with an IceQube accelerometer to measure activity (steps per h) and a CTS to measure the number of rump touches and total touch time. The correlation between plasma estradiol concentrations and overt signs of estrus ranges from near 0 for a cow coming into estrus to $>0.5$ for a cow going out of estrus. Lactating cows had shorter estrus periods because the interval from the onset of estrus activity to the LH surge was shorter. Selection for a longer estrus period (based on activity) could potentially increase the interval from the onset of activity to the LH surge and provide for a longer estrus.

In conclusion, the repeatability for rump touches during estrus was approximately 0.2 and this suggests that the maximum heritability for this estrus trait is $20 \%$. Selection for the number of rump touches during estrus, therefore, should increase overt signs of estrus that include rump touches in dairy cows. The correlation between rump touches and the number of steps taken during estrus was 0.45 . Selecting cows for increased activity should increase the number of rump touches (mounts, chin rests, etc.) because based on the correlation at least $20 \%\left(\mathrm{r}^{2}\right)$ of the variation in the number of steps was explained by the estrus cow walking in response to other cows interacting with her rump. Likewise, selecting cows for rump touches at estrus using a CTS device (or similar) should increase the number of steps during estrus. These data can be used to support large-scale phenotyping projects of cows with known genotypes to perform genome-wide association studies (GWAS) that can be used to identify genetic makers for estrus expression. These genetic markers for estrus expression can be incorporated into genetic selection indices to improve estrus expression in dairy cows. 


\section{Chapter One:}

\section{LITERATURE REVIEW}

\subsection{Introduction}

The dairy industry has undergone drastic change in the last 95 years. Since the early 20th century, the total number of dairy cows has decreased while the amount of milk produced per cow steadily increased (Washburn et al., 2002; MacDonald, et al., 2007). This increase in milk yield per cow was associated with the gained popularity of artificial insemination (AI) (Patrick, 1961). Widespread adoption of AI in the dairy industry provided an efficient method to improve herd genetics (Moore and Hasler, 2017). However, over emphasis on the selection of milk production traits led to a decline in reproductive efficiency (Lucy, 2001). The decrease in reproductive efficiency led to extensive research on the estrous cycle, estrus expression, estrus detection aids, and the potential use of estrus expression tools for genetic selection.

When using AI, cows need to be inseminated approximately 12 hours after the onset of estrus to allow the proper amount of time for sperm to capacitate and reach the site of fertilization (Foote, 1979; Nebel et al., 1994; Senger, 2012). In the initial days of AI, producers would identify cows in estrus by observing their behaviors. If the animal stood to be mounted, then she was presumed to be in estrus and fertile to insemination. As technology advanced, the ultrasound provided insight into the ovarian cycle [growth and development of follicles, growth and regression of the corpus luteum (CL), etc.] and its relation to estrus expression. Additional estrus expression research produced an enhanced understanding of the related physiological mechanisms that controlled estrus. 
Greater understanding of the physiology of estrus allowed for research on factors that control the length and intensity of estrus expression.

The development and implementation of estrus detection aids reduced the amount of labor and time required to observe estrus behaviors (i.e., standing to be mounted). Visual estrus detection aids are the most popular method but advancements in technology led to the creation of electronic detection devices. The ability to record accurate and precise data on estrus expression granted a deeper understanding of behaviors associated with estrus.

Genetic advancements within the dairy industry can be made through the incorporation of new phenotypes into selection indices (Cole et al., 2020). New estrus detection technologies allow for the collection of large data sets that will be necessary to develop a phenotype database for expression of estrus behavior. Determination of the genotype related to the length and intensity of estrus expression can be used to reverse the reproductive decline in dairy cattle.

This review covers the underlying physiology of estrus expression, factors that affect estrus expression, the evolution of estrus detection aids, and the genetic implications of estrus expression.

\subsection{Estrus Expression}

Estrus in dairy cattle is initiated through a series of physiological events that culminate in the expression of estrus. These events include changes in circulating hormone concentrations, growth and regression of structures on the ovaries, and the initiation of estrus behavior. The length of estrus, as well as, the intensity of behaviors 
associated with estrus differ for individual dairy cows and is not necessarily the same from one estrus to the next within the same cow (Allrich, 1994). This large variation in the expression of estrus behaviors is explained by the many internal and external factors acting on dairy cattle and the surrounding environment. This section of the review will cover physiological changes of the estrous cycle and some factors that affect estrus expression.

\subsubsection{Physiological Changes During the Estrous Cycle}

Recruitment: After ovulation, a transient rise in the circulating concentrations of follicle stimulating hormone (FSH) initiates the recruitment of a cohort of small follicles (Fortune, 1993). Peaks in FSH can occur two to three times during the luteal phase of the estrous cycle, resulting in follicular waves (Ginther et al., 1997). A new follicular wave starts when the dominant follicle (DF) of the previous follicular wave undergoes atresia or ovulation (Ireland et al., 2000). Follicles will begin to express FSH receptors on the granulosa cells and luteinizing hormone ( $\mathrm{LH})$ receptors on the theca cells (Bao and Allen Garverick, 1998). The concentration of FSH will begin to decline as the future DF reaches a diameter of $4 \mathrm{~mm}$ (Ginther et al., 1996). Acquisition of the FSH and LH receptors permits the follicles to produce estradiol via the two cell two gonadotropin theory (Fortune and Quirk, 1988).The production of follicular estradiol will increase as follicles continue to grow (Perry et al., 2005).

Selection: Increasing circulating concentrations of estradiol and inhibin produced by the developing follicles act on the anterior pituitary to inhibit the secretion of FSH (Martin et al., 1988; Senger, 2012). The decline in the circulating concentrations of FSH initiates the switch from FSH to LH dependent follicular growth (Smith et al., 2015). The 
inhibition of FSH and presence of high progesterone (P4; produced by the CL) results in the promotion of a low frequency high amplitude secretion of LH (Thatcher, 2017). The selected DF will continue to grow in the low FSH, high LH environment due to the acquisition of LH receptors on the granulosa and theca cells (Ginther et al., 1997). Subordinate follicles that are unable to switch from FSH to LH dependency (i.e., they fail to develop an adequate number of LH receptors) undergo atresia (Lucy, 2007). The selected DF will continue to grow to approximately $8 \mathrm{~mm}$ during this stage (Ginther et al., 1997).

Dominance: During this phase the selected follicle will establish dominance by growing at a faster rate than the subordinate follicles (Smith et al., 2015). In dairy cattle, it is possible for codominant follicles to occur (Wiltbank et al., 2000). The presence of the $\mathrm{DF}(\mathrm{s})$ will suppress new waves of follicular recruitment through the inhibition of FSH (Ginther et al., 1996). Fate of the DF(s) is dependent on the presence of the CL (Lucy, 2007). If the CL is present, the $\mathrm{DF}(\mathrm{s})$ will become atretic and a new follicular wave will begin. Regression of the CL will result in a decrease in circulating concentrations of P4. Declining levels of P4 promote a high frequency low amplitude secretion of LH (Ginther et al., 1996). The acquisition of LH receptors on both the granulosa and theca cells, and the secretion pattern of LH provide the preovulatory DF with the capability of producing high circulating concentrations of estradiol preceding the LH surge (Allrich, 1994). Due to conflicting evidence, it is unclear if circulating levels of estradiol differ in the presence of more than one DF (Kulick et al., 2001; Sartori et al., 2004). A DF will grow to a mature size of 10 - $15 \mathrm{~mm}$ during this stage (Lucy et al., 1991). 
Luteolysis: Elevated levels of P4, act on the uterine endometrium to reduce the expression of $\mathrm{P} 4$ receptors leading to an increase in the expression of estradiol receptors in the uterine epithelium (Arosh et al., 2016). Binding of follicular estradiol to the epithelial receptors induces the expression of oxytocin receptors on the endometrium (McCracken et al., 1999). Oxytocin from the posterior pituitary binds to its receptors resulting in the upregulation of oxytocin receptors and the induction of the pulsatile secretion of prostaglandin $\left(\mathrm{PGF}_{2 \alpha}\right)$ from the uterus (Spencer et al., 1995). Uterine $\mathrm{PGF}_{2 \alpha}$ travels to the CL via the utero-ovarian vascular countercurrent transport system (Senger, 2012). At the CL, $\mathrm{PGF}_{2 \alpha}$ binds to its receptors on the large luteal cells to induce the release of supplemental oxytocin from the luteal cells that bind to the endometrial receptors (McCracken et al., 1999). The pulsatile release of $\mathrm{PGF}_{2 \alpha}$ is the result of the positive feedback loop between the uterus and CL. An increase in the binding of $\mathrm{PGF}_{2 \alpha}$ to the large luteal cells initiates functional and structural luteolysis (Arosh et al., 2016). Apoptosis of the luteal cells causes the decrease in circulating P4 levels. The regression of the $\mathrm{CL}$ and decrease in circulating concentration of $\mathrm{P} 4$ allow the ovulation of a new DF.

Estrus: Peak concentration of estradiol produced by the preovulatory DF and a decrease in $\mathrm{P} 4$ production due to the regression of the $\mathrm{CL}$ are responsible for an increase in estrus behaviors (Coe and Allrich, 1989). Behaviors that are associated with estrus include sniffing, chin resting, mounting, and standing to be mounted (Allrich, 1993). Dairy cows will also exhibit an increased walking activity (Kiddy, 1977; Reimers et al., 1985), decreased rumination (Reith and Hoy, 2012; Pahl et al., 2015), increased vocalization (Röttgen et al., 2018) and increased participation in sexually active groups 
(SAGs; groups of females with intense estrus behavior) (Sveberg et al., 2013). The order of behaviors progress in intensity until standing estrus and then behaviors occur in reverse order when exiting estrus (Hurnik, 1987; Dobson et al., 2018). A high correlation between standing to be mounted and estradiol concentrations has been seen (Lyimo et al., 2000). However, estradiol concentrations and intensity of estrus are weakly correlated (Madureira et al., 2015).

Ovulation: A DF will mature to a size of $10-15 \mathrm{~mm}$ and a preovulatory size of $>15 \mathrm{~mm}$ (Lucy et al., 1991). The decreased concentration of circulating P4 promotes a positive feedback loop between estradiol and LH. This positive feedback initiates the preovulatory surge of $\mathrm{LH}$, stimulating ovulation of the follicle and release of the oocyte. Ovulation of the preovulatory dominant follicle occurs 14 - 19 hours after the end of estrus activity (Brewster and Cole, 1941; Roelofs et al., 2005a; b). The variation in timing of ovulation is a result of the length of estrus expression, discussed in section 1.2.2. If codominant preovulatory follicles are present, both DF are capable of undergoing ovulation (Lucy, 2007).

Luteinization: The preovulatory LH surge induces the luteinization (transformation of the follicular cells into luteal cells) of the granulosa and theca cells. The cells will differentiate into the small (theca cells) and large (granulosa cells) P4 secreting luteal cells (Thatcher, 2017). Luteinization is complete 3-5 days after ovulation (Gomes and Erb, 1965). Small luteal cells contain LH receptors and large luteal cells contain $\mathrm{PGF}_{2 \alpha}$ receptors. Production of $\mathrm{P} 4$ continues to increase until 7-10 days after ovulation when P4 reaches a peak and plateaus (Senger, 2012; Thatcher, 2017). During 
the time of elevated $\mathrm{P} 4$, there are two to three peaks in FSH that result in follicular waves (Ginther et al., 1997).

\subsubsection{Factors Affecting Estrus Expression}

The length and intensity of estrus behaviors can differ in dairy cattle (Holtz and Meinhardt, 1993). This variation in estrus expression can be caused by various internal and external factors.

Internal factors: This classification of factors affecting estrus expression covers variables associated with the physiology of the dairy cow. Greater steroid metabolism in high-producing cows is a notable internal factor that affects expression of estrus behaviors. The enhanced rate of steroid metabolism is a result of the heightened rate of nutrient metabolism in high-producing cows (Wiltbank et al., 2006). Lopez et al., (2004) demonstrated that elevated steroid metabolism decreased the levels of circulating estradiol resulting in a shortened length of estrus expression. Low levels of estradiol have also been attributed to the reduction in the intensity of estrus expression (Sangsritavong et al., 2002).

Dairy cattle can have a body condition score (BCS) between 1 (thin) and 5 (obese) (Ferguson et al., 1994). Cows with a BCS of 2 or lower are less likely to be identified in estrus than cows with a greater BCS (Holman et al., 2011; Aungier et al., 2012). It is theorized that cows with low BCS are difficult to detect in estrus because they have lower levels of circulating LH. The reduced levels of LH lead to decreased follicular growth and estradiol production (Roche, 2006). Decreased levels of estradiol can result in cows that have little to no signs of estrus expression. Cows that fail to show estrus are 
classified either as anovulatory (a cow that is not ovulating) or anestrus (a cow that may or may not be cycling but is not expressing estrus) (Sandeen, 2015). Further research is necessary to define the underlying mechanisms for the effects of BCS on estrus expression (Madureira et al., 2015).

Other internal factors correlated with a decrease in expression of estrus include increased parity (López-Gatius et al., 2005), increased milk production (Lopez et al., 2004), and decreased mobility as a result of lameness (Sood and Nanda, 2006; Walker et al., 2008).

External Factors: Environmental factors act on the cow to affect estrus expression. An increase in ambient temperature can cause a decrease in estrus expression (Polsky et al., 2017). However, when the number of cows in estrus increases, the intensity of estrus expression will increase (Roelofs et al., 2005a). This surge in intensity could be contributed to the increased formation of SAG (Sveberg et al., 2013). Estrus expression has also been shown to increase when the cows are milked more frequently (Orihuela, 2000). It is possible that frequent milking can aid in the visual detection of cows in estrus because cows are seen more (Caraviello et al., 2006; Burnett et al., 2017). The type of flooring used in facilities is important because cows housed on concrete floors are less likely to express estrus behaviors (Van Vliet and Van Eerdenburg, 1996; Platz et al., 2008). Cows on pasture are more likely to express estrus behaviors than cows housed in confinement barns (Palmer et al., 2010).

Synchronization Protocols: Producers can manipulate the ovarian dynamics to synchronize the timing of estrus through the administration of hormonal treatments (Peters, 1986; Larson and Ball, 1992). Progestins (progesterone or its analogs) were the 
first hormonal treatments to be used by producers. Progestins can be given as a feed additive for dairy heifers (melengestrol acetate; MGA; it is illegal for lactating dairy cows) or as an intravaginal device [Controlled Internal Drug Release (CIDR) device]. Progestins are not able to lengthen the CL lifespan but they elicit the same effect by binding to $\mathrm{P} 4$ receptors in the hypothalamus to prevent (or delay) estrus expression and ovulation (Smith et al., 2015). $\mathrm{PGF}_{2 \alpha}$ was the second hormonal treatment used by producers. Administration of $\mathrm{PGF}_{2 \alpha}$ via intramuscular injection initiates the regression of the CL resulting in the return to estrus (Lauderdale, 2009). The development of gonadotropin releasing hormone $(\mathrm{GnRH})$ as a hormonal pharmaceutical administered through an intramuscular injection allowed producers the ability to influence follicular dynamics. Administration of GnRH can induce an LH surge to cause ovulation of a DF and stimulate a new follicular wave through the subsequent increase in FSH secretion (Lauderdale, 2009; Smith et al., 2015). Through extensive research into the proper timing of administration of these hormones producers are capable of synchronizing estrus, ovulation, timing of insemination, follicular development, and CL regression (Lucy et al., 1986, 2004; Pursley et al., 1997a; Thatcher et al., 2001). The various types of estrous synchronization protocols are discussed in great detail by Stevenson and Britt (2017). Synchronization protocols can be paired with a presynchronization strategy to increase fertility to timed AI and responsiveness to the synchronization protocol (Fricke et al., 2014). One of the widely adopted protocol combinations for lactating dairy cows is Presynch-Ovsynch (Caraviello et al., 2006). The details of this protocol can be found in section 2.3.2. We decided to use the Presynch-Ovsynch protocol (Study 2; section 2) because of the increased estrus expression in lactating dairy cows (Fricke et al., 2014). 
Estrus synchronization using hormonal pharmaceuticals has become the most popular management technique for estrus manipulation in the dairy industry (Caraviello et al., 2006).

\subsection{Estrus Detection Aids}

Accurate estrus detection is essential to ensuring reproductive success via nonfixed time AI protocols (Stevenson et al., 1983). For many years, producers relied on visual detection but with advancements in technology, electronic detection methods emerged. This section of the literature review will focus on estrus detection aids from visual to electronic detection methods used in the dairy industry.

\subsubsection{Visual detection}

The primary sign of a cow in estrus is standing when mounted by another female (Hurnik, 1987). Producers that use this sign conduct visual observations of the herd 2-3 times daily for 20-30 minutes (Lauderdale, 1974; Foote, 1975). As farms began to increase in the number of cows per farm, this method of frequent observation became inconvenient and inefficient.

Subjective Visual Detection: Visual detection became the most popular way to identify cows in estrus (Stevenson and Britt, 2017) with a breeding accuracy of $\leq 50 \%$ (Van Eerdenburg et al., 2002). Using crayon, producers would mark the tail head of the cow, and if the cow had come into estrus, the mark would be rubbed by mounting activity (Foote, 1975). If the mark had been completely rubbed off, it was assumed that the cow had stood to be mounted, several times, and was ready to be inseminated (Macmillan and Curnow, 1977). 
As the dairy industry advanced, methods for marking the tail head took many forms including tail paint, tail chalk, tail spray paint and an estrus detection patch. The estrus detection patch is placed slightly above the tail head and when the cow is mounted the patch is rubbed. With each mount, a brightly colored coating is slowly exposed, and the amount of color is assessed to determine if the cow is in estrus (Johnson and Jaeger, 2016).

The low breeding accuracy was a result of the subjectivity of visually detecting estrus. This subjectivity is a result of how individuals draw different conclusions (in estrus or not in estrus) from a partially rubbed tail head. Macmillan and Curnow, (1977) demonstrated the variety of interpretations associated with tail head analysis.

A scoring system was developed in an attempt to remove the subjectivity of tail head marking analysis (Walker et al., 2014; Johnson and Jaeger, 2016; Colazo et al., 2018). Despite the implementation of the scoring systems, this method continued to have limitations associated with subjective interpretations. With the introduction of synchronization programs, subjective visual detection of estrus has become less important (Stevenson and Britt, 2017). Pursley et al. (1997b) demonstrated that estrus detection is not necessary when using a timed AI protocol.

Objective Visual Detection: The Kamar estrus detection patch (Kamar Inc., Steamboat Springs, CO) is glued to the tail head and activated by mounting behavior. When the Kamar patch is activated, the device will change color from white to red (Lauderdale, 1974; Gwazdauskas et al., 1990). The device grew in popularity in the dairy industry due to its ability to provide a definitive (yes or no) answer to a subjective question (Foote, 1975). However, false activation of the Kamar patch can occur when the 
mount is not accepted by the receiving cow (Lauderdale, 1974). Another major disadvantage of using this device was its cost and loss of the device after repeated mounting due to the chunky design (Foote, 1975).

Electronic visual estrus detection aids are devices that alert to mounting behavior through a distinguishable flashing of light. The earliest versions of these devices were the MountCount (DDx, Denver, CO) and ShowHeat (I.M.V International, Minneapolis, MN). These devices are placed on the tailhead of the cow and activated when mounting occurs within a certain time frame. Once the devices are activated, they will flash to alert the cow is in estrus (Rorie et al., 2002).

With advancements in technology a new electronic visual estrus detection device has been developed. The FlashMate ${ }^{\circledR}$ (FarmShed Labs Limited, Hamilton, New Zealand), uses a capacitive (touch) sensing technology similar to that used in devices with touchscreens (cell phones, tablets, etc.). The device is placed between the hip and the pin bone, approximately $10 \mathrm{~cm}$ ventral the tailhead, and capable of identifying a cow in estrus based on the frequency and the length of each rump contact (Orrell, 2018). When a rump activity pattern is established, the device will flash red, identifying the cow is in estrus (Gallagher, 2018). Unlike the Kamar patch there is a decreased possibility of a false positive because the rump contacts must meet the requirements of a rump contact estrus pattern to indicate that the cow is in estrus. Electronic visual estrus detection devices combine electronic and visible indications of estrus to create an objective visual estrus detection aid.

\subsubsection{Electronic Detection}


The development of electronic detection aids enabled the efficient tracking of the estrous cycle and behaviors associated with estrus. These estrus detection aids were able to fulfill all the requirements of an ideal estrus detection system that allows for 24-hour surveillance, identifies estrus with a higher accuracy than visual detection, and reduces the amount of labor necessary to detect estrus (Senger, 1994). Electronic estrus detection aids can be classified into one of the five categories according to function: pedometers, accelerometers, rumination monitors, mount detecting devices, and automatic milk sampling and $\mathrm{P} 4$ analysis.

Pedometers: The relationship between the onset of estrus and increased physical activity was first described by (Farris, 1954) and confirmed later with pedometers (Kiddy, 1977; Reimers et al., 1985). Pedometers are more likely to identify animals experiencing a silent ovulation (ovulation without expression of standing to be mounted) when compared to visual detection methods (Peter and Bosu, 1986; Peter et al., 2009). Pedometers have a low accuracy of identifying cows in estrus but when combining pedometers and visual detection aids the detection accuracy will increase (Williams et al., 1981). In the past, pedometers required a significant amount of labor because the data from the devices had to be downloaded using a handheld scanner (Lyimo et al., 2000). Now pedometers can transfer data straight to a computer during milking (Roelofs et al., 2005a). This is an important function because it reduces labor costs and producers can use a computer program to notify them when a cow is in estrus.

Accelerometers: The accelerometer is an estrus detection device that measures the number of steps, the amount of time spent lying down, and the amount of time standing (Silper et al., 2015). By combining all physical activity measurements, the device can 
generate a value that detects estrus expression based on overall restlessness (Løvendahl and Chagunda, 2010; Roelofs et al., 2010). Restlessness associated with estrus is attributed to an increase in walking (number of steps), more time spent standing and a decrease in the time spent lying down (Kiddy, 1977; Reimers et al., 1985; Silper et al., 2017). The device can be placed on a neck collar, in the ear as an ear tag, or on a monitor located on the rear right leg above the pastern. Accelerometers show similar rates of estrus detection regardless of placement (Saint-Dizier and Chastant-Maillard, 2012; Valenza et al., 2012). Similar to a pedometer, the data can be transferred directly to a computer when cows come in to be milked (Stevenson et al., 2014).

Rumination monitor: Rumination has recently been shown to decrease during estrus because cows spend less time feeding due to the increase in physical activity (Reith and Hoy, 2012; Pahl et al., 2015). These studies utilized a technology that records the sound of rumination while ignoring the sounds associated with feeding (Adin et al., 2009; Burfeind et al., 2011). The technology is a microphone that is placed, close to the neck, on a collar and will record sounds associated with rumination. This monitor is scanned when cows are milked and the data are transferred straight to a computer (Bar and Solomon, 2010). The rumination monitor was used originally to monitor the health of an animal, but with the discovery that a drop in rumination can be used to identify estrus, these devices have become an estrus detector as well. Rumination monitors are commonly equipped with collar accelerometers, leading to an increase in the sensitivity of estrus detection (e.g., SCR collar; SCR Engineers ltd., Netanya, Israel).

Mounting detection: Heatwatch ${ }^{\circledR}$ system (DDx, Denver, $\mathrm{CO}$ ) is a radiotelemetric device attached below the sacral region of each cow (Nebel et al., 2000). Each individual 
device will transmit a log consisting of the number of mounts, the time of day the mount occurred and the duration of each mount to a computer (Dransfield et al., 1998). The computer software uses the data to identify and create a list of cows in estrus for the producer (Rorie et al., 2002). Electronic mounting detection devices are more accurate than visual detection aids (Walker et al., 1996). The system's ability to accurately detect and record mounting data allows for research into the relation between estrus and timing of ovulation (Nebel et al., 2000). Using both electronic mounting detection devices and visual detection methods will result in higher rates of successful identification of cows in estrus (Xu et al., 1998). Due to the high cost of the system and high loss rate of the devices these systems are not commonly used.

Automatic milk sampling and progesterone (P4) analysis: Development of assays to determine concentration of reproductive hormones from biological fluid samples (e.g., blood or milk) led to the evolution of estrus detection via automatic milk sampling (Stevenson and Britt, 2017). Herd Navigator (Delaval Inc., Tumba, Sweden) is an automatic milk sampling system that has a fully automatic P4 analyzer (Yu and Maeda, 2017). Beginning 15 days after calving, the system will collect a single milk sample from each cow during milking and measure milk P4 concentrations. The results of the assay are sent to a computer where a $\mathrm{P} 4$ profile ( $\mathrm{P} 4$ versus days in milk) for every cow is created (Asmussen, 2010). When the concentration of P4 drops below $5 \mathrm{ng} / \mathrm{ml}$, the system will alert the producer that the cow is in estrus and approaching ovulation. The cow can be artificially inseminated 24 - 36 hours after the heat alarm (Yu and Maeda, 2017). Tracking of milk P4 concentration provides a method to detect cows in estrus and 
is more likely to detect cows that have a silent ovulation than other estrus detection aids (Blom and Ridder, 2010; Mazeris, 2010).

\subsection{Estrus Activity and Heritability}

Single trait selection for milk production traits; lead to adverse effects on cow health and decrease in cow fertility (Lucy, 2001). A recent shift in traits used in genetic selection has begun to reverse the drop in female fertility (García-Ruiz et al., 2016). This change in genetic selection priorities can be attributed to a better understanding of how genetic selection for milk production affects a variety of other important attributes of the cow including fertility.

It is well documented that an increase in estrus expression is associated with increased fertility (López-Gatius et al., 2005; Løvendahl and Chagunda, 2009; Rivera et al., 2010; Silper et al., 2017). Advancements in estrus detection aids allowed for detailed studies of estrus expression. Electronic estrus detection technologies are capable of collecting large amounts of data on behaviors and hormone concentrations associated with estrus. These data can be used to generate a database of the behavioral and hormonal phenotypes related to estrus expression (Løvendahl and Chagunda, 2010; Lucy, 2019). The data can then be used to determine the underlying genes related to the phenotypic expression of estrus (Ismael et al., 2015; VanRaden, 2020). With extensive phenotypic data, it is possible to calculate the potential heritability of various fertility traits (Schutz and Pajor, 2001).

Research on the genetics of fertility traits confirmed that it is controlled by many loci and difficult to identify all the loci because studies are underpowered (Ma et al., 
2019). Through the use of electronic estrus detection technologies, databases can collect accurate data related to fertility (Fleming et al., 2019) and the size of the studies should increase so that loci associated with fertility traits can be identified.

\subsection{Conclusion}

AI was first introduced into the dairy industry as a method to efficiently breed animals and evolved into a strategy to improve the genetics of dairy cattle. A better understanding of the physiology of estrus and the factors affecting estrus expression will lead to improvements in estrus detection, more efficient breeding of cows on farms that do not use timed AI and greater fertility for all cows regardless of whether timed AI is used or not on the farm. Electronic estrus detection aids collect large amounts of data that can be used to generate phenotype databases allowing the selection of dairy cows that have improved estrus expression. Improved estrus expression will simplify reproductive management on farms and improve efficiency. 


\section{Chapter Two:}

\section{ESTIMATES OF INTRA- AND INTER-CLASS CORRELATION COEFFICIENTS FOR RUMP TOUCHES AND THE NUMBER OF STEPS DURING ESTRUS IN POSTPARTUM COWS}

\subsection{Abstract}

Estrus traits have economic value in dairy production systems and could be incorporated into genetic selection indices. In an effort to further understand selection responses, two studies were performed to estimate the intra- and inter-class correlation coefficients for estrus traits. Holstein-Friesian cows $(n=1197 ;$ Study 1$)$ across five pasture-based grazing dairy herds were fitted with a capacitive touch sensing (CTS) device on the rump (FlashMate; Farmshed Labs Limited, Hamilton, NZ). The daily number of rump touches were subjected to a peak detection program to objectively identify periods of increased rump touches above baseline (indicative of estrus). The number of times touched and the sum of the touch duration were used to compare farms and estimate the intra-class correlation (repeatability). For Study 2, postpartum Holstein $(n=85)$ and Guernsey $(n=5)$ cows in a confinement-style dairy were used. Cows were fitted with an IceQube accelerometer (IceRobotics Ltd., Edinburgh, UK) to measure steps taken per hour and a CTS device was applied to both rumps. The inter-class correlation for the number of rump touches and number of steps taken during estrus was calculated. Data collected from 5 herds (Study 1) demonstrated a two to three-fold difference between herds in the number of rump touches and total touch time during estrus. The intra-class correlation (repeatability) for rump touches during estrus was approximately 0.2. For Study 2, the number of steps and the number of rump touches during estrus 
increased in a synchronous manner. The inter-class correlation (r) for rump touches and steps was approximately 0.45 . Selecting cows for the number of steps taken during estrus should increase the number of rump touches (mounts, chin rests, etc.) because based on the $\mathrm{r}^{2}$ at least $20 \%$ of the variation in the number of steps was explained by the estrus cow walking in response to other cows interacting with her rump. Likewise, selecting cows for rump touches at estrus using a CTS device (or similar) should increase the number of steps during estrus.

\subsection{Introduction}

Centralized milk recording and the widespread implementation of artificial insemination (AI) accelerated genetic progress for milk production traits (total milk fat and protein produced) in dairy cows during the past century (Miglior et al., 2017). Selection for production traits alone, however, had unexpected consequences that included less functional, shorter-lived cows with poor fertility (Lucy, 2001). More balanced genetic selection indices were developed in the late 20th century and early $21^{\text {st }}$ century that were designed to alleviate the strain of high production. These modern selection indices reduced the weighting on production and substituted a variety of new traits designed to increase longevity and fertility, create a healthier cow with a more functional anatomy (feet, legs and udder), and improve calving performance (Fleming et al., 2019; Ma et al., 2019; Parker Gaddis et al., 2020). New traits now account for > 50\% of most modern selection indices used for dairy cows (VanRaden, 2020).

Days from calving to first insemination or days to the establishment of next pregnancy (days open) or the calving interval are used globally as dairy fertility traits (Lucy, 2019). Historically, these traditional fertility traits depended on the detection of 
estrus for appropriate timing of insemination (Diskin, 2018). The evolution and implementation of timed AI programs negated the need for estrus expression or detection, two events that had become problematic for high-producing cows housed in confinement systems (Wiltbank and Pursley, 2014; Carvalho et al., 2018). In modern production systems that do not use timed AI, the expression of estrus is an absolute necessity for efficient reproduction (Lucy et al., 2004; Mottram, 2016; Stevenson and Britt, 2017). Estrus expression is less important in herds that use timed AI programs but nonetheless it is generally accepted that cows that express estrus near the timed AI have greater fertility (Sterry et al., 2006; Richardson et al., 2016). Many herds practice a hybrid approach where cows are inseminated after observed estrus and timed AI is used for cows that have not been observed in estrus (Fricke et al., 2014; Carvalho et al., 2018; Denis-Robichaud et al., 2018).

Estrus can be detected visually by watching for behavioral signs or remotely by measuring changes in activity (steps or head and neck movements) (Mottram, 2016; Reith and Hoy, 2018). Cows in estrus receive chin rests and mounts from other cows and when definitively in estrus will stand still when mounted (Hurnik, 1987; Allrich, 1993). Cows in estrus will also chase and attempt to mount other cows. The increased movement and general restlessness of a cow in estrus forms the basis for activity monitoring systems that can record movements for individual cows (Stevenson and Britt, 2017; Reith and Hoy, 2018). Activity monitoring systems have achieved widespread commercial application (Stevenson and Britt, 2017). Electronic estrus detection devices based on a pressure sensitive switch mounted on the tailhead have been developed (Nebel 
et al., 2000) but their commercial penetration into the dairy market is less than activity monitoring systems.

Estrus traits have economic value in dairy production systems and could be incorporated into genetic selection indices so that estrus expression is improved. The validation of new genetic markers for estrus expression requires high throughput and accurate methods to collect estrus phenotypes on a large number of cows (VanRaden, 2020). The potential for genetic selection for improved estrus expression using phenotypic data from activity systems has been established (Boichard and Brochard, 2012; Ismael et al., 2015). Analogous data for tailhead and rump touches are less because there are very few devices that record these data. Two studies were performed to further examine phenotypes associated with estrus expression that could be measured remotely on a large number of cows. The first objective (Study 1) was to examine the suitability of a rump mounted capacitive touch sensing (CTS) device (FlashMate; Farmshed Labs Limited, Hamilton, New Zealand) to record phenotypes for rump touches remotely, determine relevant parameters for the data collected, and estimate the theoretical maximum heritability from the intra-class correlation coefficient. The number and duration of rump touches and the increase in activity at estrus are not identical phenotypes for estrus expression. Although presumably correlated, their phenotypic interclass correlation has not been estimated. We conducted a second study (Study 2), therefore, to determine the phenotypic inter-class correlation between the number of rump touches during estrus measured using the CTS device and the number of steps taken during estrus using an accelerometer. 


\subsection{Materials and Methods}

The studies followed the research animal care and welfare regulations established by the University of Missouri and were approved by the Institutional Animal Care and Use Committee (IACUC). Statistical significance was declared at $P<0.05$ unless stated otherwise.

\subsubsection{Study 1}

Holstein-Friesian cows $(\mathrm{n}=1197)$ across five pasture-based grazing dairy herds located in the United States, New Zealand, and Ireland, were fitted with a capacitive touch sensing (CTS) device that is used for the detection of estrus (FlashMate device;

Farmshed Labs Limited, Hamilton, NZ). The CTS device detects body capacitance using technology that is similar to that used in devices with touchscreens (cell phones, tablets, etc.) and does not detect contacts with inert objects (fences, trees, etc.) (Walker, 2012). The commercial device has a light that begins flashing when a minimum threshold of rump touches is met within a given time period. The CTS devices were attached to the hide between the hip and the pin bone, approximately $10 \mathrm{~cm}$ ventral the tailhead, using an animal safe adhesive (Figure 2.1A). Individual cows were fitted with a CTS device at the start of the breeding period (beginning approximately $60 \mathrm{~d}$ postpartum). The CTS device remained on the cow for $60 \mathrm{~d}$ and recorded the date, time and duration of individual touches that occurred when the cow received a mount or chin rest. Devices were removed at the end of the breeding period and disassembled for data extraction (Figure 2.1).

Touches with the device were identified by a date and time as well as a duration in seconds. The number of touches on each day were summed using a PROC TIMESERIES command in SAS 9.4 (SAS Institute Inc., Cary, NC). 


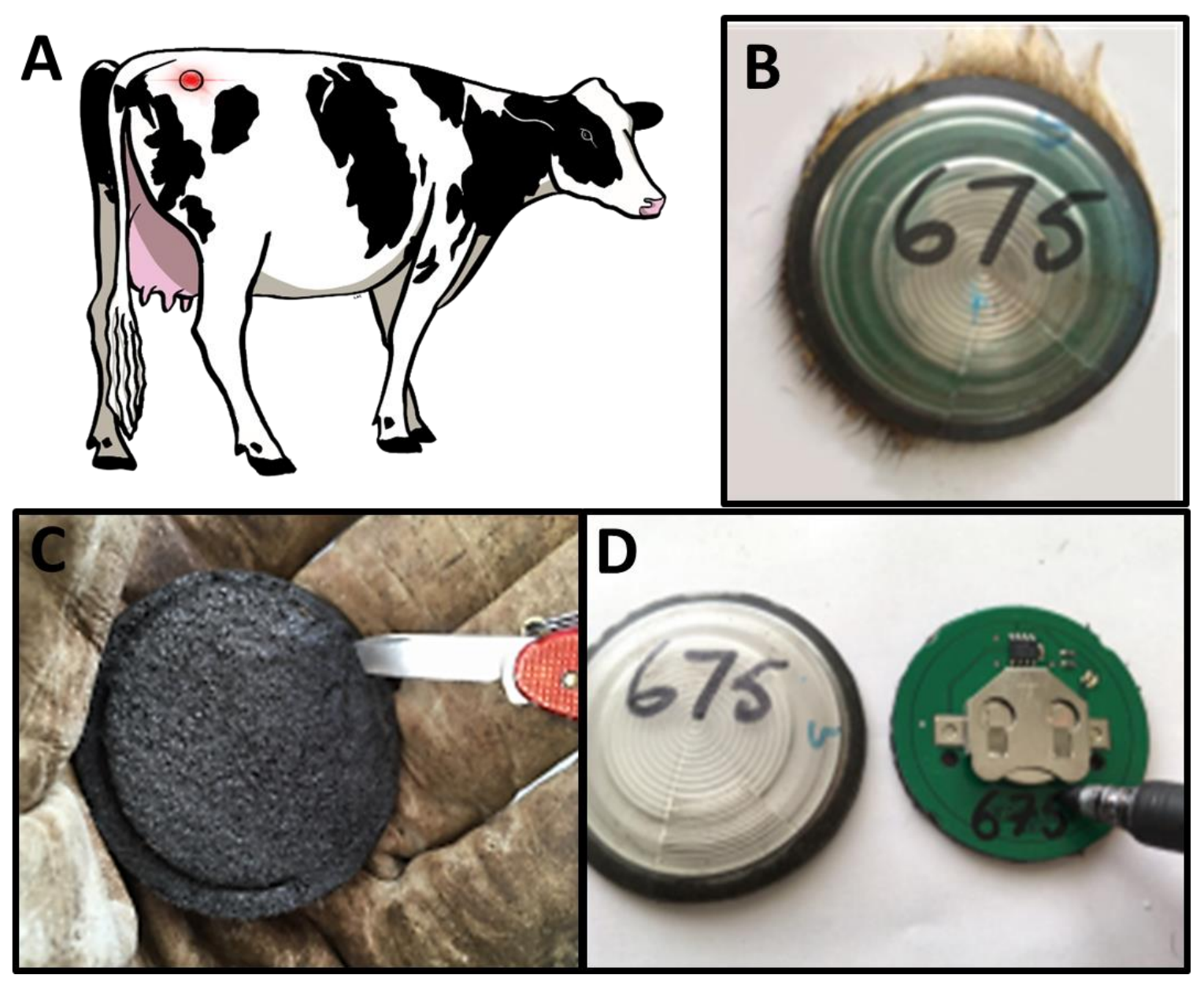

Figure 2.1. Anatomical location, removal, and disassembly for a capacitive touch sensing (CTS) device (FlashMate; Farmshed Labs Limited, Hamilton, NZ) used for measuring the number and duration of rump touches during estrus in postpartum dairy cows. The CTS devices were attached to the hide between the hip and the pin bone (A) and were removed after approximately $60 \mathrm{~d}$ (B). Hair was removed and the back of the device was opened (C). Data were extracted manually from stored electronic memory (D). 
The daily number of touches were subjected to a peak detection program to objectively identify individual peaks (increases in the number of touches above a minimum threshold within a sliding window of time; Figure 2.2) (Croghan and Williams, 2006). A start day for each individual peak was identified. For each identified peak, the number of times touched and the sum of the touch time were calculated for the window of time that included the start day and the next day. The number of days between individual peaks (inter-estrus interval) was calculated.

A cow was defined as non-cycling if the peak detection program failed to detect a peak. The percentage of cows that were non-cycling was tested by using PROC FREQ of SAS (Chi square test). For cows that had at least one peak (cycling), the number of touches and the total touch time for each individual estrus peak as well as the inter-estrus interval were tested for normality using PROC UNIVARIATE of SAS. Data for number of touches and total touch time were not normally distributed and possessed a positive (right-hand) skew. A $\log 10$ transformation was used to reduce the skewness reported by PROC UNIVARIATE. Both the non-transformed and $\log 10$ data were analyzed using PROC MIXED of SAS. The effects of farm and peak number were tested. Peak number was defined as a repeated variable. Cow nested within farm was defined as the subject variable. The inter-estrus interval also possessed a positive skew and both nontransformed and transformed data were analyzed using PROC MIXED. The effects of farm were tested. Cow nested within farm was defined as random. The theoretical maximum heritability for number of touches and the total touch time was estimated by calculating the intra-class correlation coefficient (Wolak et al., 2012). 


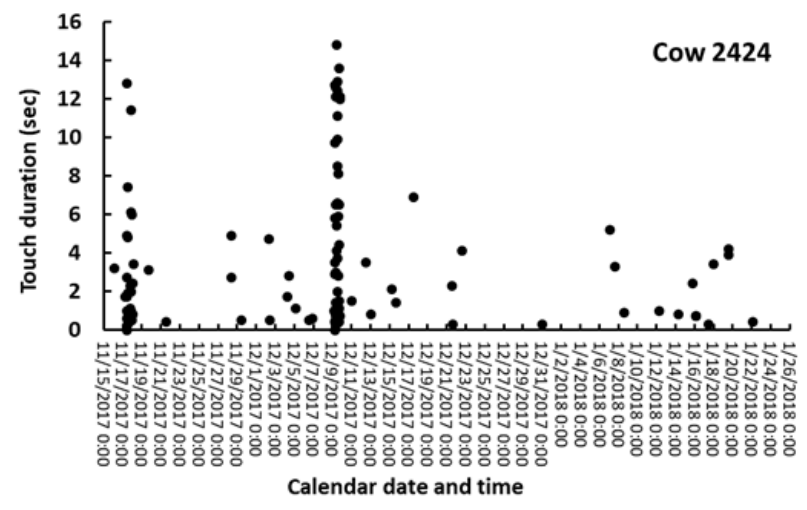

\begin{tabular}{l}
\hline Raw data from the capacitive \\
touch sensing (CTS) device \\
including calendar date, time, \\
and touch duration are \\
offloaded into Excel \\
spreadsheet.
\end{tabular}
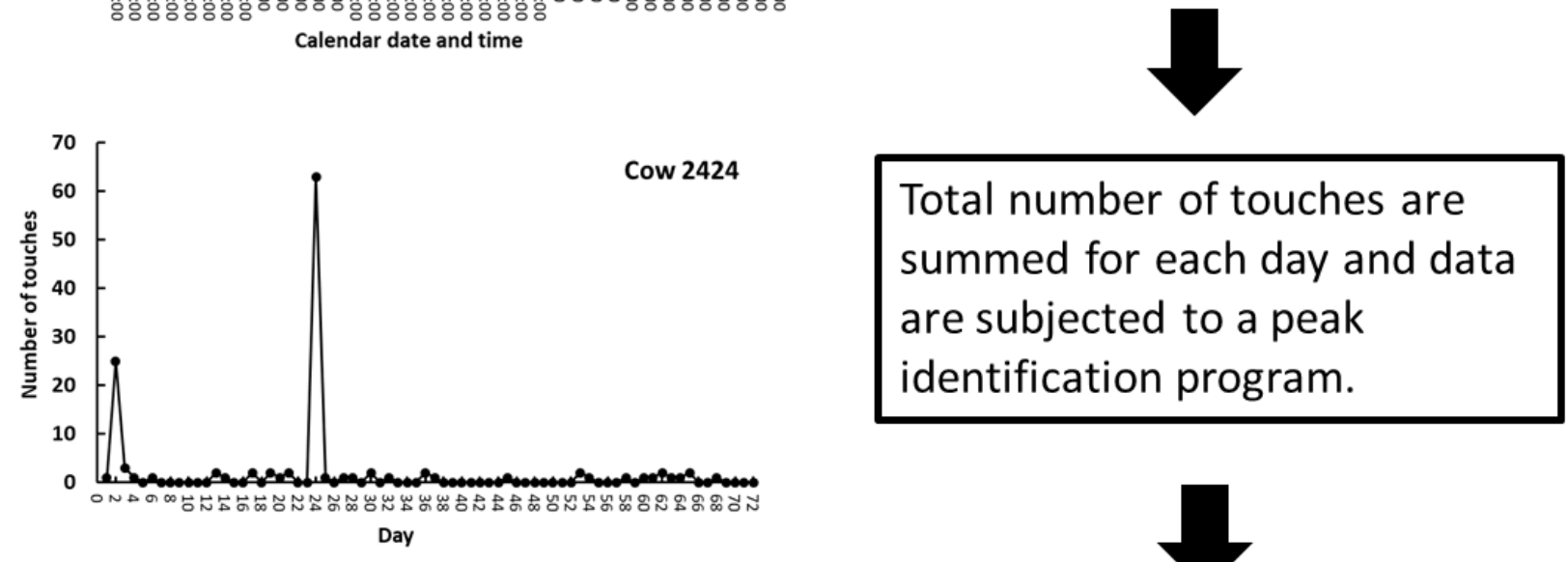

\begin{tabular}{|c|c|c|c|}
\hline Cow & $\begin{array}{c}\text { Peak } \\
\text { number }\end{array}$ & Start day & End day \\
\hline 2424 & 1 & 2 & 4 \\
\hline 2424 & 2 & 24 & 26 \\
\hline
\end{tabular}

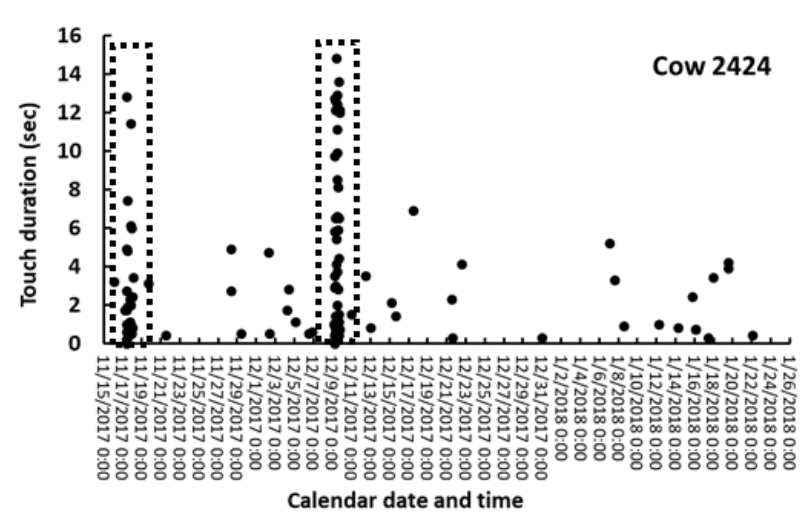

Peaks identified by start day and end day.

Total number of touches and total touch time summed during the peak (dotted box).

Figure 2.2. Strategy for the identification and analysis of the number and duration of rump touches during estrus in postpartum dairy cows fitted with a capacitive touch sensing (CTS) device (FlashMate; Farmshed Labs Limited, Hamilton, NZ). 
A model was fit with PROC MIXED that included peak number and farm. Peak number was defined as a repeated variable with cow nested within farm as the subject variable. If a cow had a third estrus peak it was not included in the analyses because 162 out of 166 cows (98\%) with a third peak came from a single farm (Farm 2). The intraclass correlation coefficient was the common covariance divided by the sum of the common covariance and the residual covariance.

\subsubsection{Study 2}

Animals and facilities: Postpartum lactating Holstein $(\mathrm{n}=85)$ and Guernsey $(\mathrm{n}=5)$ cows at the University of Missouri dairy (Midway, Missouri) were enrolled in the study. Nineteen cows were used in consecutive years, so the total number of postpartum periods was 109. Cows were housed in a grooved concrete floor four-row freestall barn with water or mattress beds covered with cedar shavings. Cows were fed a TMR, ad libitum consisting of corn silage, alfalfa haylage, alfalfa hay, brewer's grain, soybean meal, soy hulls, dry corn, and vitamin/mineral premix balanced to meet nutrient requirements outlined by the National Research Council (National Research Council, 2001).

Study design: The study took place during 2 years, the first year from October 2018 to January $2019(n=57)$ and the second year from October 2019 to January $2020(n=52)$. There were 21 primiparous cows and 36 multiparous cows during year 1 , and 14 primiparous and 38 multiparous cows during year 2. Cows were milked daily with an average daily milk production of $37.6 \pm 7.4 \mathrm{~kg} / \mathrm{d}$ during the trial and $305 \mathrm{ME}$ of $11473 \pm$ $1671 \mathrm{~kg}($ mean $\pm \mathrm{SD})$. 


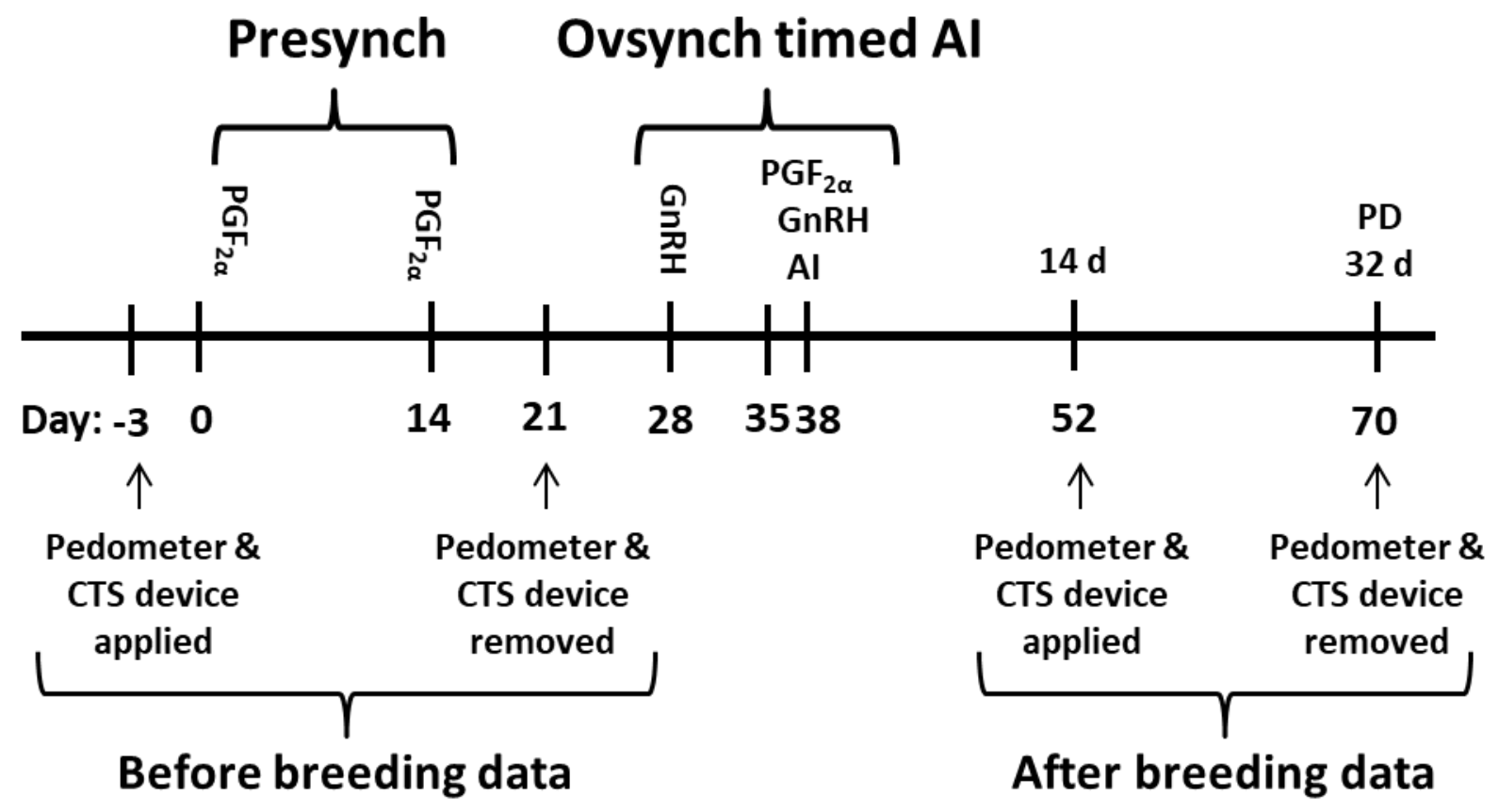

Figure 2.3. Timeline for the collection of phenotypic data for estrus expression in postpartum dairy cows using both an accelerometer (IceQube; IceRobotics Ltd., Edinburgh, UK) and a capacitive touch sensing (CTS) device (FlashMate; Farmshed Labs Limited, Hamilton, NZ). Data were collected during the "Presynch" period of the Presynch Ovsynch program and also following the timed AI [d 14 to pregnancy diagnosis (PD)]. 
Cows were organized into weekly groups and enrolled in a timed AI program ("Presynch Ovsynch 56") with AI occurring $38 \mathrm{~d}$ after the initial $\mathrm{PGF}_{2 \alpha}$ injection (Figure 2.3). Cows were treated with a $\mathrm{PGF}_{2 \alpha}$ injection (PG1) and a second injection of $\mathrm{PGF}_{2 \alpha}$ (PG2) was administered $14 \mathrm{~d}$ later. An injection of GnRH (GnRH1) was given $14 \mathrm{~d}$ after PG2. Seven days after GnRH1, an injection of $\mathrm{PGF}_{2 \alpha}(\mathrm{PG} 3)$ was administered approximately $0800 \mathrm{~h}$ and a second injection of $\mathrm{GnRH}(\mathrm{GnRH} 2)$ was given at $56 \mathrm{~h}$ after PG3. Timed AI was performed $16 \mathrm{~h}$ after GnRH2. Pregnancy diagnosis was done at $32 \mathrm{~d}$ after AI by using an ultrasound equipped with a $5 \mathrm{MHz}$ linear probe (Sonosite Edge; FUJIFILM Sonosite, Inc. Bothell, WA). The $\mathrm{PGF}_{2 \alpha}$ and GnRH for Year 1 were Lutalyse (25 mg dinoprost tromethamine, i.m.) and Factrel (100 $\mu$ g gonadorelin, i.m.) from Zoetis Inc. (Florham Park, NJ). The $\mathrm{PGF}_{2 \alpha}$ and GnRH for Year 2 were estroPLAN $(250 \mu \mathrm{g}$ cloprostenol sodium, i.m.) and GONAbreed (100 $\mu \mathrm{g}$ gonadorelin acetate, i.m.) from Parnell Technologies Pty. Ltd. (Overland Park, KS).

Estrus data were collected during two periods. The first period was before breeding and began $3 \mathrm{~d}$ before PG1 and ended $7 \mathrm{~d}$ after PG2 (Figure 2.3). The second period was after breeding and began $14 \mathrm{~d}$ after $\mathrm{AI}$ and ended at the pregnancy exam ( $32 \mathrm{~d}$ after $\mathrm{AI})$ (Figure 2.2). At the start of each period, the right rear leg of cows was fitted with an IceQube accelerometer (IceRobotics Ltd., Edinburgh, UK) to measure steps taken per hour. At the same time, a CTS device (FlashMate; Farmshed Labs Limited, Hamilton, NZ) was applied to the left and the right rump. Data (steps per $\mathrm{h}$ for the accelerometer and touch number and time for the CTS device) were downloaded from each device after they were removed from the cow. 


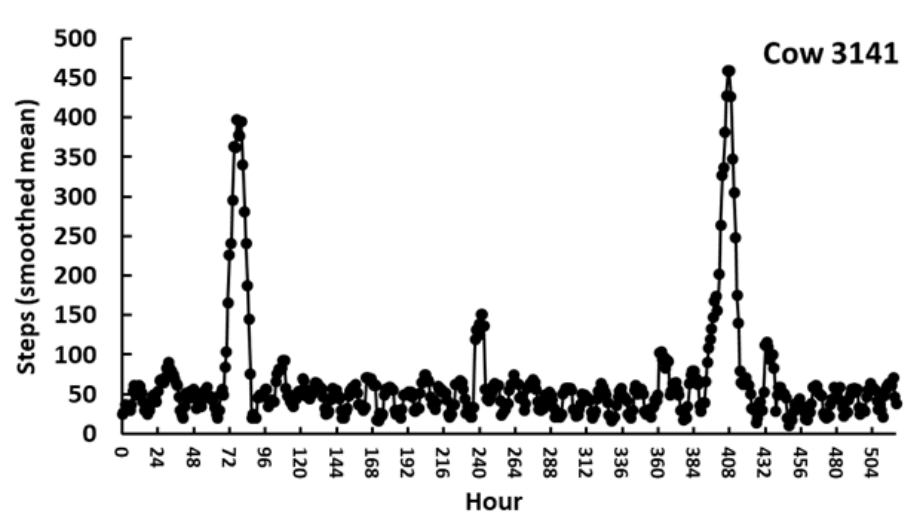

Raw data from an accelerometer (steps) were offloaded into an Excel spreadsheet, summarized by hour and smoothed.

\begin{tabular}{|c|c|c|c|}
\hline Cow & Peak & Start hour & End hour \\
\hline 3141 & 1 & 71 & 85 \\
\hline 3141 & 2 & 395 & 414 \\
\hline
\end{tabular}

Peaks identified by start hour and end hour.

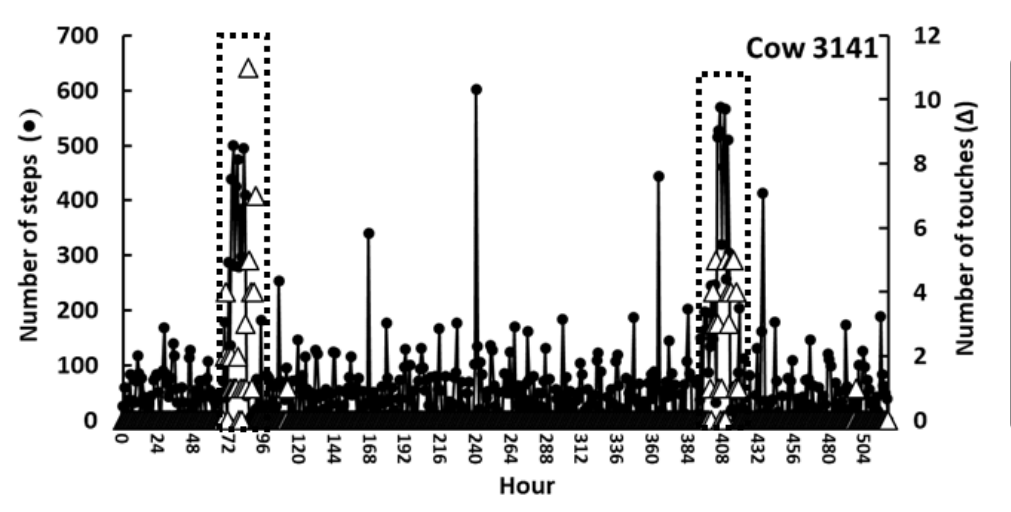

Total number of rump touches, total touch time, and steps summed during the estrus peak.

Figure 2.4. Strategy for the identification and analysis of estrus periods using an accelerometer (IceQube; IceRobotics Ltd., Edinburgh, UK) and a capacitive touch sensing (CTS) device (FlashMate; Farmshed Labs Limited, Hamilton, NZ). 
Estrus peak identification and analysis: The number of steps per $\mathrm{h}$ were subjected to a peak detection program to objectively identify individual estrus peaks (increases in the number of steps above a minimum threshold within a sliding window of time) using the same algorithm described for Study 1 (Croghan and Williams, 2006). The number of steps per $\mathrm{h}$ were smoothed by using a $7 \mathrm{~h}$ moving average (Figure 2.4) and peaks in the number of steps were identified objectively. The start time and end time of the estrus peak was used to define the estrus period.

Statistical analysis: Data (number of touches and touch time) from the left and right CTS device during each $\mathrm{h}$ were summed. Afterwards, two approaches for statistical analysis were employed. The first was a repeated measures analysis that examined the number of steps, the number of touches, and the total touch time during each hour of the estrus period. Hour 0 was defined as the start of the estrus peak. The number of steps, number of touches, and the total touch time during the subsequent $24 \mathrm{~h}$ were analyzed using PROC MIXED of SAS. Data were analyzed for the effects of parity, hour, parity by hour, peak number and parity by peak number. Hour was defined as repeated and cow nested within parity was defined as the subject variable. In a second approach, the number of rump touches, total touch time and the total number of steps was summed for the estrus period. These data were tested for normality using PROC UNIVARIATE as described for Study 1. A $\log 10$ transformation was used to reduce the skewness reported by PROC UNIVARIATE. Both the non-transformed and $\log 10$ data were analyzed using PROC MIXED of SAS. The effects of parity and peak number were tested. Peak number was defined as the repeated variable. Cow nested within parity was defined as the subject variable. 


\subsubsection{Capacitive Touch Sensing (CTS) Device Validation}

Postpartum lactating Holstein $\mathrm{x}$ Jersey cows $(\mathrm{n}=23 ; 14$ primiparous and 9 multiparous) at the University of Missouri dairy were used. Cows were managed as a pasture-based grazing herd and treated with a modified Presynch Ovsynch protocol. Cows were treated with a $\mathrm{PGF}_{2 \alpha}(\mathrm{PG} 1$; Lutalyse) injection and a second injection of $\mathrm{PGF}_{2 \alpha}(\mathrm{PG} 2)$ was administered $14 \mathrm{~d}$ later. Twelve d after PG2, an injection of GnRH (GnRH1; Factrel) was given along with the insertion of a CIDR (Eazi-Breed CIDR, 1.38 g progesterone, intravaginal, Zoetis Inc.). Seven d later, the CIDR was removed and the cows were administered a third injection of $\mathrm{PGF}_{2 \alpha}(\mathrm{PG} 3)$. Cows were inseminated within $12 \mathrm{~h}$ of observed estrus.

At the time of PG1, cows were fitted with an accelerometer (IceQube) to measure the number of steps and a CTS device (FlashMate) to record the number of rump touches. Forty-eight $\mathrm{h}$ after PG2, cows were observed for $3 \mathrm{~d}$ and the number of rump touches was recorded by trained observers. For the purpose of the validation, a rump touch was defined as a full mount, attempted mount and/or chin rest. The number of observed touches were summed over $1 \mathrm{~h}$ intervals from 0700 to $1900 \mathrm{~h}$ on $\mathrm{d} 2$ and 3 and from 0700 to $1300 \mathrm{~h}$ on $\mathrm{d} 4$ after PG2. A second period of observation began $48 \mathrm{~h}$ after PG3 and CIDR removal. The number of observed touches were summed over $1 \mathrm{~h}$ intervals from 0900 to 1800 on d 2 and 0900 to $1300 \mathrm{~h}$ on d 3 after PG3 and CIDR removal. The CTS device and accelerometer were removed after breeding.

The accelerometer data were processed as described for Study 2 (Figure 2.4) so that estrus periods could be identified. The number of observed touches and the number of CTS device recorded touches were summed during the periods of estrus defined by the 
accelerometer peaks. These data were tested for normality using PROC UNIVARIATE as described for Study 1. The effects of parity and peak number were tested using PROC MIXED. Peak number was defined as the repeated variable. Cow nested within parity was defined as the subject variable. The correlation between the number of observed touches and the number of device-recorded touches as well as the correlation between the number of steps and the number of device-recorded touches was calculated by using PROC REG of SAS.

\subsection{Results}

\subsubsection{Study 1}

There were 1759 estrus peaks detected for the 1197 cows across 5 farms. Four hundred and eighty-seven cows had at least two peaks and could be used to calculate the inter-estrus interval. Data for the total number of touches per estrus, total touch time, and inter-estrus interval were not normally distributed (positive skew) when tested using PROC UNIVARIATE (Shapiro-Wilk, $P<0.001$; Kolmogorov-Smirnov, $P<0.01$ Cramer-von Mises $P<0.005$; and Anderson-Darling, $P<0.005$; P-values were identical for the number of touches, total touch time, and inter-estrus interval). The mean, SD, median, skewness, and kurtosis were 33.5, 21.2, 29, 1.47, and 3.18 for number of touches during estrus (Figure 2.5A); 99.1, 74.6, 81.2, 1.76, and 5.12 for total touch time during estrus (Figure 2.5B) and 24.4, 9.7, 22, 1.34, and 2.17 for inter-estrus interval (Figure 2.6) (respectively). A $\log 10$ transformation reduced the skewness and kurtosis for the number of touches $(-0.28$ and -0.05$)$ and the total touch time (-0.49 and 0.29$)$, and reduced skewness for inter-estrus interval (-0.51 and 2.54) (respectively) but tests for nonnormality remained significant $(P<0.01)$. 
Table 2.1. Number of touches and total touch time during estrus and the number of days between estrus peaks (inter-estrus interval) identified by using a capacitive touch sensing (CTS) device (FlashMate; Farmshed Labs Limited, Hamilton, NZ).

\begin{tabular}{|c|c|c|c|c|c|}
\hline \multirow[b]{2}{*}{ Farm } & \multirow[b]{2}{*}{$\mathrm{n}$} & \multirow[b]{2}{*}{$\begin{array}{l}\text { Non-cycling } \\
\text { cows }^{1} \\
{[\text { no./no. }(\%)]}\end{array}$} & \multicolumn{3}{|c|}{ Cycling cows ${ }^{2}$} \\
\hline & & & $\begin{array}{l}\text { Number of } \\
\text { touches }\end{array}$ & $\begin{array}{l}\text { Total touch } \\
\text { time }(\mathrm{sec})\end{array}$ & $\begin{array}{l}\text { Inter-estrus } \\
\text { interval (d) }\end{array}$ \\
\hline 1 & 65 & $4 / 64(6.3)^{b c}$ & $27.1 \pm 2.1^{\mathrm{b}}$ & $60.5 \pm 5.0^{b}$ & $19.1 \pm 1.7^{\mathrm{b}}$ \\
\hline 2 & 781 & $47 / 781(6.0)^{\mathrm{a}}$ & $37.6 \pm 0.6^{\mathrm{a}}$ & $116.0 \pm 2.2^{\mathrm{a}}$ & $25.1 \pm 0.5^{\mathrm{a}}$ \\
\hline 3 & 127 & $14 / 127(11.0)^{\mathrm{c}}$ & $18.9 \pm 1.1^{\mathrm{c}}$ & $38.6 \pm 2.6^{c}$ & $24.1 \pm 2.6^{\mathrm{a}}$ \\
\hline 4 & 91 & $11 / 91(12.1)^{\mathrm{c}}$ & $25.7 \pm 1.7^{b}$ & $58.2 \pm 4.4^{\mathrm{b}}$ & $22.7 \pm 1.3^{\mathrm{a}}$ \\
\hline 5 & 134 & $15 / 134(11.2)^{\mathrm{c}}$ & $19.3 \pm 1.0^{\mathrm{c}}$ & $42.6 \pm 2.3^{c}$ & $18.8 \pm 1.0^{\mathrm{b}}$ \\
\hline
\end{tabular}

${ }^{1}$ Proportions with different superscript differ at $P<0.05$ (Chi square test).

${ }^{2}$ Data were $\log 10$ transformed prior to statistical analysis to reduce right hand skew in the original data. True means and SEM are reported. Based on the analysis of $\log 10$ transformed data, means within a column with different superscript differ at $P<0.05$. 


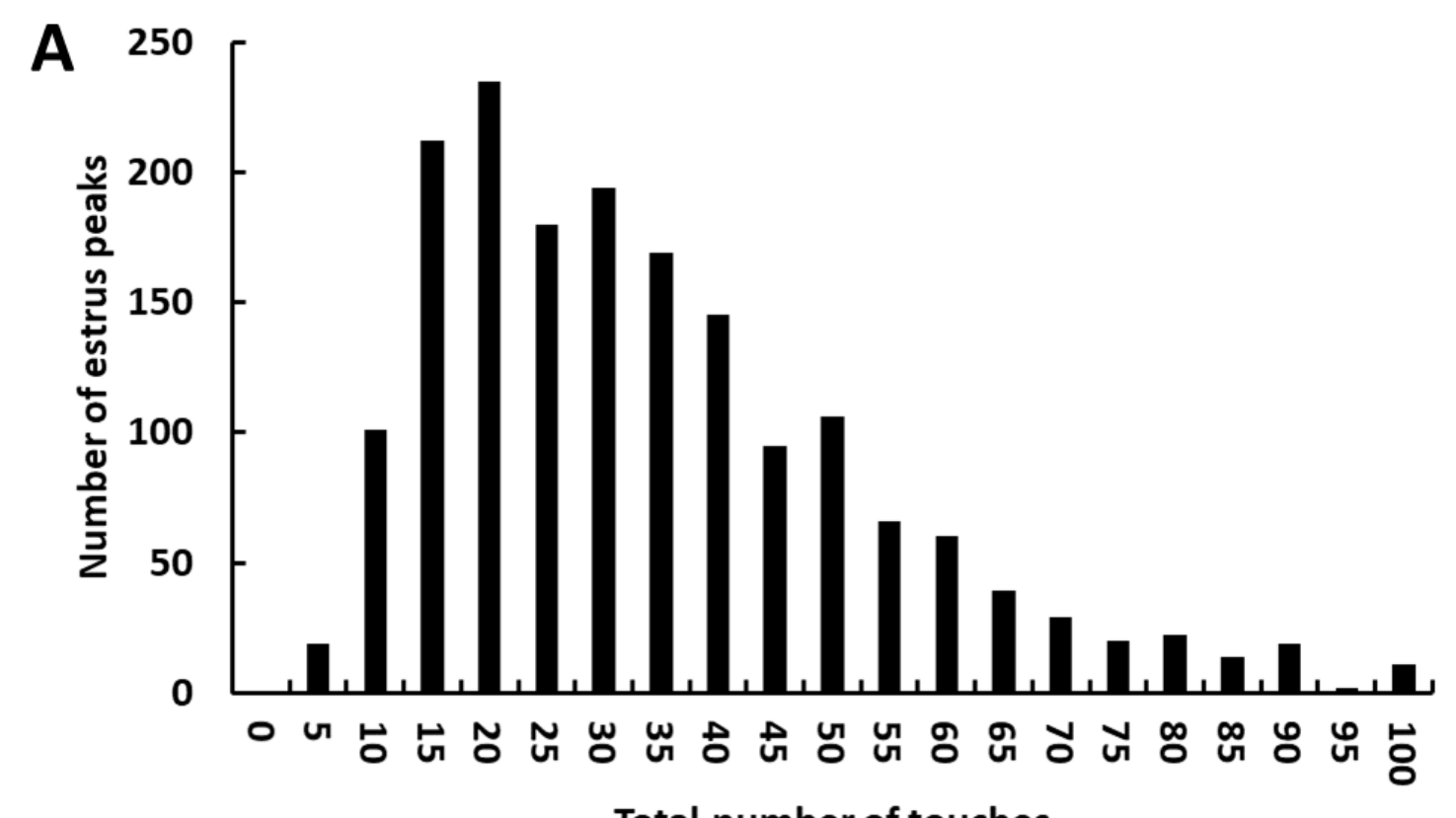

Total number of touches

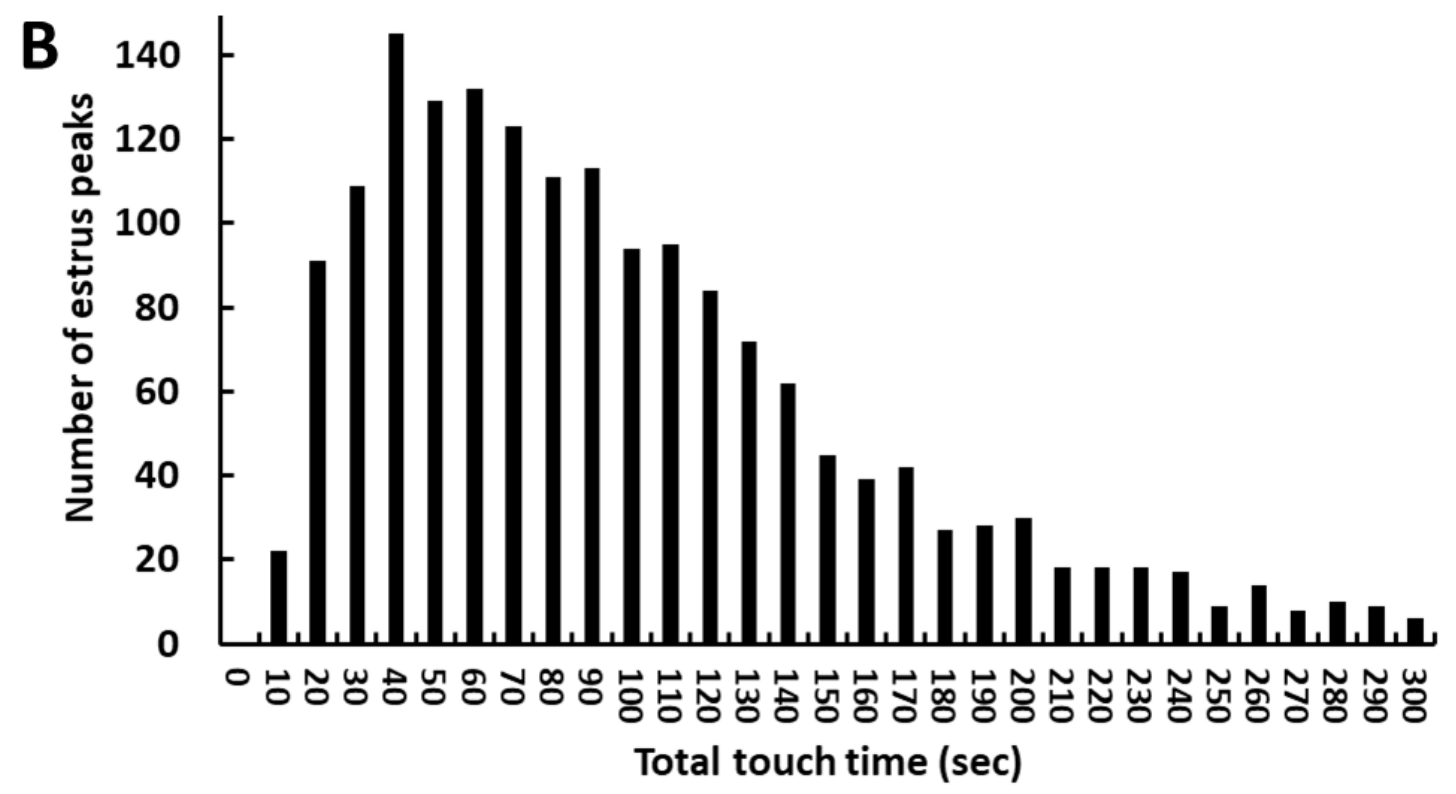

Figure 2.5. Histograms for the number of estrus events with different number of touches (A) and different total touch time (B) during estrus as measured by a capacitive touch sensing (CTS) device (FlashMate; Farmshed Labs Limited, Hamilton, NZ). There were 1759 estrus peaks for the 1197 cows across 5 farms. X-axis label " 5 " in A represents 1 to 5 touches, etc. X-axis label “ 10 ” in B represents 1 to $10 \mathrm{sec}$, etc. 


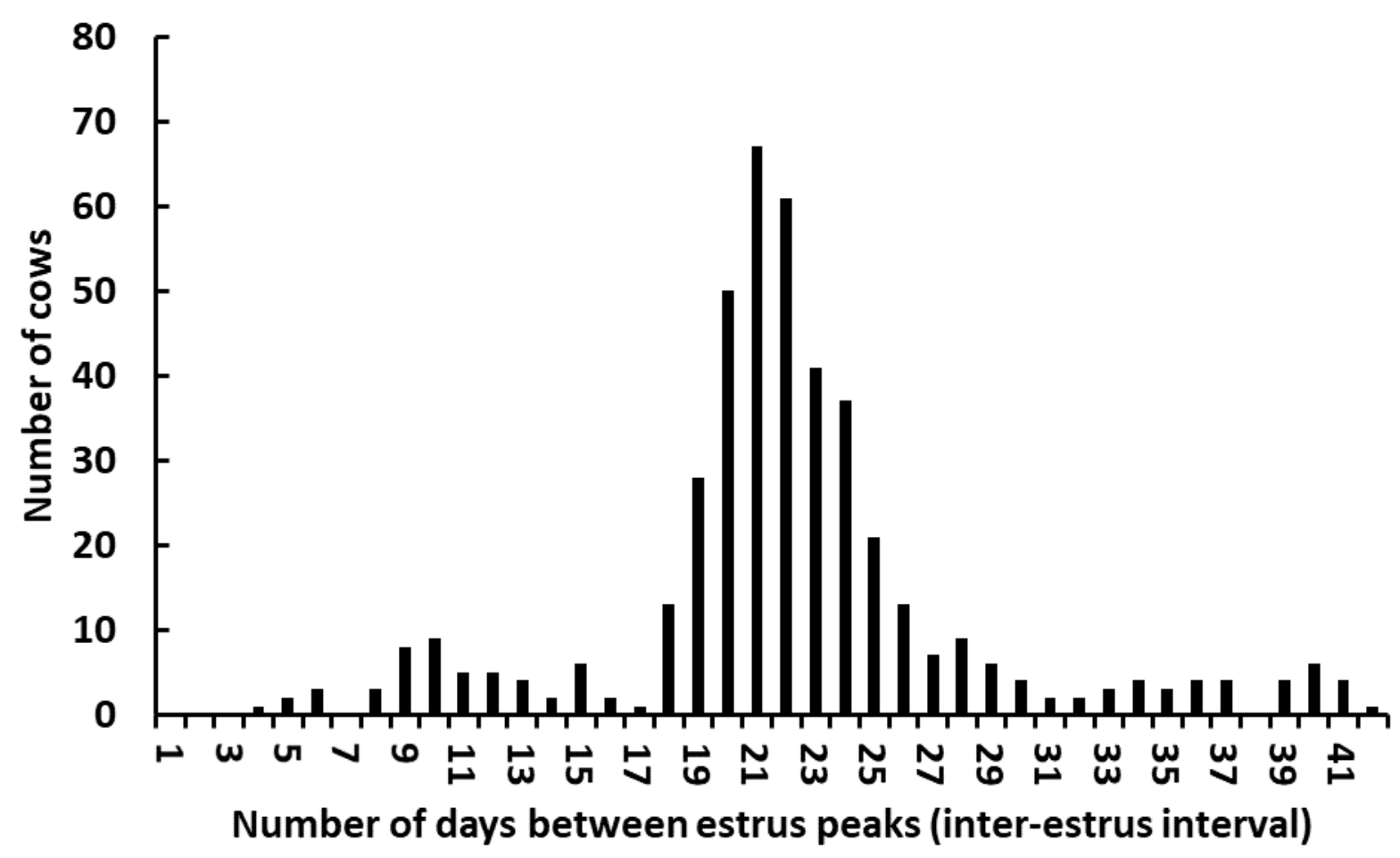

Figure 2.6. Histogram for the number of days between estrus peaks (inter-estrus interval) as measured by a capacitive touch sensing (CTS) device (FlashMate; Farmshed Labs Limited, Hamilton, NZ). There were 487 inter-estrus intervals across 5 farms. 
The $\log 10$ transformed data were used for further analyses and true means and SE are reported (Table 2.1).

Across all herds there were 91 out of 1197 (7.6\%) cows that did not have a detected estrus peak and were classified as non-cycling. Herds differed for the percentage of cows classified as non-cycling $(P<0.05$; Chi square test; Table 2.1). There were 1106 cows with at least one estrus peak (cycling cows). There was an effect of farm $(P<0.001)$ for the total number of touches during estrus, the total touch time, and the inter-estrus interval (Table 2.1). There was an effect of peak number on the total touch time but not the total number of touches. The total touch time ( $\mathrm{sec}$ ) was greater for the second estrus peak $(89.0 \pm 2.1$ vs. $115.2 \pm 3.6$; Peak 1 vs. Peak $2 ; P<0.002)$.

The intra-class correlation coefficient (repeatability) for the non-transformed and $\log 10$ transformed data were $21.9 \%(P<0.001)$ and $22.3 \%(P<0.001)$ for number of touches and $18.7 \%(P<0.001)$ and $21.1 \%(P<0.001)$ for total touch time (respectively).

\subsubsection{Study 2}

There were 90 cows that represented 109 postpartum periods across the two years. Nineteen cows were used both years. Data for the CTS device and accelerometer were obtained for 99 before breeding periods and 94 after breeding periods (Figure 2.3). Based on the analysis of accelerometer data (steps per h), estrus was detected in $76(77 \%)$ of cows before AI and 37 (39\%) of cows after AI. There were 92 cows with a pregnancy diagnosis and 41 were pregnant $(45 \%)$. A peak in the number of steps per $\mathrm{h}$ was detected in 36 of the 51 non-pregnant cows (71\%) and 11 of the 41 pregnant cows (27\%). The area of the step per h peak detected in the pregnant cows was lesser than the area detected in 
the non-pregnant cows $(710 \pm 384$ vs. $3275 \pm 212 ; P<0.001)$. The peaks detected after AI in cows diagnosed pregnant were assumed to be false positives based on their relatively small area and were not considered in further analyses.

Based on accelerometer data (steps per h) and across both years there were a total of 148 estrus periods with 111 periods before AI and 37 periods after AI. Of the 76 cows with at least one estrus before AI there were 41 cows with one peak and 35 cows with two peaks. Estrus periods during the period before AI were clustered 2 to $4 \mathrm{~d}$ after the $\mathrm{PGF}_{2 \alpha}$ injections (Figure 2.7A). The estrus after AI appeared to occur during two periods [d 17 to 24 and d 27 to 31 (Figure 2.7B)].

The number of touches and total touch time for CTS devices mounted on the left and right rump were similar and not affected by parity. There was a correlation between the number of touches and touch time for left- and right- mounted devices defined by the equations left touches $=3.30+$ right touches $x 0.86\left(r^{2}=0.46 ; P<0.001\right)$ and left touch time $=14.7+$ left touch time $x 0.72\left(r^{2}=0.25 ; P<0.001\right)$. The subsequent analyses reported herein were for the sum of touches and touch time for devices mounted on the left and right side.

The number of steps and the number of rump touches increased (effect of hour; $P<$ 0.001) during the estrus period (Figure 2.8). There was also an increase in the total touch time from a minimum of $0.52 \pm 0.61 \mathrm{sec}$ at hour 0 to a maximum of $5.51 \pm 0.61 \mathrm{sec}$ at hour $9(P<0.001)$. There was no effect of parity on the number of steps, rump touches, or touch time during estrus. 

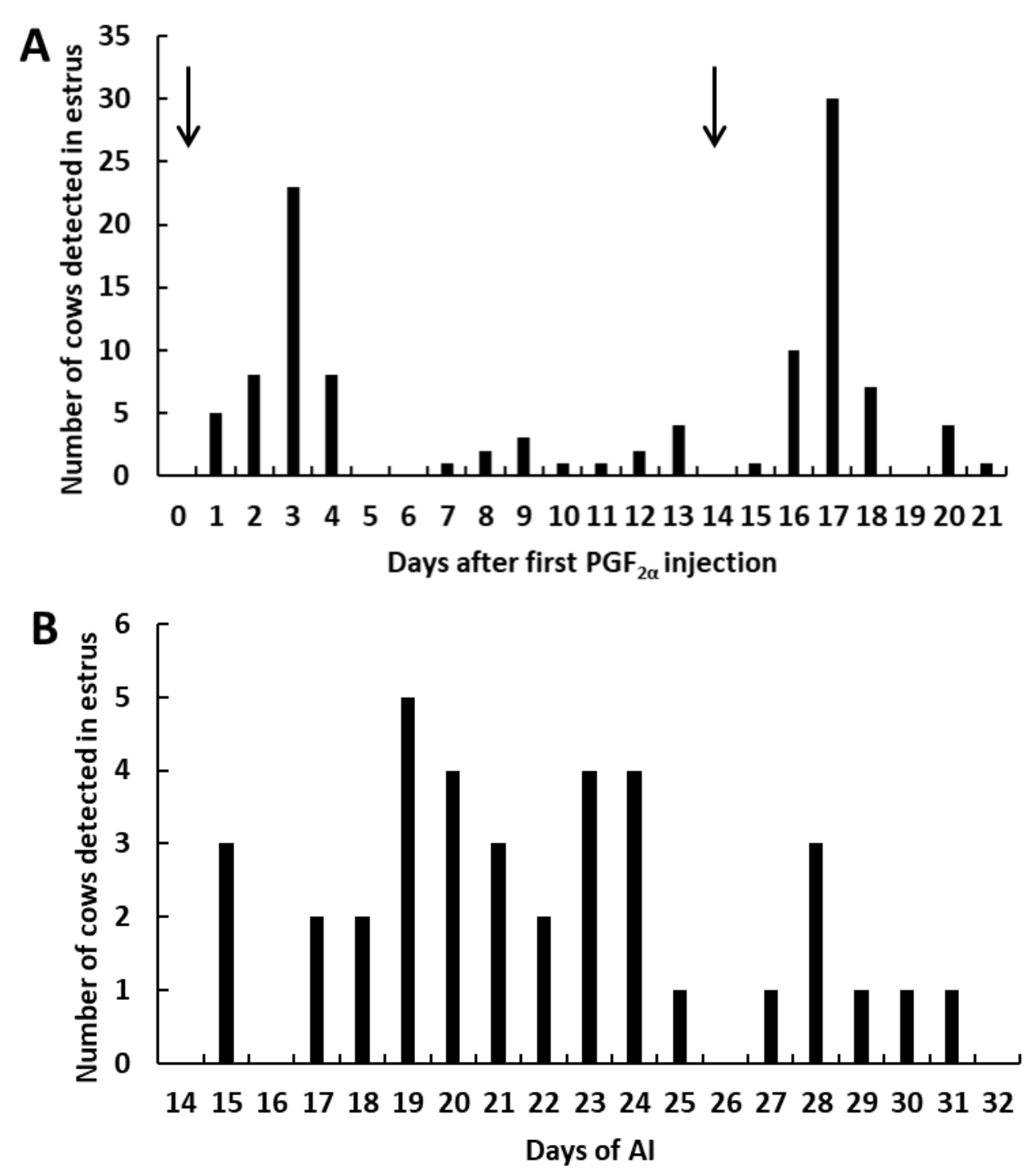

Figure 2.7. Histograms for the number of estrus events on different days after $\mathrm{PGF}_{2 \alpha}$ injection (A) and on different days after AI (B). Cows were fit with an accelerometer (IceQube; IceRobotics Ltd., Edinburgh, UK) and the daily number of steps per hour were subjected to a peak detection program to objectively identify individual activity peaks indicative of estrus (increases in the activity above a minimum threshold within a sliding window of time). Down arrows indicate the days of $\mathrm{PGF}_{2 \alpha}$ injection (PG1 and PG2 within the Presynch program). 


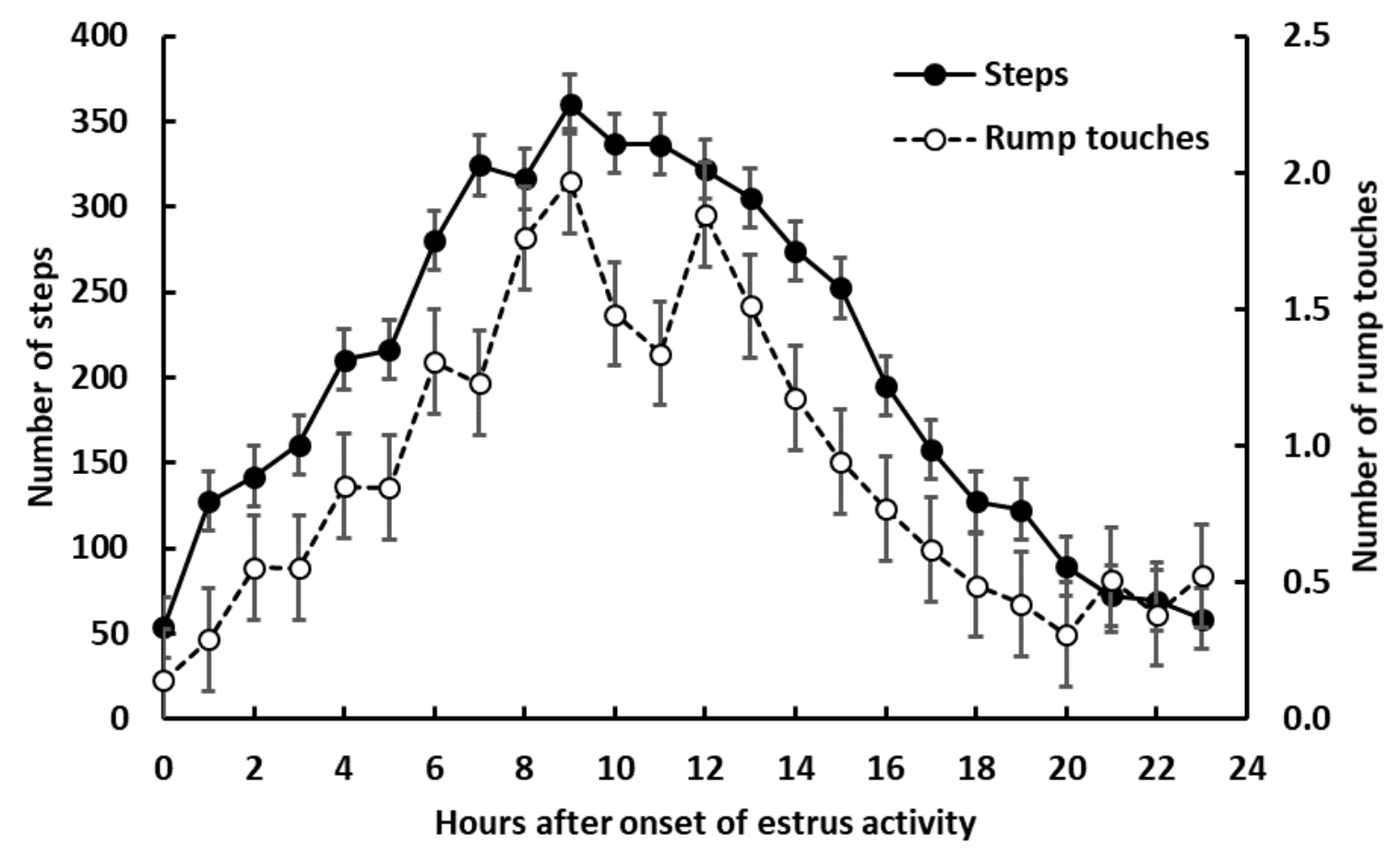

Figure 2.8. Least square means and SEM (bar) for the number of steps measured using an accelerometer (IceQube; IceRobotics Ltd., Edinburgh, UK) and the number of rump touches measured using a capacitive touch sensing (CTS) device (FlashMate device; Farmshed Labs Limited, Hamilton, NZ) during an estrus period. There was an effect of hour $(P<0.001)$ for both the number of steps and the number of touches during estrus. 
There was an effect of peak number for the number of steps $(P<0.05)$, rump touches $(P$ $<0.003)$, and total touch time $(P<0.002)$ (peak $1=$ first peak during the before breeding period; peak 2 = second peak during the before breeding period; and peak 3 = peak in non-pregnant cows after AI). Peak 3 was lesser than either Peak 1 or 2 for the number of steps per hour during estrus, $(212 \pm 10,220 \pm 11$, and $191 \pm 11$ for Peak 1, 2, and 3, respectively; $P<0.05)$. Peak 2 was greater than peak 1 or 3 for the number of touches per hour during estrus $(0.83 \pm 0.08,1.18 \pm 0.11$, and $0.80 \pm 0.01$ for Peak 1,2 , and 3 , respectively, $P<0.01)$ and the total touch time per hour during estrus $(2.34 \pm 0.25,3.50$ \pm 0.34 , and 2.11 \pm 0.32 for Peak 1, 2, and 3, respectively, $P<0.01$ )

The number of steps, total number of touches, and touch time were summed for each estrus period. The mean, SD, median, skewness, and kurtosis were 4846, 2347, 4552, 1.13, and 1.61 for the number of steps during estrus (Figure 2.9A); 20.6, 19.0, 16.0, 0.85, and -0.21 for the number of touches during estrus (Figure 2.9B) and 57.9, 58.0, 40.4, 1.21, and 1.06 for the total touch time (Figure 2.9C) (respectively). Data for the total number of steps per estrus, touches per estrus, total touch time per estrus were not normally distributed when tested using PROC UNIVARIATE (Shapiro-Wilk, $P<0.001$; Kolmogorov-Smirnov, $P<0.01$ Cramer-von Mises $P<0.005$; and Anderson-Darling, $P$ $<0.005)$. After the $\log 10$ transformation, the skewness and kurtosis were -0.30 and 0.007 for the number of steps, -1.27 and 0.59 for the number of touches and -1.37 and 0.79 for total touch time (respectively). Both $\log 10$ transformed and untransformed data were analyzed for the effects of parity and peak number. Neither $\log 10$ transformed nor untransformed data were affected by parity or peak number. The intra-class correlation coefficient for the $\log 10$ transformed and non-transformed data were $26.0 \%(P<0.05)$ 
and $37.2 \%(P<0.01)$ for number of steps. The intra-class correlation coefficients for number of touches and touch time could not be estimated from these data.

The total number of steps during estrus were regressed on the total number of touches (sum of left and right side; Figure 2.10A) and on the total touch time. The regression equations were number of steps $=3655+$ number of touches x $59.0\left(\mathrm{r}^{2}=0.22 ; P<0.001\right.$; Figure 2.10A $)$ and number of steps $=3834+$ total touch time $\mathrm{x} 17.9\left(\mathrm{r}^{2}=0.18 ; P<\right.$ 0.001). The inter-class correlation coefficients (r) for the number of steps and the number of touches and the number of steps and the total touch time were 0.46 and 0.43 (respectively).

\subsubsection{Capacitive Touch Sensing (CTS) Device Validation}

Sixteen of the 23 cows assigned to the validation study had at least one estrus during the observation periods. There were 24 estruses with data for the number of observed touches and the number of CTS device recorded touches within a period of estrus defined by the accelerometer. The mean, SD, median, skewness, and kurtosis were 4.0, 3.8, 3.5, 0.56 , and -1.11 for number of touches during estrus; $7.9,7.9,6.8,0.79$, and -0.33 for total touch time during estrus; and 10.4, 14.1, 4.5, 1.48 and 0.88 for the number of observed

touches during estrus (respectively). There was an effect of parity $(P<0.01)$ on the total touch time $(11.2 \pm 1.6$ vs. $4.8 \pm 1.8)$, a tendency for an effect of parity $(P<0.10)$ on the number of CTS touches $(5.5 \pm 0.9$ vs. $3.3 \pm 1.0)$ but no effect of parity on the total number of observed touches $(8.9 \pm 5.0$ vs. $5.0 \pm 6.0)$ (primiparous vs. multiparous). The effect of peak was not significant for the touch time, number of CTS touches, or number of observed touches. 

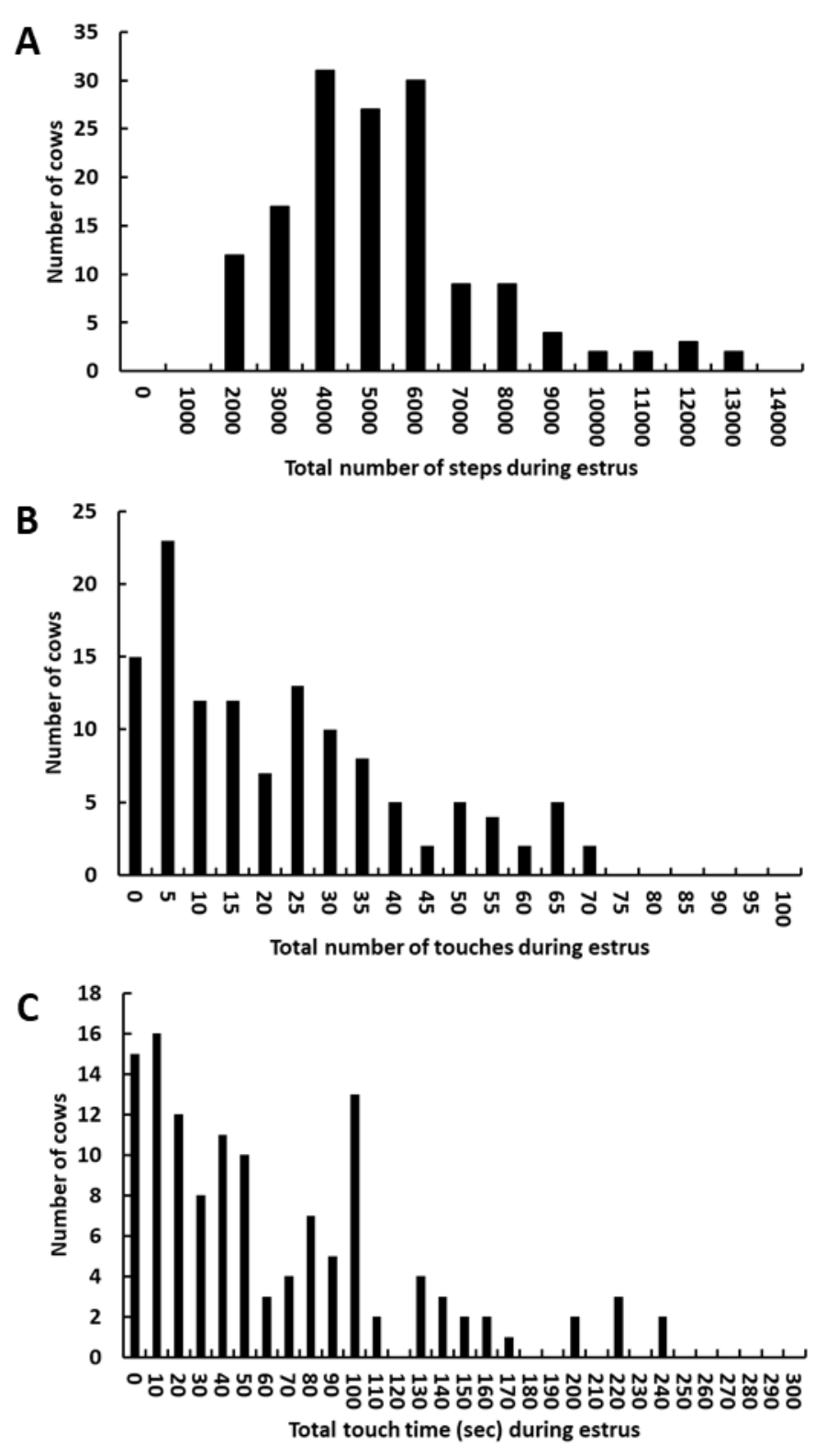

Figure 2.9. Histograms for the number of cows with different numbers of steps (A) rump touches (B) and total touch time (C) during estrus as measured by using an accelerometer (A; IceQube; IceRobotics Ltd., Edinburgh, UK) or a capacitive touch sensing (CTS) device (B and C; FlashMate; Farmshed Labs Limited, Hamilton, NZ). X-axis label “2000" in A represents 1001 to 2000 steps, etc. X-axis label " 5 " in B represents 1 to 5 touches etc., and X-axis label " 10 " in C represents 1 to 10 sec, etc. 

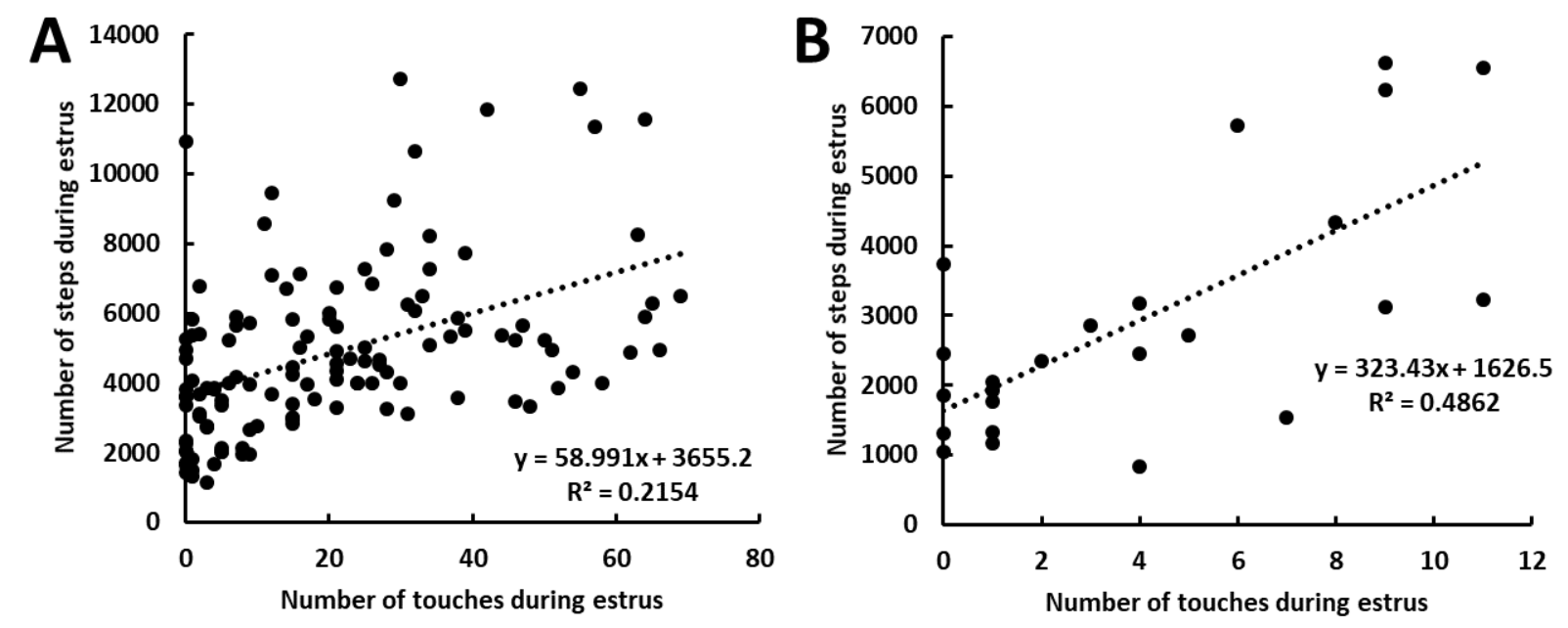

Figure 2.10. Regression of the total number of steps measured by using an accelerometer (IceQube; IceRobotics Ltd., Edinburgh, UK) on the number of rump touches measured by a capacitive touch sensing (CTS) device (FlashMate; Farmshed Labs Limited, Hamilton, NZ) during an estrus period in postpartum dairy cows from Study 2 (A) and the validation study (B). The number of steps increased with an increase in the number of rump touches in both studies $(P<0.001)$. 
The regression of the number of CTS touches on the number of observed touches was significant $\left(\mathrm{CTS}\right.$ touches $=2.17+0.1802 \mathrm{x}$ observed touches; $\left.\mathrm{r}^{2}=0.45 ; P<0.001\right)$.

The regression of the number of steps on the number of CTS touches was defined by the equation: number steps $=1627+323 \mathrm{x}$ number of touches $\left(\mathrm{r}^{2}=0.49 ; P<0.001\right.$; Figure 2.10B). The regression of the number of steps on the total touch time was defined by the equation: number steps $=1920+129 \times$ touch time $\left(r^{2}=0.33 ; P<0.001\right)$. The inter-class correlation coefficients (r) for the number of steps and the number of touches and the number of steps and the total touch time were 0.70 and 0.58 (respectively).

\subsection{Discussion}

The expression of estrus is an important trait that could potentially be subjected to genomic selection (Boichard and Brochard, 2012; Fleming et al., 2019; Ma et al., 2019). The validation of new genetic markers for estrus expression traits requires high throughput and accurate methods to collect estrus phenotypes on a large number of cows (VanRaden, 2020). In support of this effort, we completed two studies that evaluated two different phenotypes for estrous behavior. The first phenotype was for rump touches which is a measure of the number of touches that a cow receives when in estrus. Touches to the rump are slightly different from a true standing event because a cow might be mounted or receive a chin rest from another cow but may not stand still (the definitive sign of estrus) (Hurnik, 1987; Allrich, 1993). The device that we used was not designed to be placed directly on top of the tailhead of the cow but instead was placed laterally on the rump (Figure 2.1). This alternative placement avoids the physical forces that are experienced by devices placed directly on the tailhead where the mounting cow's sternum lands directly on the recipient cow's tailbone. The physical forces can potentially damage 
or dislodge the recording device. Placing the device laterally on the rump obviates the direct measurement of tailhead touches but instead measures chin rests and mounts as the mounting cow slides off the recipient. These rump touches can be quantified efficiently by using a small device that is commercially available, inexpensive, and suitable for the collection of phenotypic data (FlashMate or CTS device). The CTS device is not a pressure activated sensor like the HeatWatch or similar device (Nebel et al., 2000) but instead uses body capacitance sensing with technology that is similar to that used for touchscreens ((Walker, 2012). We performed a small validation trial to verify that the devices measured touches during estrus. Observers recorded rump touches for the cow and did not attempt to record whether the device was actually contacted each time the rump was touched. The CTS were mounted on one side only. Despite these limitations, the coefficient of determination $\left(\mathrm{r}^{2}\right)$ for observed and recorded rump touches approached $50 \%$.

The second phenotype for estrous behavior was the number of steps per $\mathrm{h}$ measured by an accelerometer. Cows that come into estrus have more steps in part because they are being chased by cows who are attempting to mount (Hurnik, 1987; Allrich, 1993). Cows in estrus are also restless and will walk the pen in search of other cows in estrus. Accelerometers (attached to either the leg or neck) are used commercially on farms (Mottram, 2016; Reith and Hoy, 2018) and are a potential source of estrus phenotypes for a large number of cows.

In each case, we avoided the use of commercial algorithms to detect periods of estrus. The collective objective of both studies was the evaluation of phenotypes for estrus expression. This objective is different from commercial algorithms whose purpose is to 
detect estrus in real time. The algorithm that we used was adapted from a peak detection program written for SAS 9.4 (Croghan and Williams, 2006). Data were smoothed and inflection points were identified for the start and stop of each estrus peak. The program itself calculates the start time, end time, area and maximum for each peak. For our purposes we took the start and end time from the program and returned to the original dataset to sum the total number of touches and touch time (Study 1; Figure 2.2) or the total number of steps, touches, and touch time (Study 2; Figure 2.4) during the estrus period. The identified peaks followed expected patterns for estrus expression. In Study 1, for example, the interval from first to second estrus peak followed an expected return interval of approximately $21 \mathrm{~d}$ (Figure 2.6). For Study 2, peaks in estrus activity (steps per h) occurred 2 to $4 \mathrm{~d}$ after an injection of $\mathrm{PGF}_{2 \alpha}$ (Figure 2.7A) when they would be expected to occur (Lucy et al., 2004).

Data for the number of touches and total touch time were not normally distributed. A histogram of the data demonstrated a positive (righthand) skew (Figure 2.5). The positive skew is explained by individual cows with very intense estrus expression. A large variance and positive skew is a characteristic of estrus phenotypes (Hurnik, 1987; Allrich, 1993). Data from Study 1 were $\log 10$ transformed prior to analysis and the skewness, and kurtosis values improved. As expected, we observed an effect of herd for most of the data that we collected in Study 1. The percentage of non-cycling cows (cows without any evidence of a peak in rump touches) ranged from 6.0 to $12.1 \%$; a percentage that is typical for postpartum cows entering the breeding period (Santos et al., 2016). The number of touches and total touch time demonstrated a two to three-fold range from lowest to highest herds. The herds that we used for Study 1 were all pasture-based 
grazing herds. Compared with confinement, pasture-based herds should have greater estrus expression (Palmer et al., 2010) and our data support this conclusion. Confinement cows in Study 2, for example, where the number of touches and touch time were summed across two (left and right) CTS devices had approximately the same number of touches and touch time compared with Study 1 cows that carried a single device. Other factors that could explain the differences in estrus expression could be the number of cows in estrus at the same time, nutrition, genetics, weather, and barn/pasture conditions (Madureira et al., 2015; Polsky et al., 2017; Stevenson and Britt, 2017).

Approximately one-third of the cows in Study 1 had two estrus events. Most of the second estruses occurred 19 to $27 \mathrm{~d}$ after the first estrus (Figure 2.6). There also appeared to be a small population of cows returning to estrus between 9 and $12 \mathrm{~d}$ (Figure 2.6). The first population (d 9 to 12) represented short cycle cows (Santos et al., 2016). The second population represents true returns to estrus with the slight positive skew representing cows that underwent embryonic loss after first breeding (Ealy and Seekford, 2019). The second estrus enabled us to calculate a repeatability or intra-class correlation coefficient for estrus expression because we had two estrus observations per cow. The intra-class correlation coefficient can be used to approximate the maximum heritability for a trait (Wolak et al., 2012). In either case (number of touches or total time), the intra-class correlation coefficient was approximately $20 \%$. Reproductive traits are heavily influenced by environmental factors and typically have heritability of 5 to 10\% (Mottram, 2016; Reith and Hoy, 2018; Lucy, 2019). Our heritability estimate based on these data is consistent with a relatively low heritability for estrus expression traits. 
The second study (Study 2) tested the correlation between rump touches and steps per h during estrus. Cows in estrus have an increase in rump touches but they also have greater activity. Presumably the rump touches are correlated with activity but to our knowledge the correlation between the two phenotypes has not been estimated. The mostlikely phenotype for genomic selection of estrus expression will be the increase in activity at estrus because there are a large about of activity data that is theoretically available within the dairy industry (Ismael et al., 2015; Mottram, 2016; Stevenson and Britt, 2017). The question that we had was whether activity at estrus (steps per $\mathrm{h}$ in this study) was a true proxy for rump touches at estrus. If the correlation is high then selecting for activity should lead to cattle that are more active and also experience more rump touches (riding, mounting, and chin rests). If the correlation is low then selection for activity will lead to cows that are more active but do not necessarily show other signs.

Study 2 differed from Study 1 because cows in a traditional confinement freestall barn were used. Estrus periods were identified based on an increase in accelerometer activity (steps) and the total steps, touches and touch time were calculated during the estrus window (Figure 2.4). We used the accelerometer activity in lieu of rump touches to identify estrus periods because the number of steps is calculated at a regular hourly interval and the programming within the algorithm is simpler. We found estrus periods from 2 to $4 \mathrm{~d}$ after the injection of $\mathrm{PGF}_{2 \alpha}$ (Figure 2.7A) and non-pregnant cows returned to estrus within 15 to $25 \mathrm{~d}$ or 27 to $31 \mathrm{~d}$ after AI (Figure 2.7B). These estrus periods are within an expected timeframe for $\mathrm{PGF}_{2 \alpha}$-treated cows (Lucy et al., 2004) and for cows that are not pregnant after AI (Greenham et al., 2019). Seventy-seven percent of cows had a detectable increase in activity (steps per $\mathrm{h}$ ) before AI (Figure $2.7 \mathrm{~A}$ ) and $71 \%$ of the 
non-pregnant cows had a detectable increase in activity after AI (Figure 2.7B). These percentages for detected estrus using activity are similar to those reported by Fricke et al. (2014). We also detected estrus peaks (an increase in the number of steps per h) in pregnant cows after AI but these peaks were approximately one-fourth the size of those in non-pregnant cows.

We initially examined the relationship between the number of touches and the number of steps from 0 to $23 \mathrm{~h}$ after the start of the estrus (Figure 2.8). This analysis was done for all estruses (before and after AI). The profiles for the number of steps and the number of rump touches were nearly identical (Figure 2.8) and similar to total touch time (data not shown). Regardless of how estrus expression was measured (steps or rump touches), the measurements progressively increased to approximately $10 \mathrm{~h}$ and declined thereafter. One interpretation from these data is that the increase in steps is a consequence of rump touches (chin rests and mounting) during estrus. The timing of activity and rump touches that we report (Figure 2.8) differed slightly from Dobson et al. (2018) who found that the period of rump touches was slightly ahead of the period of activity (Dobson et al., 2018).

We next summed the number of steps, the number of touches and the total touch time during the entire estrus period (Figure 2.9). The total number of touches (Figure 2.9B) and the touch time (Figure 2.9C) demonstrated a positive skew as was found for Study 1. The positive skew appeared to be less pronounced for the number of steps (Figure 2.9A). The number of steps was regressed on the number of touches during estrus (Figure 2.10A) and on the total touch time during estrus. The inter-class correlation (r) for the regression of number of steps on the number of touches was 0.46 and for the number of 
steps on the total touch time was 0.43 . The $\mathrm{r}^{2}$ represents the amount of variation explained by the regression. Approximately one-fifth (20\%) of the variation in the number of steps, therefore, was explained by the number of rump touches that the cow received. The intra-class correlation (estimate of maximum heritability) for the number of steps during estrus was $26 \%$.

Study 2 demonstrated that rump touches and steps during estrus were moderately correlated $(\mathrm{r}=\sim 0.5)$. Study 2 was performed with postpartum cows in a freestall barn. The validation study was conducted with postpartum cows on grass pasture. The validation study was smaller ( $\mathrm{n}=24$ estrus events) and not specifically designed to test the correlation between steps and rump touches (CTS device). Nonetheless, the interclass correlation (r) for the number of rump touches and the number of steps was 0.70 (Figure 2.10B). The numerically greater $\mathrm{r}$ for the validation study compared with Study 2 may indicate that grass pasture or dirt lots where cows have superior footing may provide a better design for studying and collecting estrus phenotypes. Based on the $\mathrm{r}^{2}$, from 20 (freestall) to 50 (grass pasture) percent of the variation in steps per h during estrus is the walking and movement that the cow does in response to rump touches (mounts and chin rests). Selecting for activity, therefore, should increase behavioral signs of estrus in a confinement or pasture-based setting. Conversely, selecting for rump touches should increase the amount of activity (steps per h or other) at estrus. Phenotyping of a large number of cows could be done by assembling datasets from leg-mounted accelerometers, neck-mounted collars, or rump-mounted devices similar to the CTS device described herein. 


\subsection{Conclusions}

Two studies were conducted to assess different methods for the collection of estrus phenotypes. Data collected from 5 pasture-based herds using a device that detected and recorded rump touches demonstrated a two to three-fold difference between herds in the number of touches and touch time at estrus. In a second study, rump touches and steps during estrus were measured on the same cows in a freestall barn. The inter-class correlation (r) for rump touches during estrus and steps during estrus was approximately 0.45. Either method (rump touches or steps during estrus) had an intra-class correlation coefficient (estimate of maximum heritability) of approximately 0.2 . Selecting cows for steps per h or other activity during estrus should increase the amount of rump touches (mounts, chin rests, etc.) because at least $20 \%$ of the variation $\left(r^{2}\right)$ in estrus activity is explained by the estrus cow walking in response to other cows interacting with her rump. Likewise, selecting cows for rump touches at estrus using a CTS device (or similar) should increase activity at estrus. 


\section{Chapter Three:}

\section{SIMULTANEOUS MEASUREMENTS OF ESTRUS BEHAVIOR AND PLASMA CONCENTRATIONS OF ESTRADIOL DURING ESTRUS IN LACTATING AND NONLACTATING DAIRY COWS}

\subsection{Abstract}

Estrus is an important behavior that can potentially be subjected to genomic selection. Circulating estradiol concentrations at estrus may be a useful phenotype if the absolute concentrations of estradiol are associated with overt phenotypes for estrus [greater activity and (or) rump touches (mounts, chinrests, etc.)] that can be easily observed on farm. The objective was to measure plasma estradiol concentrations at estrus and associate these measurements with the increase in the number of steps and rump touches at estrus. We also tested the effect of lactation on the estrus traits that we measured. Cows ( $\mathrm{n}=11$ lactating and $\mathrm{n}=9$ nonlactating) were treated with $\mathrm{PGF}_{2 \alpha}$ to synchronize estrus. The jugular vein was cannulated to collect blood every $2 \mathrm{~h}$ for plasma estradiol measurement. Plasma LH was measured during the periestrual period to determine the time of the LH surge. Cows were fitted with an IceQube (IceRobotics Ltd., Edinburgh, UK) accelerometer to measure activity (steps per $h$ ) and a capacitive touch sensing (CTS) device (FlashMate; Farmshed Labs Limited, Hamilton, NZ) to measure the number of rump touches and total touch time. Plasma estradiol concentrations were poorly correlated with overt signs of estrus during the period leading up to maximum estrus activity. After peak estrus activity (when cows were going out of estrus and plasma estradiol concentrations were decreasing) there was a strong correlation between overt signs of estrus and plasma estradiol concentrations. Effective selection for improved 
estrus expression based on plasma estradiol concentrations will depend on whether the cow is coming into or going out of estrus at the time of blood sampling. Lactation shortened the number of hours in estrus when estrus was defined by an increase in activity (steps per h) but did not affect the number of rump touches or total touch time. Lactating cows ended the estrus period sooner because the interval from the onset of estrus activity to the LH surge was shorter. Selection for a longer estrus period (based on activity) could potentially increase the interval from the onset of activity to the LH surge and provide for a longer estrus. Understanding the mechanisms that control the sensitivity of the cow to estradiol and making appropriate selection decisions based on these mechanisms will likely increase overt signs of estrus in dairy cows.

\subsection{Introduction}

Cows are inseminated approximately $12 \mathrm{~h}$ after the onset of estrus so that sperm have adequate time to capacitate inside the female reproductive tract before ovulation. Detection of estrus is an absolute necessity, therefore, to appropriately time the AI of cows (Lucy et al., 2004; Mottram, 2016; Stevenson and Britt, 2017). Expression of estrus beyond a minimum level for detection is desirable as well because cows that express a more intense estrus have greater pregnancy per AI (Madureira et al., 2015). In the United States, timed AI programs have decreased the dependence on the detection of estrus because cows are inseminated at a set time. A predetermined sequence of treatments controls luteal function, follicular maturation and ovulation so that the time of AI is optimum. Although estrus expression is not a requirement, it is generally accepted that cows that express estrus near the timed AI have greater fertility (Sterry et al., 2006; Richardson et al., 2016). Many herds use a combination of timed AI and AI after 
observed estrus (hybrid approach) to maximize the number of pregnancies and shorten the interval from calving to pregnancy (Cavalieri et al., 2003; Fricke et al., 2014; DenisRobichaud et al., 2018).

Genetic selection for improved estrus expression is possible but the validation of new genetic markers will require high throughput and accurate methods to collect estrus phenotypes from a large number of cows (VanRaden, 2020). Data from commercial systems that measure the increase in animal activity at estrus have been used for this purpose and their utility established (Boichard and Brochard, 2012; Ismael et al., 2015). It is also possible to remotely measure the number of tailhead or rump touches during estrus but there are very little data because few farms use these systems (Nebel et al., 2000). The expression of estrus depends on an endocrine mechanism where estradiol from the dominant follicle acts on the hypothalamus (Hurnik, 1987; Allrich, 1993). Lactating cows have greater metabolism of circulating estradiol and suboptimal estradiol concentration during estrus (Lopez et al., 2002, 2004). Expression of estrus in lactating cows, therefore, could theoretically be improved through selection for greater circulating estradiol at estrus. We designed a study to test the relationship between circulating estradiol and overt phenotypes for estrus expression [increased activity and an increase in rump touches (mounting, chin rests, etc.)]. The hypothesis was that plasma estradiol concentrations at estrus would be associated with the increase in the number of steps at estrus and the increase in the number of rump touches and total touch time at estrus. We also hypothesized that lactation would decrease plasma estradiol concentrations and estrus expression. 


\subsection{Materials and Methods}

The studies followed the research animal care and welfare regulations established by the University of Missouri and were approved by the Institutional Animal Care and Use Committee (IACUC). Nonpregnant lactating $(n=11 ; 237 \pm 69$ DIM; mean \pm SD) and non-lactating $(\mathrm{n}=9)$ Holstein and Holstein-Jersey crossbred cows at the University of Missouri dairy (Columbia, Missouri) were enrolled in the study. Nonlactating cows were a minimum of 6 wk dry. Six cows in the lactating cow group were also used in the nonlactating cow group following dry-off. The study took place during October 2019 (late lactation cows, $n=5$ ), November 2019 (late lactation cows, $n=6$ ), and January 2020 (nonlactating cows, $n=9$ ). For lactating cows, there were 2 crossbred primiparous, 3 crossbred multiparous, 2 Holstein primiparous and 4 Holstein multiparous. For nonlactating cows, there were 1 crossbred primiparous, 2 crossbred multiparous, 3 Holstein primiparous and 3 Holstein multiparous. The lactating cows were milked twice daily with an average daily milk production of $23.3 \pm 3.2 \mathrm{~kg} / \mathrm{d}$ during the trial. Cows were treated with a $\mathrm{PGF}_{2 \alpha}$ injection (estroPLAN, $250 \mu \mathrm{g}$ cloprostenol sodium, i.m.) and a second injection of $\mathrm{PGF}_{2 \alpha}$ was administered $14 \mathrm{~d}$ later. An additional $\mathrm{PGF}_{2 \alpha}$ injection was administered $8 \mathrm{~h}$ after the second $\mathrm{PGF}_{2 \alpha}$ injection. Approximately $24 \mathrm{~h}$ after the second $\mathrm{PGF}_{2 \alpha}$ injection, the right rear leg of cows was fitted with an IceQube accelerometer (IceRobotics Ltd., Edinburgh, UK) to measure activity in steps taken per h. At the same time, a capacitive touch sensing (CTS) device (FlashMate; Farmshed Labs Limited, Hamilton, NZ) was applied to the left and the right rump between the hip and the pin bone, approximately $10 \mathrm{~cm}$ ventral the tailhead, using an animal safe adhesive. The CTS device uses capacitive (touch) sensing technology similar to that used in devices with 
touchscreens (cell phones, tablets, etc.) and detects large shifts in body capacitance that occur when a cow is in contact with the CTS device. Capacitive sensing technology will not detect touches with inert objects as they do not exhibit body capacitance (fences, rails, etc) (Walker, 2012). The CTS device recorded the date, time and duration of individual touches that occurred when the cow received a mount or chin rest. After device application, 2 jugular cannulas (primary and backup) were inserted for the purpose of blood sample collection.

Cows were moved to a covered dry lot with a dirt floor after the jugular cannulation and device application and blood sample collection began within $6 \mathrm{~h}$ (approximately $36 \mathrm{~h}$ after the second $\mathrm{PGF}_{2 \alpha}$ injection) and continued every $2 \mathrm{~h}$ until ovulation. Blood was collected into $10 \mathrm{~mL}$ EDTA (ethylenediaminetetraacetic anticoagulant) Vacutainer tubes and processed immediately by centrifugation at $4{ }^{\circ} \mathrm{C}$ for $15 \mathrm{~min}$ at $1,500 \mathrm{x}$. Plasma was aliquoted and stored at $-20^{\circ} \mathrm{C}$. Plasma estradiol was measured using a radioimmunoassay previously validated in our laboratory (Kirby et al., 1997). The intra- and inter-assay CV for the estradiol assays were 11 and $18 \%$, respectively. Plasma LH concentrations were measured using a bovine LH ELISA kit (Abnova, Taipei City, Taiwan) recently used to characterize the LH surge during estrus in postpartum dairy cows (Adriaens et al., 2019). The intra- and inter-assay CV for the LH assays were 3 and 6\%, respectively. Samples were assayed for LH during a $20 \mathrm{~h}$ period when cows were in estrus (10 samples per cow). The beginning of the LH surge was defined as the first sample at the onset of the LH surge that was a minimum of 2 SD above the average of the two previous samples. The sample with the greatest LH concentration was defined as the LH peak. The end of 
the LH surge was defined as the last sample that was a minimum of 2 SD above the average of the two subsequent samples.

Ovaries were examined once daily by using transrectal ultrasound to verify regression of the corpus luteum, development of the preovulatory follicle, and ovulation after estrus. Cannulas, accelerometers, and CTS devices were removed after the cow was observed in estrus and ovulation was confirmed by ultrasonography. Lactating and nonlactating cows were fed the same TMR ad libitum that consisted of corn silage, alfalfa haylage, alfalfa hay, brewer's grain, soybean meal, soy hulls, dry corn, and vitamin/mineral premix.

The daily number of steps per $\mathrm{h}$ were subjected to a peak detection program to objectively identify individual activity peaks (increases in the number of steps per $h$ above a minimum threshold within a sliding window of time) using an algorithm described by Croghan and Williams (2006). The number of steps per hour were smoothed by using a $7 \mathrm{~h}$ moving average and peaks in activity (steps per h) were identified objectively. The start time and end time of the increase in activity above baseline was used to define the estrus period. Data (number of touches and total touch time) from the left and right CTS device during each hour were averaged. There were three cows that lost one of the CTS devices and data from a single side were used for these cows.

Three approaches for statistical analysis were employed. The first was a simple approach where the total time in estrus (based on activity; results derived from the algorithm), the total number of steps, touches, total touch time during estrus, and the interval from the start of estrus to the beginning, peak, and end of the LH surge were tested for the effects of status (lactating or nonlactating), parity (primiparous or 
multiparous), and breed (Holstein or crossbred) using PROC MIXED of SAS 9.4 (SAS Institute Inc. Cary, NC). The second was a repeated measures analysis that examined the number of steps, the number of touches, the total touch time, and plasma estradiol concentrations during the estrus period. Hour 0 was defined as the start of the estrus (based on activity; results derived from the algorithm). The number of steps, number of touches, the total touch time, and plasma estradiol from -12 to $30 \mathrm{~h}$ were analyzed using PROC MIXED of SAS 9.4. Data were analyzed for the effects of status (lactating or nonlactating), parity, breed, hour, status by hour, breed by hour, and parity by hour. Hour was defined as repeated and cow nested within parity and breed was defined as the subject variable. Data for number of touches and total touch time were not normally distributed and possessed a positive (right-hand) skew. A $\log 10$ transformation [ $\log 10$ (original value +0.1 ) $]$ was used to reduce the skewness reported by PROC UNIVARIATE. Both the non-transformed and $\log 10$ data were analyzed using PROC MIXED of SAS 9.4. The partial correlation coefficients (r) between plasma estradiol and the number of steps, rump touches, and total touch time were tested by using PROC GLM of SAS 9.4 using a model that included status, parity, and breed. Simple regressions were performed using PROC REG of SAS 9.4. Steps, rump touches, and total touch time were summed across $2 \mathrm{~h}$ intervals for the calculation of partial correlations and simple regressions to accommodate the $2 \mathrm{~h}$ interval for estradiol sampling and analysis.

The third analysis was similar to the second except that hourly data were analyzed relative to the peak of the LH surge (sample with greatest LH concentrations). The peak LH sample was defined as $0 \mathrm{~h}$ with time preceding and after this sample defined as 
negative and positive hours. Data are presented as LSM \pm SEM and statistical significance was declared at $P<0.05$ unless stated otherwise.

\subsection{Results}

The time from the second $\mathrm{PGF}_{2 \alpha}$ injection to the beginning of estrus (first increase in activity measured in steps per h) was approximately $2 \mathrm{~d}$ and did not depend on lactation, parity, or breed (Table 3.1). The total amount of time in estrus (based on activity) and the total number of steps during estrus, however, were affected by lactation (Table 3.1). Nonlactating cows were in estrus for approximately $5 \mathrm{~h}$ longer than lactating cows $(P<$ 0.025). The longer period of estrus was associated with a greater number of steps during estrus for nonlactating cows $(P<0.009)$. Although the period of estrus defined by activity was longer for non-lactating cows, the number of touches and total touch time were similar for lactating and non-lactating cows. Neither parity nor breed affected total time in estrus, the number of steps, the number of rump touches or the total touch time. The time from the start of estrus to the beginning of the LH surge tended to be shorter for lactating compared with nonlactating cows $(P<0.093$; Table 3.1). The time from the start of estrus to the LH peak and start of estrus to the end of the LH surge was numerically shorter in lactating compared with nonlactating cows but was not significant $(P>0.10$; Table 3.1). Neither parity nor breed affected the timing of the LH surge.

In an initial series of analyses, we examined at one- (steps, touches, and total touch time) or two-h (estradiol) intervals the number of steps, plasma estradiol, the number of touches, and the total touch time (Figure 3.1). 
Table 3.1. Least square means and SE for estrus phenotypes in lactating and nonlactating dairy cows measured after an injection of $\mathrm{PGF}_{2 \alpha}{ }^{1}$.

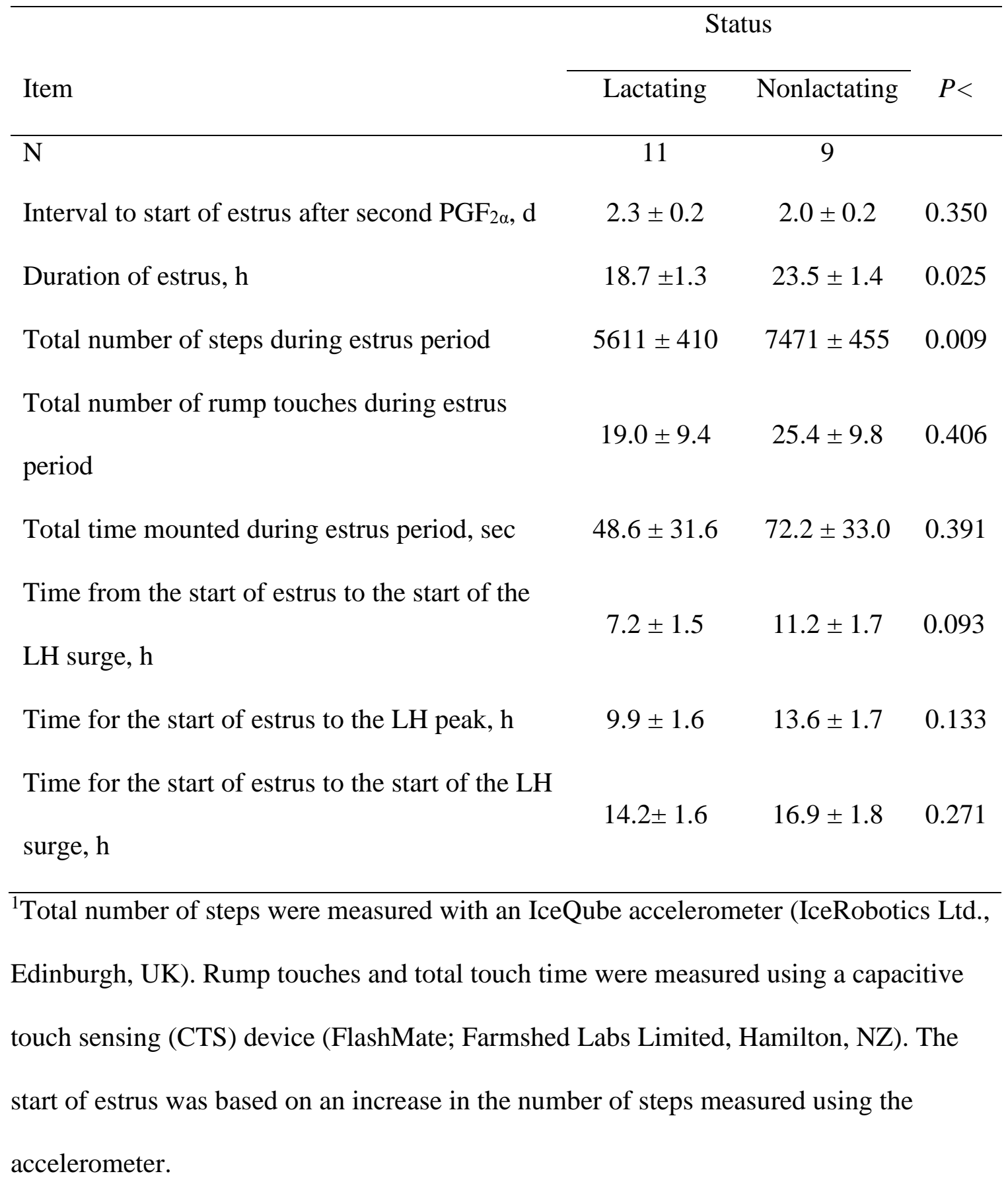


When normality was tested with PROC UNIVARIATE, the skewness and kurtosis were within acceptable limits $(-2$ to +2$)$ for plasma estradiol and number of steps but skewness and kurtosis exceeded acceptable limits for the number of touches and total touch time. A $\log 10$ transformation reduced the skewness and kurtosis for the number of touches (1.38 and 0.36 ) and total touch time (1.47 and 0.63) (respectively). The $\log 10$ transformed data were used for touches and total touch time for statistical analyses. True means and SEM are reported in the graphs (Figure 3.1C and 3.1D). Parity and breed did not affect these data and a reduced statistical model that included status (lactating or nonlactating), hour, and status by hour was used. The longer estrus period in nonlactating cows (Table 3.1) was explained by a longer period of increased activity (Figure 1A; status by hour; $P<0.001$ ) and also greater plasma estradiol (Figure 3.1B; status; $P<$ 0.007). The lactating cows had a greater number of rump touches (Figure 3.1C; status by hour; $P<0.001$ ) and a greater touch time (Figure 1D; status by hour; $P<0.001$ ) early during the estrus period. These same measures were increased later during the estrus period in nonlactating cows (Figures 3.1C and 3.1D). Our interpretation was that the lactating cows had shorter estrus periods where rump touches closely associated in time with the increase in activity. In nonlactating cows there appeared to be a period of increased activity before the maximum period of rump touches was initiated (Figures 3.1A, 3.1C, and 3.1D). The timing that we observed (increase in activity that was ahead of the increase in the number of rump touches or total touch time) differed from the results of Dobson et al. (2018) who reported that the increase in activity was somewhat delayed relative to other estrus behaviors that were recorded visually (Dobson et al., 2018). 

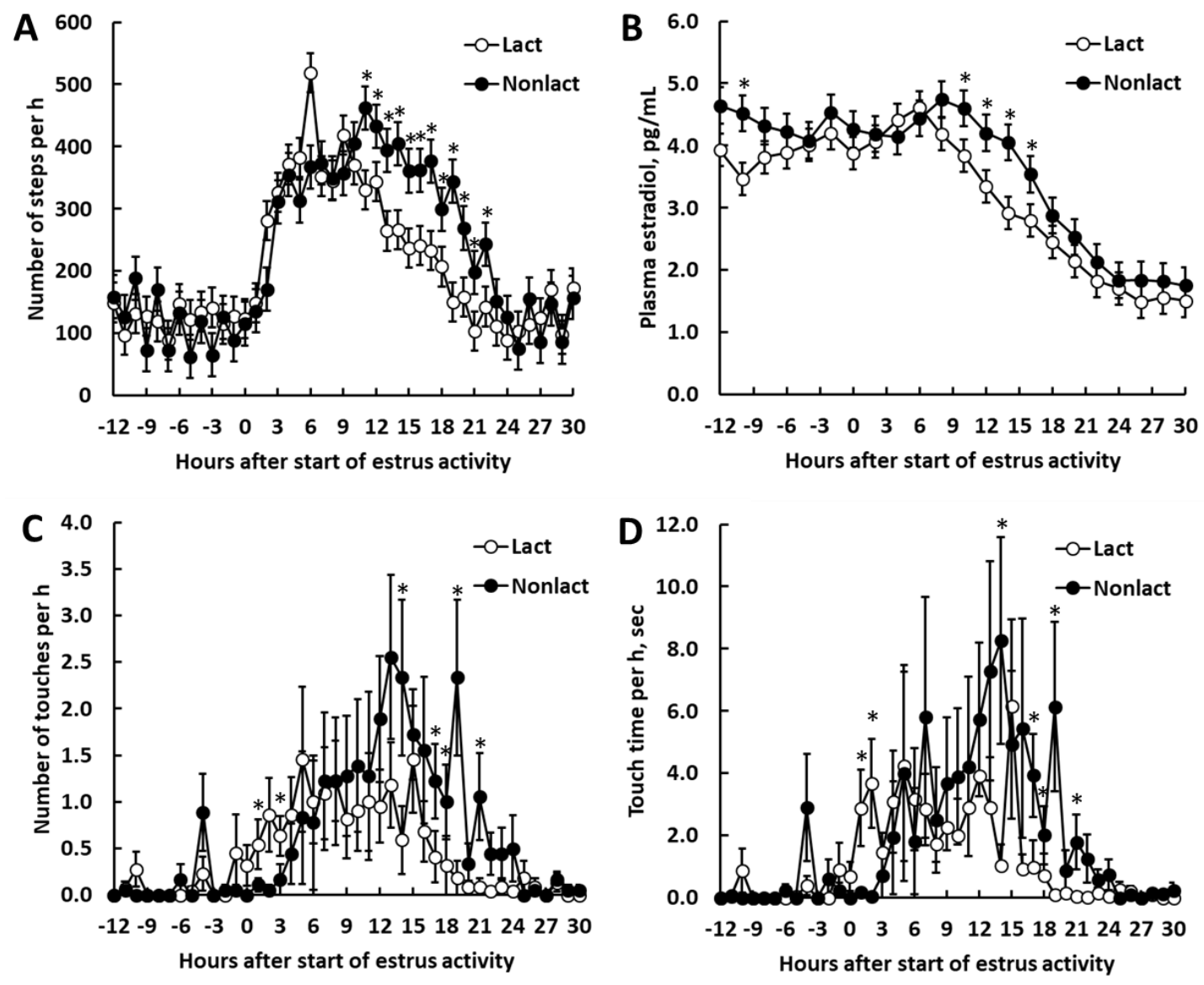

Figure 3.1. Number of steps taken per h (A), plasma estradiol concentrations (B), number of rump touches (C) and total touch time (D) for lactating (Lact) and nonlactating (Nonlact) dairy cows after an injection of $\mathrm{PGF}_{2 \alpha}$. Data are expressed relative to the start in estrus activity (hour 0 ) that was based on steps per h. Total number of steps were measured with an IceQube accelerometer (IceRobotics Ltd., Edinburgh, UK). Rump touches and total touch time were measured using a capacitive touch sensing (CTS) device (FlashMate; Farmshed Labs Limited, Hamilton, NZ). ${ }^{*}=P<0.05$ for Lact vs. Nonlact within $h$. 
We recorded rump touches and total touch time using a CTS device that is relatively new technology suitable for on-farm commercial application as well as for research application similar to the present trial. The CTS device does not discriminate between mounts, chin rests, or other interactions from cows. Dobson et al. (2018) measured activity with neck collars whereas the present study used leg mounted devices that measured steps per h. Silper et al. (2015) reported that the neck collar used by Dobson et al. (2018) recorded a later onset of estrus compared with the leg mounted device that we used. It is possible that the two systems are measuring different movements of the cow with slightly different timing relative to other estrus behaviors.

Plasma estradiol concentrations decreased sooner after the initiation of estrus in lactating compared with nonlactating cows (Figure 3.1B) perhaps because the LH surge was occurring sooner after the start of estrus in lactating cows (Table 3.1). The LH surge began approximately $7 \mathrm{~h}$ after the start of estrus in lactating cows and approximately $11 \mathrm{~h}$ after the start of estrus in nonlactating cows. The plasma estradiol concentrations began to decrease shortly after the respective LH surge intervals for lactating and nonlactating cows (Figure 3.1B). A shorter interval from the start of estrus to the LH surge in lactating cows, therefore, apparently caused the premature luteinization of the preovulatory follicle and an earlier decrease in estradiol relative to the start of estrus for lactating compared with nonlactating cows. The earlier decrease in estradiol theoretically caused the shorter estrus period in the lactating cows that we studied. Although their estrus period was shorter, we did not detect fewer rump touches or lesser total touch time in lactating compared with nonlactating cows. The number of rump interactions including mounts, stands, and chin rests during estrus are highly variable when measured for individual 
estrus events (Hurnik, 1987; Allrich, 1993). The high variability may have precluded detection of statistical significance despite numerical differences for lactating versus nonlactating cows.

For the entire periestrus period (-12 to $30 \mathrm{~h}$; Figure 3.1), the partial correlation coefficient (r) for the number of steps and the number of rump touches was 0.48 ( $P<$ $0.001)$ and for the number of steps and total touch time was $0.42(P<0.001)$. These correlation coefficients were similar to correlation coefficients reported by Roelofs et al. (2005) who measured steps using a pedometer and visually measured estrus behavior. There was also a correlation between the number of steps and plasma estradiol $(r=0.38$; $P<0.001)$, the number of rump touches and plasma estradiol $(\mathrm{r}=0.14 ; P<0.01)$ and total touch time and plasma estradiol $(\mathrm{r}=0.13 ; P<0.01)$. Although significant, the correlations with estradiol were relatively low. Others have also reported relatively low correlations between plasma estradiol and estrus phenotypes in both heifers (Silper et al., 2015; $r<0.15$ ) and cows (Madureira et al., 2015; $r=0.02$ ). The correlations were significant across the entire estrus period (-12 to $30 \mathrm{~h}$ ) but the early period from -12 to $8 \mathrm{~h}$ (Figure 3.1) was clearly different from the later period (after $8 \mathrm{~h}$ ) because there was relatively little change in estradiol during the early period (-12 to $8 \mathrm{~h})$ and yet a large change in activity occurred after $0 \mathrm{~h}$ (Figures 3.1A and 3.1B). During the later period (after $8 \mathrm{~h}$ ) both activity and the number of steps decreased along with the decline in plasma estradiol concentrations. After $8 \mathrm{~h}$, the number of steps and plasma estradiol were highly correlated $(\mathrm{r}=0.74 ; P<0.001)$ and explained by the regression equation: number of steps during $2 \mathrm{~h}=2.5+165 \mathrm{x}$ plasma estradiol concentration $\left(P<0.001 ; \mathrm{r}^{2}=0.55\right)$. Likewise, there was a correlation between the number of rump touches and estradiol $(r=$ 
$0.39 ; P<0.001)$ and the total touch time and estradiol $(\mathrm{r}=0.33 ; P<0.001)$ defined by the regression equations: number of touches during $2 \mathrm{~h}=-0.85+0.81 \times$ plasma estradiol concentrations $\left(P<0.001 ; \mathrm{r}^{2}=0.17\right)$ and total touch time during $2 \mathrm{~h}=-2.22+2.16 \mathrm{x}$ plasma estradiol concentrations $\left(P<0.001 ; \mathrm{r}^{2}=0.12\right)$. During the early period (before 8 $h)$, the correlations between number of touches $(r=-0.03)$ and total touch time $(r=-0.01)$ with plasma estradiol were not significant $(P>0.10)$ and the correlation between steps and plasma estradiol was low $(\mathrm{r}=0.18 ; P<0.013)$.

The preceding paragraphs described analyses that moved forward from the initiation of estrus (based on the onset of the estrus activity). We performed additional analyses that moved backward and forward from the peak of the LH surge. We then examined estradiol concentrations, activity, rump touches, and total touch time during the $12 \mathrm{~h}$ preceding and $12 \mathrm{~h}$ after the peak of the LH surge (Figure 3.2). For the purpose of these analyses the LH peak was defined as time $0 \mathrm{~h}$. The period of time (-12 to $12 \mathrm{~h}$ ) represented the period of greatest activity (steps per $h$ ) that was centered around the LH peak.

As with the analyses presented in Figure 3.1, the log10 transformed data were used for touches and total touch time for statistical analyses to reduce a positive skew in the original dataset. True means and SEM are reported in the rump touches and total touch time graphs (Figure 3.2C and 3.2D). There was no effect of parity or breed so a reduced statistical model that included status (lactating or nonlactating), hour, and status by hour was used. As expected, there was an effect of $h(P<0.001)$ on the number of steps with the maximum number of steps per hour $(433 \pm 32)$ occurring at $-1 \mathrm{~h}$ (Figure $3.2 \mathrm{~A})$. 

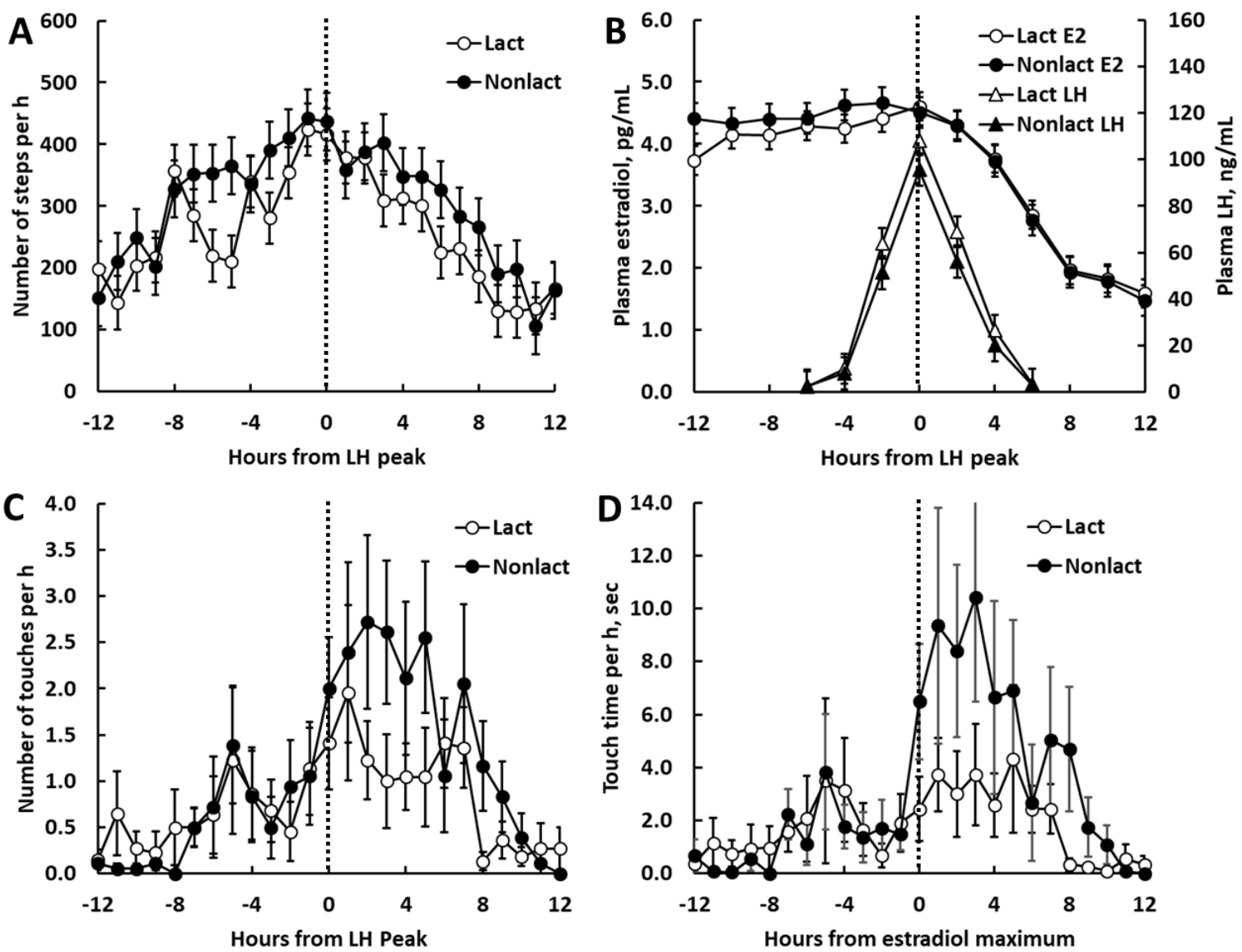

Figure 3.2. Number of steps taken per h (A), plasma estradiol and LH concentrations (B), number of rump touches (C) and total touch time (D) for lactating (Lact) and nonlactating (Nonlact) dairy cows after an injection of $\mathrm{PGF}_{2 \alpha}$. Data are expressed relative to the peak of the LH surge ( $0 \mathrm{~h}$, vertical dotted line). Total number of steps were measured with an IceQube accelerometer (IceRobotics Ltd., Edinburgh, UK). Rump touches and total touch time were measured using a capacitive touch sensing (CTS) device (FlashMate; Farmshed Labs Limited, Hamilton, NZ). There was an effect of status (Lact vs. Nonlact; $P<0.028$ ) for number of steps per h (A) and the status by h interaction was not significant $(P>0.10)$. Status or status by h was not significant $(P>0.10)$ in $\mathrm{B}$, C, or D. 
This number of steps was approximately 3 times the baseline. The number of steps decreased rapidly after the peak of the LH surge. There was an effect of status $(P<$ 0.028) because nonlactating cows had a greater number of steps per h compared with lactating cows $(304 \pm 14$ versus $261 \pm 13)$. There was an effect of $\mathrm{h}(P<0.001)$ for plasma estradiol concentrations (Figure 3.2B). Plasma estradiol increased from $4.1 \pm 0.2$ $\mathrm{pg} / \mathrm{mL}$ at $-12 \mathrm{~h}$ to $4.6 \pm 0.2 \mathrm{pg} / \mathrm{mL}$ at $0 \mathrm{~h}$ and then decreased to a minimum at $12 \mathrm{~h}(1.5 \pm$ $0.2 \mathrm{pg} / \mathrm{mL}$ ). Status (lactating versus nonlactating) or status by here not significant $(P>$ 0.10; Figure 3.2B). Plasma concentrations of LH increased $(P<0.001)$ during the LH surge and were not affected by status or an interaction of status and h (Figure 3.2B). There was an increase in the number of rump touches per $\mathrm{h}(P<0.001$; Figure 3.2C) and total touch time per $\mathrm{h}(P<0.001$; Figure 3.2D) from $-12 \mathrm{~h}(0.13 \pm 0.06$ and $0.51 \pm 0.33)$ to a maximum at $1 \mathrm{~h}(2.15 \pm 0.66$ and $6.26 \pm 2.18)$ and then a decrease to baseline by $8 \mathrm{~h}$ $(0.15 \pm 0.13$ and $0.19 \pm 0.18)$ (respectively) There was no effect of status or a status by $h$ interaction for the number of rump touches or total touch time (Figure 3.2C and 3.2D).

Viewed across time, it appeared that there was an increase and subsequent decrease in activity (steps per h) that was explained in part by rump touches (Figure 3.2). Chasing and mounting involves the rump of the cow and increases the number of steps taken by the recipient cow. We expected to see an increase in plasma estradiol during the mostactive period of estrus, but this was not the case (Figure 3.2B). Instead, we observed relatively stable estradiol concentration up until the LH surge with rapidly declining estradiol thereafter (Figure 3.2B). Most of the available literature would support our data in that there is a relatively small increase in plasma estradiol concentrations as a cow approaches estrus (Chenault et al., 1975, 1976; Aungier et al., 2015). We do not believe 
that the failure to detect an increase in estradiol during estrus was a technical problem with the assay because we have used the same assay to demonstrate a robust increase in plasma estradiol in sows developing multiple follicles and approaching estrus (Bracken et al., 2006).

The decrease in circulating estradiol after the LH surge can be explained by the luteinization of the follicle caused by the LH surge (Adams and Ratto, 2013). Plasma estradiol concentrations were decreasing (Figure 3.2B) when cows were receiving the greatest number of rump touches and greatest total touch time ( 0 to $8 \mathrm{~h}$ after the $\mathrm{LH}$ surge; Figure 3.2C and 3.2D). Cows were progressively less active during this period of declining estradiol (Figure 3.2A and 3.2B). Previous studies support the behavioral and endocrine profile that we observed. Mounting and standing behaviors begin at approximately the same time as the onset of the LH surge with circulating estradiol concentrations decreasing rapidly after the LH surge (Chenault et al., 1975, 1976; Thatcher and Chenault, 1976; Roelofs et al., 2004; Aungier et al., 2015). Cows will continue to express estrus while $\mathrm{LH}$ and estradiol concentrations are decreasing.

When estrus data were expressed relative to the LH surge (Figure 3.2) there was an early period where there was a relatively small change in estradiol (approximately 0.5 $\mathrm{pg} / \mathrm{mL} ;-12$ to $0 \mathrm{~h}$ ) but there was a large change in activity (Figures 3.2A and 3.2B). There was also an increase in the number of touches (Figure 3.2C) and total touch time (Figure 3.2D) that began approximately $8 \mathrm{~h}$ before the LH surge. After the LH surge, there was an intense estrus period ( 0 to $4 \mathrm{~h}$ ) defined by high activity (Figure $3.2 \mathrm{~A}$ ) with a large number of touches (Figure 3.2C) and increased total touch time (Figure 3.2D). The activity and rump touches decreased with the decreasing plasma estradiol after this initial 
period of intense estrus. During the period of estrus leading up to the LH surge (-12 to 0 h), the partial correlation coefficient $(\mathrm{r})$ was not significant $(P>0.10)$ for the correlation of estradiol with either the number of steps $(r=-0.01)$ or the number of touches $(r=-$ $0.01)$ or the total touch time $(\mathrm{r}=-0.05)$. The lack of correlation was present despite a twofold range in estradiol concentrations for individual cows at $0 \mathrm{~h}(3.15$ to $6.45 \mathrm{pg} / \mathrm{mL})$ and a large range among individual cows for measures of estrus expression at $0 \mathrm{~h}$ (58 to 639, 0 to 4 , and 0 to $16.45 \mathrm{sec}$ for the number of steps, number of touches, and total touch time per $\mathrm{h}$, respectively). After $0 \mathrm{~h}$ when plasma estradiol concentrations were decreasing and the cows were going out of estrus (Figure 3.2), the plasma estradiol concentrations were correlated with the number of steps $(\mathrm{r}=0.65 ; P<0.001)$, the number of rump touches $(\mathrm{r}$ $=0.42 ; P<0.001)$, and the total touch time $(\mathrm{r}=0.38 ; P<0.001)$.

\subsection{Discussion}

With respect to our first stated hypothesis, we found that the relationship between plasma estradiol and overt signs of estrus changed during the estrus period. During the initiation of estrus activity (early period), the correlation between circulating estradiol, activity, and rump touches was low suggesting the sensitivity of the animal to estradiol dictates the initiation of estrus. Other investigators have come to similar conclusions concerning circulating estradiol, estradiol sensitivity, and estrus activity. Aungier et al. (2015), for example, reported that estradiol concentration were $80 \%$ of maximum values

during the $15 \mathrm{~h}$ period before the start of standing estrus (Aungier et al., 2015). Lyimo et al. (2000) reported that most overt signs of estrus were not correlated with plasma estradiol concentrations. van Eerdenburg et al. (2000) demonstrated changes in estrogen receptor $\alpha$ expression in the hypothalamus near estrus and speculated that sensitivity to 
estradiol may change during the periestrual period. The collective interpretation is that cows are initially insensitive to estradiol and that the hypothalamus must undergo a maturation process during which there is expression of estrogen receptor $\alpha$. Cows display signs of estrus during the early period but the expression of estradiol receptor $\alpha$ in the hypothalamus (and not plasma estradiol per se) is controlling the estrus expression (van Eerdenburg, 2008). Estradiol insensitivity for estrus expression is apparently overcome at approximately the same time that estradiol insensitivity for the LH surge is overcome. During the estradiol sensitive period, the cow has an LH surge and expresses signs of estrus the magnitude of which are correlated with plasma estradiol concentrations.

We found that cows expressed signs of estrus as estradiol concentrations decreased (Figures 3.1 and 3.2). Our results are consistent with Aungier et al. (2015) who reported that $90 \%$ of the cows in their study continued to express estrus as the estradiol concentrations decreased. As far as we are aware, none of the aforementioned studies examined the early period of estrus (when cows appear to be insensitive to estradiol) separately from the late period of estrus. Late in the estrus period (when cows were going out of estrus) there was a strong correlation between estradiol and activity suggesting that the decrease in estradiol after the luteinization of the follicle determines the intensity of estrus. The correlation (r) between activity and estradiol was approximately twice the correlation between rump touches or total touch time and estradiol. Rump interactions, therefore, may be less affected by plasma estradiol concentrations when compared with activity measured in steps per $h$.

The second hypothesis was that lactation would affect estrus activity and estradiol concentrations. Our data supported this hypothesis and agreed in general with 
conclusions made by Lopez et al. (2004). The lactating cows that we studied had shorter estrus periods (Figure 3.1A) and lesser estradiol during estrus (Figure 3.1B). Lopez et al. (2004) also reported a shorter duration of estrus and lesser estradiol in high producing versus low producing lactating cows. The cows that we used in the present study were late lactation cows that would have been categorized as low producing $(<39.5 \mathrm{~kg} / \mathrm{d}$ milk) by Lopez et al. (2004). Our comparison was lactating versus nonlactating and we were able to demonstrate an effect of lactation despite the relatively low production of the cows that we studied. The reason that estrus periods were shorter and estradiol concentrations were less was because the lactating cows had a shorter interval from the start of estrus to the LH surge. This led to the premature termination of estrus (Figure 3.1). Our data do not support a mechanism of lesser estradiol at estrus leading to lesser estrus expression or a mechanism involving greater metabolism of estradiol in lactating cows (mechanisms proposed by Lopez et al., 2004). Lactating cows in the present study had similar concentrations of estradiol during the pre-estrus period when compared with nonlactating cows (Figure 3.2B) and the clearance of estradiol from plasma after the $\mathrm{LH}$ surge was identical for lactating and nonlactating cows (Figure 3.2B). The present study using low-production lactating cows should be repeated with high production cows in early lactation for comparison with the results of Lopez et al. (2004).

\subsection{Conclusions}

Plasma estradiol concentrations were poorly correlated with overt signs of estrus during the period leading up to maximum estrus activity. During this period, the sensitivity of the cow to estradiol and not the absolute concentration of estradiol appeared to dictate the intensity of estrus. After peak estrus activity (when cows were going out of 
estrus and plasma estradiol concentrations were decreasing) there was a strong correlation between overt signs of estrus and plasma estradiol concentrations. Effective selection for improved estrus expression based on plasma estradiol concentrations will depend on the time of blood sampling because the correlation between plasma estradiol concentrations and overt signs of estrus ranges from near 0 for a cow coming into estrus to $>0.5$ for a cow going out of estrus. Lactation shortened the number of hours in estrus when estrus was defined by an increase in activity (steps per h) but did not affect the number of rump touches or total touch time. Lactating cows ended the estrus period sooner because the interval from the onset of estrus activity to the LH surge was shorter. The LH surge caused the luteinization of the follicle and a decrease in circulating estradiol. Selection for a longer estrus period (based on activity) could potentially increase the interval from the onset of activity to the $\mathrm{LH}$ surge and provide for a longer estrus. Understanding the mechanisms that control the sensitivity of the cow to estradiol and making appropriate selection decisions based on these mechanisms will likely increase overt signs of estrus in dairy cows. 


\section{Chapter Four:}

\section{SUMMARY AND CONCLUSIONS}

Historically, the dairy industry primary focus was on the improvement of milk production. Single trait selection for high milk production, led to the adverse effect on cow health and declines in fertility (Lucy, 2001). Recently, it has been proposed that dairy cattle fertility can be improved through the use of genetic selection (Lucy, 2019). The use of genomics requires a greater understanding of the underlying genetics associated with fertility. The goal of the research presented in this thesis was to investigate phenotypes associated with estrus behavior [greater activity and (or) rump touches (mounts, chinrests, etc.)] and estradiol concentration during estrus. Our hypothesis was that technology could be used to remotely collect large amounts of data on estrus behaviors to estimate heritability and the correlation of phenotypic estrus traits (estrus behaviors and estradiol concentrations). Further, that estrus traits would be highly correlated, and implementation of technology could assist in identification of desired phenotypic traits for genetic selection.

More than 1000 estrus events from a variety of cows were evaluated during these experiments. Use of CTS devices (rump contacts) and accelerometers (activity or number of steps) to remotely record estrus behaviors, for a large number of estrus events, was successful. Data logged by these devices were able to be harnessed to identify estrus peaks. Evaluation of the data reveled that at least $20 \%$ of the variation in the number of steps during estrus was explained by the number of rump contacts. Genetic selection of cows to improve fertility based on phenotypic estrus expression is possible. The maximum heritability (repeatability; intra-class correlation coefficient) for the number of 
rump contacts and the number of steps taken during estrus was approximately 0.2. This low heritability is consistent with the heritability of reproductive traits but nonetheless indicates that genetic selection is possible.

Analysis of the hormone concentrations during estrus showed a poor correlation of estradiol concentrations with behavioral signs of estrus. However, the studies indicated that the absolute concentration of estradiol does not determine intensity of estrus. Instead it appeared that the sensitivity to estradiol is the key to understanding the intensity of estrus expression. This is based on the evidence presented by van Eerdenberg (2008), that the expression of estradiol receptor $\alpha$ in the hypothalamus is decreased at the beginning of estrus resulting in the high levels of estradiol required to elicit a response until the LH surge. This theory aligns with our evidence that the peak in estrus behaviors occurs after the LH surge. We also found that the concentration of estradiol can influence the length the estrus period, but it is dependent on lactation status of the cow. Lactating cows tend to have lower levels of estradiol and a shorter estrus period. The shorter period of estrus is explained by a shorter interval from the onset of estrus to the LH surge.

The research presented in this thesis supports the notion that phenotypes for estrus expression can be used in genetic selection programs for dairy cattle. Electronic estrus detection technologies can accurately record large quantities of data to develop a phenotype database. Although heritability of the estrus traits discussed are relatively low, estrus expression traits are, nonetheless, heritable. A deeper understanding into the underlying phenotypes related to estrus expression can improve fertility through genetic selection. 


\section{LITERATURE CITED}

Adams, G.P., and M.H. Ratto. 2013. Ovulation-inducing factor in seminal plasma: a review. Anim. Reprod. Sci. 136:148-156. doi:10.1016/j.anireprosci.2012.10.004.

Adin, G., R. Solomon, M. Nikbachat, A. Zenou, E. Yosef, A. Brosh, A. Shabtay, S.J. Mabjeesh, I. Halachmi, and J. Miron. 2009. Effect of feeding cows in early lactation with diets differing in roughage-neutral detergent fiber content on intake behavior, rumination, and milk production. J. Dairy Sci. 92:3364-3373. doi:10.3168/jds.2009-2078.

Adriaens, I., W. Saeys, C. Lamberigts, M. Berth, K. Geerinckx, J. Leroy, B. De Ketelaere, and B. Aernouts. 2019. Short communication: Sensitivity of estrus alerts and relationship with timing of the luteinizing hormone surge. J. Dairy Sci. 102:1775-1779. doi:10.3168/jds.2018-15514.

Allrich, R.D. 1993. Estrous behavior and detection in cattle. Veterinary Clinics of North America: Food Animal Practice 9:249-262. doi:10.1016/S0749-0720(15)30644-7.

Allrich, R.D. 1994. Endocrine and neural control of estrus in dairy cows. J. Dairy Sci. $77: 2738-2744$.

Arosh, J.A., S.K. Banu, and J.A. McCracken. 2016. Novel concepts on the role of prostaglandins on luteal maintenance and maternal recognition and establishment of pregnancy in ruminants. J. Dairy Sci. 99:5926-5940. doi:10.3168/jds.201510335. 
Asmussen, T. 2010. Herd navigator or "how to benefit from frequent measurements." Pages 291-293 in ICAR 37th Annual Meeting. International Committee for Animal Recording (ICAR).

Aungier, S.P.M., J.F. Roche, M. Sheehy, and M.A. Crowe. 2012. Effects of management and health on the use of activity monitoring for estrus detection in dairy cows. J. Dairy Sci. 95:2452-2466. doi:10.3168/jds.2011-4653.

Aungier, S.P.M., J.F. Roche, P. Duffy, S. Scully, and M.A. Crowe. 2015. The relationship between activity clusters detected by an automatic activity monitor and endocrine changes during the periestrous period in lactating dairy cows. J. Dairy Sci. 98:1666-1684. doi:10.3168/jds.2013-7405.

Bao, B., and H. Allen Garverick. 1998. Expression of steroidogenic enzyme and gonadotropin receptor genes in bovine follicles during ovarian follicular waves: A review. J. Anim Sci. 76:1903-1921. doi:10.2527/1998.7671903x.

Bar, D., and R. Solomon. 2010. Rumination collars: what can they tell us. The First North American Conference on Precision Dairy Management. precisiondairy.com.

Blom, J.Y., and C. Ridder. 2010. Reproductive management and performance can be improved by use of delaval herd navigator®. The First North American Conference on Precision Dairy Management. pdfs.semanticscholar.org.

Boichard, D., and M. Brochard. 2012. New phenotypes for new breeding goals in dairy cattle. Animal 6:544-550. doi:10.1017/S1751731112000018. 
Bracken, C.J., R.P. Radcliff, B.L. McCormack, D.H. Keisler, and M.C. Lucy. 2006. Decreased follicular size during late lactation caused by treatment with charcoaltreated follicular fluid delays onset of estrus and ovulation after weaning in sows. J. Anim. Sci. 84:2110-2117. doi:10.2527/jas.2006-012.

Brewster, J.E., and C.L. Cole. 1941. The time of ovulation in cattle. J. Dairy Sci. 24:111115. doi:10.3168/jds.S0022-0302(41)95391-2.

Burfeind, O., K. Schirmann, M.A.G. von Keyserlingk, D.M. Veira, D.M. Weary, and W. Heuwieser. 2011. Evaluation of a system for monitoring rumination in heifers and calves. J. Dairy Sci. 94:426-430. doi:10.3168/jds.2010-3239.

Burnett, T.A., A.M.L. Madureira, B.F. Silper, A.C.C. Fernandes, and R.L.A. Cerri. 2017. Integrating an automated activity monitor into an artificial insemination program and the associated risk factors affecting reproductive performance of dairy cows. J. Dairy Sci. 100:5005-5018. doi:10.3168/jds.2016-12246.

Caraviello, D.Z., K.A. Weigel, P.M. Fricke, M.C. Wiltbank, M.J. Florent, N.B. Cook, K.V. Nordlund, N.R. Zwald, and C.L. Rawson. 2006. Survey of management practices on reproductive performance of dairy cattle on large US commercial farms. J. Dairy Sci. 89:4723-4735. doi:10.3168/jds.S0022-0302(06)72522-X.

Carvalho, P.D., V.G. Santos, J.O. Giordano, M.C. Wiltbank, and P.M. Fricke. 2018. Development of fertility programs to achieve high 21-day pregnancy rates in high-producing dairy cows. Therio. 114:165-172. doi:10.1016/j.theriogenology.2018.03.037. 
Cavalieri, J., V. Eagles, M. Ryan, and K.L. Macmillan. 2003. Comparison of four methods for detection of oestrus in dairy cows with resynchronised oestrous cycles. Aust. Vet. J. 81:422-425. doi:10.1111/j.1751-0813.2003.tb11553.x.

Chenault, J.R., W.W. Thatcher, P.S. Kalra, R.M. Abrams, and C.J. Wilcox. 1975. Transitory changes in plasma progestins, estradiol, and luteinizing hormone approaching ovulation in the bovine. J. Dairy Sci. 58:709-717. doi:10.3168/jds.S0022-0302(75)84632-7.

Chenault, J.R., W.W. Thatcher, P.S. Kalra, R.M. Abrams, and C.J. Wilcox. 1976. Plasma progestins, estradiol, and luteinizing hormone following prostaglandin F2 alpha injection. J. Dairy Sci. 59:1342-1346. doi:10.3168/jds.S0022-0302(76)84366-4.

Coe, B.L., and R.D. Allrich. 1989. Relationship between endogenous estradiol-17 $\beta$ and estrous behavior in heifers. J. Anim. Sci. 67:1546-1551. doi:10.2527/jas1989.6761546x.

Colazo, M.G., P. Whittaker, K. Macmillan, D. Bignell, G. Boender, R. de Carvalho Guimaraes, and R.J. Mapletoft. 2018. Evaluation of a modified GnRH-based timed-AI protocol associated with estrus detection in beef heifers inseminated with sex-selected or conventional semen. Therio. 118:90-95. doi:10.1016/j.theriogenology.2018.05.037.

Cole, J.B., S.A.E. Eaglen, C. Maltecca, H.A. Mulder, and J.E. Pryce. 2020. The future of phenomics in dairy cattle breeding. Anim. Front 10:37-44. doi:10.1093/af/vfaa007. 
Croghan, C.W., and R.W. Williams. 2006. Detection and quantification of asymmetric peaks. Page SouthEast SAS User Group, October 8-10, 2016, Atlanta, GA.

Denis-Robichaud, J., R.L.A. Cerri, A. Jones-Bitton, and S.J. LeBlanc. 2018. Performance of automated activity monitoring systems used in combination with timed artificial insemination compared to timed artificial insemination only in early lactation in dairy cows. J. Dairy Sci. 101:624-636. doi:10.3168/jds.2016-12256.

Diskin, M.G. 2018. Review: Semen handling, time of insemination and insemination technique in cattle. Animal 12:s75-s84. doi:10.1017/S1751731118000952.

Dobson, H., J. Williams, J.E. Routly, D.N. Jones, J. Cameron, A. Holman-Coates, and R.F. Smith. 2018. Short communication: Chronology of different sexual behaviors and motion activity during estrus in dairy cows. J. Dairy Sci. 101:82918295. doi:10.3168/jds.2017-14341.

Dransfield, M.B., R.L. Nebel, R.E. Pearson, and L.D. Warnick. 1998. Timing of insemination for dairy cows identified in estrus by a radiotelemetric estrus detection system. J. Dairy Sci. 81:1874-1882. doi:10.3168/jds.S00220302(98)75758-3.

Ealy, A.D., and Z.K. Seekford. 2019. Symposium review: Predicting pregnancy loss in dairy cattle. J. Dairy Sci. 102:11798-11804. doi:10.3168/jds.2019-17176.

Farris, E.J. 1954. Activity of dairy cows during estrus. J. Am. Vet. Med. Assoc. 125:117120. 
Ferguson, J.D., D.T. Galligan, and N. Thomsen. 1994. Principal descriptors of body condition score in holstein cows. J. Dairy Sci. 77:2695-2703.

FlashMate® Touch activated in-heat detector. 2018. Accessed November 18, 2018. https://am.gallagher.com/media/10560/flashmate-dl-flyer-web.pdf.

Fleming, A., C.F. Baes, A. a. A. Martin, T.C.S. Chud, F. Malchiodi, L.F. Brito, and F. Miglior. 2019. Symposium review: The choice and collection of new relevant phenotypes for fertility selection. J. Dairy Sci. 102:3722-3734. doi:10.3168/jds.2018-15470.

Foote, R.H. 1975. Estrus detection and estrus detection aids. J. Dairy Sci. 58:248-256. doi:10.3168/jds.S0022-0302(75)84555-3.

Foote, R.H. 1979. Time of artificial insemination and fertility in dairy cattle. J. Dairy Sci. 62:355-358. doi:10.3168/jds.S0022-0302(79)83248-8.

Fortune, J.E. 1993. Follicular dynamics during the bovine estrous cycle: A limiting factor in improvement of fertility?. Anim. Reprod. Sci. 33:111-125. doi:10.1016/03784320(93)90110-D.

Fortune, J.E., and S.M. Quirk. 1988. Regulation of steroidogenesis in bovine preovulatory follicles. J. Anim. Sci. 66:1-8.doi:10.1093/ansci/66.suppl_2.1.

Fricke, P.M., P.D. Carvalho, J.O. Giordano, A. Valenza, G. Lopes, and M.C. Amundson. 2014. Expression and detection of estrus in dairy cows: the role of new technologies. Animal 8 Suppl 1:134-143. doi:10.1017/S1751731114000299. 
García-Ruiz, A., J.B. Cole, P.M. VanRaden, G.R. Wiggans, F.J. Ruiz-López, and C.P. Van Tassell. 2016. Changes in genetic selection differentials and generation intervals in US Holstein dairy cattle as a result of genomic selection. Proc. Natl. Acad. Sci. U. S. A. 113:E3995-4004. doi:10.1073/pnas.1519061113.

Ginther, O.J., K. Kot, L.J. Kulick, and M.C. Wiltbank. 1997. Emergence and deviation of follicles during the development of follicular waves in cattle. Therio. 48:75-87. doi:10.1016/S0093-691X(97)00192-1.

Ginther, O.J., M.C. Wiltbank, P.M. Fricke, J.R. Gibbons, and K. Kot. 1996. Selection of the dominant follicle in cattle. Biol. Reprod. 55:1187-1194. doi:10.1095/biolreprod55.6.1187.

Gomes, W.R., and R.E. Erb. 1965. Progesterone in bovine reproduction: A review. J. Dairy Sci. 48:314-330. doi:10.3168/jds.S0022-0302(65)88222-4.

Greenham, T., G. Oikonomou, and D.H. Grove-White. 2019. A description of interestrus and interservice intervals and associated fertility in 16 United Kingdom dairy herds. J. Dairy Sci. 102:824-832. doi:10.3168/jds.2018-14755.

Gwazdauskas, F.C., R.L. Nebel, D.J. Sprecher, W.D. Whittier, and M.L. McGilliard. 1990. Effectiveness of rump-mounted devices and androgenized females for detection of estrus in dairy cattle. J. Dairy Sci. 73:2965-2970. doi:10.3168/jds.S0022-0302(90)78985-0. 
Holman, A., J. Thompson, J.E. Routly, J. Cameron, D.N. Jones, D. Grove-White, R.F. Smith, and H. Dobson. 2011. Comparison of oestrus detection methods in dairy cattle. Vet. Rec. 169:47. doi:10.1136/vr.d2344.

Holtz, W., and H. Meinhardt. 1993. Die brunstdiagnose beim rind. Reprod. Domest. Anim. 28:315-341. doi:10.1111/j.1439-0531.1993.tb01007.x.

Hurnik, J.F. 1987. Sexual behavior of female domestic mammals. Vet. Clin. North Am. Food Anim. Pract. 3:423-461. doi:10.1016/s0749-0720(15)31162-2.

Ireland, J.J., M. Mihm, E. Austin, M.G. Diskin, and J.F. Roche. 2000. Historical perspective of turnover of dominant follicles during the bovine estrous cycle: Key concepts, studies, advancements, and terms. J. Dairy Sci. 83:1648-1658. doi:10.3168/jds.S0022-0302(00)75033-8.

Ismael, A., E. Strandberg, M. Kargo, A. Fogh, and P. Løvendahl. 2015. Estrus traits derived from activity measurements are heritable and closely related to the time from calving to first insemination. J. Dairy Sci. 98:3470-3477. doi:10.3168/jds.2014-8940.

Johnson, S.K., and J.R. Jaeger. 2016. Effectiveness of heat detection patches for determining cyclicity status in peripubertal heifers. Kansas Agricultural Experiment Station Research Reports 2:3. doi:10.4148/2378-5977.1178.

Kiddy, C.A. 1977. Variation in physical activity as an indication of estrus in dairy cows. J. Dairy Sci. 60:235-243. doi:10.3168/jds.S0022-0302(77)83859-9. 
Kirby, C.J., M.F. Smith, D.H. Keisler, and M.C. Lucy. 1997. Follicular function in lactating dairy cows treated with sustained-release bovine somatotropin1. J. Dairy Sci. 80:273-285. doi:10.3168/jds.S0022-0302(97)75935-6.

Kulick, L.J., D.R. Bergfelt, K. Kot, and O.J. Ginther. 2001. Follicle selection in cattle: Follicle deviation and codominance within sequential waves. Biol. Reprod. 65:839-846. doi:10.1095/biolreprod65.3.839.

Larson, L.L., and P.J. Ball. 1992. Regulation of estrous cycles in dairy cattle: A review. Therio. 38:255-267. doi:10.1016/0093-691X(92)90234-I.

Lauderdale, J.W. 1974. Estrus detection and synchronization of dairy cattle in large herds. J. Dairy Sci. 57:348-354. doi:10.3168/jds.S0022-0302(74)84892-7.

Lauderdale, J.W. 2009. ASAS centennial paper: Contributions in the Journal of Animal Science to the development of protocols for breeding management of cattle through synchronization of estrus and ovulation. J. Anim. Sci. 87:801-812. doi:10.2527/jas.2008-1407.

López-Gatius, F., P. Santolaria, I. Mundet, and J.L. Yániz. 2005. Walking activity at estrus and subsequent fertility in dairy cows. Therio. 63:1419-1429. doi:10.1016/j.theriogenology.2004.07.007.

Lopez, H., T.D. Bunch, and M.P. Shipka. 2002. Estrogen concentrations in milk at estrus and ovulation in dairy cows. Anim. Reprod. Sci. 72:37-46. doi:10.1016/s03784320(02)00074-X. 
Lopez, H., L.D. Satter, and M.C. Wiltbank. 2004. Relationship between level of milk production and estrous behavior of lactating dairy cows. Anim. Reprod. Sci. 81:209-223. doi:10.1016/j.anireprosci.2003.10.009.

Løvendahl, P., and M.G.G. Chagunda. 2009. Short communication: Genetic variation in estrus activity traits. J. Dairy Sci. 92:4683-4688. doi:10.3168/jds.2008-1736.

Løvendahl, P., and M.G.G. Chagunda. 2010. On the use of physical activity monitoring for estrus detection in dairy cows. J. Dairy Sci. 93:249-259. doi:10.3168/jds.2008-1721.

Lucy, M.C. 2001. Reproductive loss in high-producing dairy cattle: where will it end? J. Dairy Sci. 84:1277-1293. doi:10.3168/jds.S0022-0302(01)70158-0.

Lucy, M.C. 2007. The bovine dominant ovarian follicle. J. Anim. Sci. 85:E89-E99. doi:10.2527/jas.2006-663.

Lucy, M.C. 2019. Symposium review: Selection for fertility in the modern dairy cowCurrent status and future direction for genetic selection. J. Dairy Sci. 102:37063721. doi:10.3168/jds.2018-15544.

Lucy, M.C., S. McDougall, and D.P. Nation. 2004. The use of hormonal treatments to improve the reproductive performance of lactating dairy cows in feedlot or pasture-based management systems. Anim. Reprod. Sci. 82-83:495-512. doi:10.1016/j.anireprosci.2004.05.004. 
Lucy, M.C., C.R. Staples, F.M. Michel, W.W. Thatcher, and D.J. Bolt. 1991. Effect of feeding calcium soaps to early postpartum dairy cows on plasma prostaglandin $F_{2 \alpha}$, luteinizing hormone, and follicular growth. J. Dairy Sci. 74:483-489. doi:10.3168/jds.S0022-0302(91)78195-2.

Lucy, M.C., J.S. Stevenson, and E.P. Call. 1986. Controlling first service and calving interval by prostaglandin $\mathrm{F}_{2 \alpha}$, gonadotropin-releasing hormone, and timed insemination. J. Dairy Sci. 69:2186-2194. doi:10.3168/jds.S00220302(86)80652-X.

Lyimo, Z.C., M. Nielen, W. Ouweltjes, T.A. Kruip, and F.J. van Eerdenburg. 2000. Relationship among estradiol, cortisol and intensity of estrous behavior in dairy cattle. Therio. 53:1783-1795. doi:10.1016/s0093-691x(00)00314-9.

Ma, L., J.B. Cole, Y. Da, and P.M. VanRaden. 2019. Symposium review: Genetics, genome-wide association study, and genetic improvement of dairy fertility traits. J. Dairy Sci. 102:3735-3743. doi:10.3168/jds.2018-15269.

MacDonald, J.M., E. J. O’Donoghue, W. D. McBride, R. F. Nehring, C. L. Sandretto, and R. Mosheim. 2007. Profits, costs, and the changing structure of dairy farming. Accessed November 17, 2018. http://www.ers.usda.gov:80/media/188030/err47_1_.pdf.

Macmillan, K.L., and R.J. Curnow. 1977. Tail painting — a simple form of oestrus detection in New Zealand dairy herds. New Zealand Journal of Experimental Agriculture 5:357-361. doi:10.1080/03015521.1977.10425996. 
Madureira, A.M.L., B.F. Silper, T.A. Burnett, L. Polsky, L.H. Cruppe, D.M. Veira, J.L.M. Vasconcelos, and R.L.A. Cerri. 2015. Factors affecting expression of estrus measured by activity monitors and conception risk of lactating dairy cows. J. Dairy Sci. 98:7003-7014. doi:10.3168/jds.2015-9672.

Martin, G.B., C.A. Price, J.C. Thiéry, and R. Webb. 1988. Interactions between inhibin, oestradiol and progesterone in the control of gonadotrophin secretion in the ewe. J. Reprod. Fertil. 82:319-328. doi:10.1530/jrf.0.0820319.

Mazeris, F. 2010. DeLaval herd navigator: Proactive herd management. Pages 26-27 in Proceedings of First North American Conference on Precision Dairy Management. precisiondairy.com.

McCracken, J.A., E.E. Custer, and J.C. Lamsa. 1999. Luteolysis: A neuroendocrinemediated event. Physiol. Rev. 79:263-323. doi:10.1152/physrev.1999.79.2.263.

Miglior, F., A. Fleming, F. Malchiodi, L.F. Brito, P. Martin, and C.F. Baes. 2017. A 100Year Review: Identification and genetic selection of economically important traits in dairy cattle. J. Dairy Sci. 100:10251-10271. doi:10.3168/jds.2017-12968.

Moore, S.G., and J.F. Hasler. 2017. A 100-Year Review: Reproductive technologies in dairy science. J. Dairy Sci. 100:10314-10331. doi:10.3168/jds.2017-13138.

Mottram, T. 2016. Animal board invited review: Precision livestock farming for dairy cows with a focus on oestrus detection. Animal 10:1575-1584. doi:10.1017/S1751731115002517. 
National Research Council. 2001. Nutrient requirements of dairy cattle. 7th Rev. Ed. Natl. Acad. Sci., Washington, DC.

Nebel, R.L., M.G. Dransfield, S.M. Jobst, and J.H. Bame. 2000. Automated electronic systems for the detection of oestrus and timing of AI in cattle. Anim. Reprod. Sci. 60-61:713-723. doi:10.1016/s0378-4320(00)00090-7.

Nebel, R.L., W.L. Walker, M.L. McGilliard, C.H. Allen, and G.S. Heckman. 1994. Timing of artificial insemination of dairy cows: Fixed time once daily versus morning and afternoon. J. Dairy Sci. 77:3185-3191. doi:10.3168/jds.S00220302(94)77261-1.

Orihuela, A. 2000. Some factors affecting the behavioural manifestation of oestrus in cattle: A review. Appl. Anim. Behav. Sci. 70:1-16. doi:10.1016/s01681591(00)00139-8.

Orrell, P. 2018. The role of biotechnology in the Australian beef and dairy industries. marcusoldham.vic.edu.au.

Pahl, C., E. Hartung, K. Mahlkow-Nerge, and A. Haeussermann. 2015. Feeding characteristics and rumination time of dairy cows around estrus. J. Dairy Sci. 98:148-154. doi:10.3168/jds.2014-8025.

Palmer, M.A., G. Olmos, L.A. Boyle, and J.F. Mee. 2010. Estrus detection and estrus characteristics in housed and pastured Holstein-Friesian cows. Therio. 74:255264. doi:10.1016/j.theriogenology.2010.02.009. 
Patrick,T.E., H.C.K.A.C.B. 1961. Artificial Insemination of Cattle. Louisiana State University and Agricultural and Mechanical College Agricultural Experiment Station.

Parker Gaddis, K.L., P.M. VanRaden, J.B. Cole, H.D. Norman, E. Niccolazi, and J.W. Dürr. 2020. Symposium review: Development, implementation, and perspectives of health evaluations in the United States. J. Dairy Sci.. doi:10.3168/jds.201917687.

Perry, G.A., M.F. Smith, M.C. Lucy, J.A. Green, T.E. Parks, M.D. MacNeil, A.J. Roberts, and T.W. Geary. 2005. Relationship between follicle size at insemination and pregnancy success. Proc. Natl. Acad. Sci. U. S. A. 102:5268-5273. doi:10.1073/pnas.0501700102.

Peter, A.T., and W.T. Bosu. 1986. Postpartum ovarian activity in dairy cows: Correlation between behavioral estrus, pedometer measurements and ovulations. Therio. 26:111-115. doi:10.1016/0093-691X(86)90117-2.

Peter, A.T., P.L.A.M. Vos, and D.J. Ambrose. 2009. Postpartum anestrus in dairy cattle. Therio. 71:1333-1342. doi:10.1016/j.theriogenology.2008.11.012.

Peters, A.R. 1986. Hormonal control of the bovine oestrous cycle. II. Pharmacological principles. Br. Vet. J. 142:20-29. doi:10.1016/0007-1935(86)90003-5.

Platz, S., F. Ahrens, J. Bendel, H.H.D. Meyer, and M.H. Erhard. 2008. What happens with cow behavior when replacing concrete slatted floor by rubber coating: a case study. J. Dairy Sci. 91:999-1004. doi:10.3168/jds.2007-0584. 
Polsky, L.B., A.M.L. Madureira, E.L.D. Filho, S. Soriano, A.F. Sica, J.L.M. Vasconcelos, and R.L.A. Cerri. 2017. Association between ambient temperature and humidity, vaginal temperature, and automatic activity monitoring on induced estrus in lactating cows. J. Dairy Sci. 100:8590-8601. doi:10.3168/jds.201712656.

Pursley, J.R., M.R. Kosorok, and M.C. Wiltbank. 1997a. Reproductive management of lactating dairy cows using synchronization of ovulation. J. Dairy Sci. 80:301-306. doi:10.3168/jds.S0022-0302(97)75938-1.

Pursley, J.R., M.C. Wiltbank, J.S. Stevenson, J.S. Ottobre, H.A. Garverick, and L.L. Anderson. 1997b. Pregnancy rates per artificial insemination for cows and heifers inseminated at a synchronized ovulation or synchronized estrus. J. Dairy Sci. 80:295-300. doi:10.3168/jds.S0022-0302(97)75937-X.

Reimers, T.J., R.D. Smith, and S.K. Newman. 1985. Management factors affecting reproductive performance of dairy cows in the northeastern United States. J. Dairy Sci. 68:963-972. doi:10.3168/jds.S0022-0302(85)80916-4.

Reith, S., and S. Hoy. 2012. Relationship between daily rumination time and estrus of dairy cows. J. Dairy Sci. 95:6416-6420. doi:10.3168/jds.2012-5316.

Reith, S., and S. Hoy. 2018. Review: Behavioral signs of estrus and the potential of fully automated systems for detection of estrus in dairy cattle. Animal 12:398-407. doi:10.1017/S1751731117001975. 
Richardson, B.N., S.L. Hill, J.S. Stevenson, G.D. Djira, and G.A. Perry. 2016. Expression of estrus before fixed-time AI affects conception rates and factors that impact expression of estrus and the repeatability of expression of estrus in sequential breeding seasons. Anim. Reprod. Sci. 166:133-140. doi:10.1016/j.anireprosci.2016.01.013.

Rivera, F., C. Narciso, R. Oliveira, R.L.A. Cerri, A. Correa-Calderón, R.C. Chebel, and J.E.P. Santos. 2010. Effect of bovine somatotropin (500 mg) administered at tenday intervals on ovulatory responses, expression of estrus, and fertility in dairy cows. J. Dairy Sci. 93:1500-1510. doi:10.3168/jds.2009-2489.

Roche, J.F. 2006. The effect of nutritional management of the dairy cow on reproductive efficiency. Anim. Reprod. Sci. 96:282-296. doi:10.1016/j.anireprosci.2006.08.007.

Roelofs, J.B., E.G. Bouwman, S.J. Dieleman, F.J.C.M. Van Eerdenburg, L.M.T.E. KaalLansbergen, N.M. Soede, and B. Kemp. 2004. Influence of repeated rectal ultrasound examinations on hormone profiles and behaviour around oestrus and ovulation in dairy cattle. Therio. 62:1337-1352. doi:10.1016/j.theriogenology.2004.02.002.

Roelofs, J.B., F.J.C.M. van Eerdenburg, N.M. Soede, and B. Kemp. 2005a. Pedometer readings for estrous detection and as predictor for time of ovulation in dairy cattle. Therio. 64:1690-1703. doi:10.1016/j.theriogenology.2005.04.004. 
Roelofs, J.B., F.J.C.M. van Eerdenburg, N.M. Soede, and B. Kemp. 2005b. Various behavioral signs of estrous and their relationship with time of ovulation in dairy cattle. Therio. 63:1366-1377. doi:10.1016/j.theriogenology.2004.07.009.

Roelofs, J., F. López-Gatius, R.H.F. Hunter, F.J.C.M. van Eerdenburg, and C. Hanzen. 2010. When is a cow in estrus? Clinical and practical aspects. Therio. 74:327344. doi:10.1016/j.theriogenology.2010.02.016.

Rorie, R.W., T.R. Bilby, and T.D. Lester. 2002. Application of electronic estrus detection technologies to reproductive management of cattle. Therio. 57:137-148. doi:10.1016/s0093-691x(01)00663-x.

Röttgen, V., F. Becker, A. Tuchscherer, C. Wrenzycki, S. Düpjan, P.C. Schön, and B. Puppe. 2018. Vocalization as an indicator of estrus climax in Holstein heifers during natural estrus and superovulation. J. Dairy Sci. 101:2383-2394. doi:10.3168/jds.2017-13412.

Saint-Dizier, M., and S. Chastant-Maillard. 2012. Towards an automated detection of oestrus in dairy cattle: Automated oestrus detection in dairy Cattle. Reprod. Domest. Anim. 47:1056-1061. doi:10.1111/j.1439-0531.2011.01971.x.

Sandeen, A. 2015. Anovular or anestrous: Do you know the difference? Accessed June 9, 2020. https://www.progressivedairy.com/topics/a-i-breeding/anovular-oranestrous-do-you-know-the-difference.

Sangsritavong, S., D.K. Combs, R. Sartori, L.E. Armentano, and M.C. Wiltbank. 2002. High feed intake increases liver blood flow and metabolism of progesterone and 
estradiol-17beta in dairy cattle. J. Dairy Sci. 85:2831-2842.

doi:10.3168/jds.S0022-0302(02)74370-1.

Santos, J.E.P., R.S. Bisinotto, and E.S. Ribeiro. 2016. Mechanisms underlying reduced fertility in anovular dairy cows. Therio. 86:254-262. doi:10.1016/j.theriogenology.2016.04.038.

Sartori, R., J.M. Haughian, R.D. Shaver, G.J.M. Rosa, and M.C. Wiltbank. 2004. Comparison of ovarian function and circulating steroids in estrous cycles of Holstein heifers and lactating cows. J. Dairy Sci. 87:905-920. doi:10.3168/jds.S0022-0302(04)73235-X.

Schutz, M.M., and E.A. Pajor. 2001. Genetic control of dairy cattle behavior. J. Dairy Sci. 84:E31-E38. doi:10.3168/jds.S0022-0302(01)70194-4.

Senger, P.L. 1994. The estrus detection problem: New concepts, technologies, and possibilities. J. Dairy Sci. 77:2745-2753. doi:10.3168/jds.S0022-0302(94)772179.

Senger, P.L. 2012. Pathways to pregnancy \& parturition. Third edition. Current Conceptions, Inc., Redmond, OR.

Silper, B.F., A.M.L. Madureira, M. Kaur, T.A. Burnett, and R.L.A. Cerri. 2015. Short communication: Comparison of estrus characteristics in Holstein heifers by 2 activity monitoring systems. J. Dairy Sci. 98:3158-3165. doi:10.3168/jds.20149185. 
Silper, B.F., A.M.L. Madureira, L.B. Polsky, S. Soriano, A.F. Sica, J.L.M. Vasconcelos, and R.L.A. Cerri. 2017. Daily lying behavior of lactating Holstein cows during an estrus synchronization protocol and its associations with fertility. J. Dairy Sci. 100:8484-8495. doi:10.3168/jds.2016-12160.

Smith, M.F., G.A. Perry, K.G. Pohler, S.E. Dickinson, and D.J. Patterson. 2015. Establishment of pregnancy in beef cattle: Application of basic principles. Pages 9-14 in Proceedings of the Applied Reproductive Strategies in Beef Cattle Conference.

Sood, P., and A.S. Nanda. 2006. Effect of lameness on estrous behavior in crossbred cows. Therio. 66:1375-1380. doi:10.1016/j.theriogenology.2006.04.031.

Spencer, T.E., W.C. Becker, P. George, M.A. Mirando, T.F. Ogle, and F.W. Bazer. 1995. Ovine interferon-tau regulates expression of endometrial receptors for estrogen and oxytocin but not progesterone. Biol. Reprod. 53:732-745. doi:10.1095/biolreprod53.3.732.

Sterry, R.A., M.L. Welle, and P.M. Fricke. 2006. Treatment with gonadotropin-releasing hormone after first timed artificial insemination improves fertility in noncycling lactating dairy cows. J. Dairy Sci. 89:4237-4245. doi:10.3168/jds.S00220302(06)72469-9.

Stevenson, J.S., M.K. Schmidt, and E.P. Call. 1983. Estrous intensity and conception rates in Holsteins. J. Dairy Sci. 66:275-280. doi:10.3168/jds.S00220302(83)81787-1. 
Stevenson, J.S., S.L. Hill, R.L. Nebel, and J.M. DeJarnette. 2014. Ovulation timing and conception risk after automated activity monitoring in lactating dairy cows. J. Dairy Sci. 97:4296-4308. doi:10.3168/jds.2013-7873.

Stevenson, J.S., and J.H. Britt. 2017. A 100-Year Review: Practical female reproductive management. J. Dairy Sci. 100:10292-10313. doi:10.3168/jds.2017-12959.

Sveberg, G., A.O. Refsdal, H.W. Erhard, E. Kommisrud, M. Aldrin, I.F. Tvete, F. Buckley, A. Waldmann, and E. Ropstad. 2013. Sexually active groups in cattle-A novel estrus sign. J. Dairy Sci. 96:4375-4386. doi:10.3168/jds.2012-6407.

Thatcher, W.W., and J.R. Chenault. 1976. Reproductive physiological responses of cattle to exogenous prostaglandin F2alpha. J. Dairy Sci. 59:1366-1375. doi:10.3168/jds.S0022-0302(76)84369-X.

Thatcher, W.W., F. Moreira, J.E.P. Santos, R.C. Mattos, F.L. Lopes, S.M. Pancarci, and C.A. Risco. 2001. Effects of hormonal treatments on reproductive performance and embryo production. Therio. 55:75-89. doi:10.1016/S0093-691X(00)00447-7.

Thatcher, W.W. 2017. A 100-Year Review: Historical development of female reproductive physiology in dairy cattle. J. Dairy Sci. 100:10272-10291. doi:10.3168/jds.2017-13399.

Valenza, A., J.O. Giordano, G. Lopes Jr, L. Vincenti, M.C. Amundson, and P.M. Fricke. 2012. Assessment of an accelerometer system for detection of estrus and treatment with gonadotropin-releasing hormone at the time of insemination in lactating dairy cows. J. Dairy Sci. 95:7115-7127. doi:10.3168/jds.2012-5639. 
van Eerdenburg, F.J., I.A. Daemen, E.M. van der Beek, and F.W. van Leeuwen. 2000. Changes in estrogen-alpha receptor immunoreactivity during the estrous cycle in lactating dairy cattle. Brain Res. 880:219-223. doi:10.1016/s00068993(00)02870-5.

van Eerdenburg, F.J.C.M., D. Karthaus, M.A.M. Taverne, I. Merics, and O. Szenci. 2002. The relationship between estrous behavioral score and time of ovulation in dairy cattle. J. Dairy Sci. 85:1150-1156. doi:10.3168/jds.S0022-0302(02)74177-5.

van Eerdenburg, F.J.C.M. 2008. Possible causes for the diminished expression of estrus behaviour. Vet Quart 30:79-100.

VanRaden, P.M. 2020. Symposium review: How to implement genomic selection. J. Dairy Sci. doi:10.3168/jds.2019-17684.

Van Vliet, J.H., and F.J.C.M. Van Eerdenburg. 1996. Sexual activities and oestrus detection in lactating Holstein cows. Appl. Anim. Behav. Sci. 50:57-69. doi:10.1016/0168-1591(96)01068-4.

Walker, W.L., R.L. Nebel, and M.L. McGilliard. 1996. Time of ovulation relative to mounting activity in dairy cattle. J. Dairy Sci. 79:1555-1561. doi:10.3168/jds.S0022-0302(96)76517-7.

Walker, S.L., R.F. Smith, D.N. Jones, J.E. Routly, and H. Dobson. 2008. Chronic stress, hormone profiles and estrus intensity in dairy cattle. Horm. Behav. 53:493-501. doi:10.1016/j.yhbeh.2007.12.003. 
Walker, G. 2012. A review of technologies for sensing contact location on the surface of a display. Journal of the Society for Information Display 20:413-440. doi:10.1002/jsid.100.

Walker, R.S., B. Buttrey, J. Gurie, and G.T. Gentry. 2014. Evaluating heat detector patch response to determine gonadotropin-releasing hormone use at timed artificial insemination on pregnancy rates in beef cattle. The Professional Animal Scientist 30:613-619. doi:10.15232/pas.2014-01324.

Washburn, S.P., W.J. Silvia, C.H. Brown, B.T. McDaniel, and A.J. McAllister. 2002. Trends in reproductive performance in Southeastern Holstein and Jersey DHI herds. J. Dairy Sci. 85:244-251. doi:10.3168/jds.S0022-0302(02)74073-3.

Williams, W.F., D.R. Yver, and T.S. Gross. 1981. Comparison of estrus detection techniques in dairy heifers. J. Dairy Sci. 64:1738-1741. doi:10.3168/jds.S00220302(81)82757-9.

Wiltbank, M.C., P.M. Fricke, S. Sangsritavong, R. Sartori, and O.J. Ginther. 2000. Mechanisms that prevent and produce double ovulations in dairy cattle. J. Dairy Sci. 83:2998-3007. doi:10.3168/jds.S0022-0302(00)75201-5.

Wiltbank, M., H. Lopez, R. Sartori, S. Sangsritavong, and A. Gümen. 2006. Changes in reproductive physiology of lactating dairy cows due to elevated steroid metabolism. Therio. 65:17-29. doi:10.1016/j.theriogenology.2005.10.003. 
Wiltbank, M.C., and J.R. Pursley. 2014. The cow as an induced ovulator: timed AI after synchronization of ovulation. Therio. 81:170-185. doi:10.1016/j.theriogenology.2013.09.017.

Wolak, M.E., D.J. Fairbairn, and Y.R. Paulsen. 2012. Guidelines for estimating repeatability. Methods in Ecology and Evolution 3:129-137. doi:10.1111/j.2041210X.2011.00125.x.

Xu, Z.Z., D.J. McKnight, R. Vishwanath, C.J. Pitt, and L.J. Burton. 1998. Estrus detection using radiotelemetry or visual observation and tail painting for dairy cows on pasture. J. Dairy Sci. 81:2890-2896. doi:10.3168/jds.S00220302(98)75849-7.

Yu, G.-M., and T. Maeda. 2017. Inline Progesterone Monitoring in the Dairy Industry. Trends Biotechnol. 35:579-582. doi:10.1016/j.tibtech.2017.02.007. 